\title{
SALUD MENTAL:
}

De un ejercicio conceptual a un modelo de formación

Diana Marcela Bedoya Gallego

Diana Cristina Buitrago Duque

María Vilma Restrepo Restrepo Alba Vanegas Arbeláez 
Eorporación Universitaria Minuto de Dios

Presidente del Consejo de Fundadores

P. Diego Jaramillo Cuartas, cjm

Rector General Corporación Universitaria Minuto de Dios - UNIMINUTO

P. Harold Castilla Devoz, cjm

Vicerrectora General Académica

Marelen Castillo Torres

Rector Seccional Antioquia - Chocó

P. Huberto Obando Gil, cjm

Vicerrector Académico Seccional Antioquia - Chocó

Jorge Arbey Toro Ocampo

Directora General de Publicaciones

Rocío del Pilar Montoya Chacón

Directora de Investigación Seccional Antioquia - Chocó

Elizabeth Meneses Ospina

Decano de la Facultad de Ciencias Humanas y Sociales Seccional Antioquia - Chocó Wilson de Jesús Mazo Gómez

Líder de Investigación de la Facultad de Ciencias Humanas y Sociales Seccional Antioquia - Chocó

Eliana Maritza Gómez Rodríguez

Analista de Publicaciones y Divulgación Científica Seccional Antioquia - Chocó Diana Sofía Villa Múnera 
Salud mental: de un ejercicio conceptual a un modelo de formación / Diana Marcela Bedoya Gallego, Diana Cristina Buitrago Duque, María Vilma Restrepo Restrepo y Alba Vanegas Arbeláez. Bogotá: Corporación Universitaria Minuto de Dios. UNIMINUTO, 2020.

ISBN: 978-958-763-385-6

139p. il.; Colección de investigación

1.Educación en Salud Mental -- Enseñanza -- Colombia 2.Formación profesional -- Salud mental -- Colombia 3.Desarrollo curricular -- Colombia 4.Estudiantes -- Salud mental -- Colombia 5.Salud mental -- Investigaciones -- Colombia i.Buitrago Duque, Diana Cristina ii.Restrepo Restrepo, María Vilma iii.Vanegas Arbeláez, Alba

CDD: 362.2 HYPERLINK “http://dewey.org/webdewey/index_11. html?recordld=ddc:T1--0715"0715 S15s BRGH

Registro Catálogo UNIMINUTO No. 98294

Archivo descargable en MARC a través del link: https://tinyurl.com/bib98294

\section{Autoras}

Diana Marcela Bedoya Gallego, Diana Cristina Buitrago Duque, María Vilma Restrepo Restrepo y Alba Vanegas Arbeláez

Corrección de estilo

Karen Grisales Velosa

Diseño y diagramación

Sandra Milena Rodríguez Ríos

Primera edición: enero de 2020

Libro digital

(C) Corporación Universitaria Minuto de Dios - UNIMINUTO

Calle 81 B \# 72 B - 70

Bogotá D.C. - Colombia

2020

Esta publicación es resultado de los proyectos de investigación "Conceptualización de salud mental", financiado por la Universidad de Antioquia; "Formación del talento humano en Salud Mental en seis programas de pregrado en Colombia" con código C114-033, financiada por la Corporación Universitaria Minuto de Dios - UNIMINUTO; y "Modelo de Formación Transdisciplinar en Salud Mental para seis programas de pregrado en Antioquia", con código CB15-2, financiada por Corporación Universitaria Minuto de Dios - UNIMINUTO.

Este libro está protegido por el Registro de Propiedad Intelectual. Se autoriza su reproducción parcial en cualquier formato, incluido el electrónico, con la condición de que se cite la fuente de forma clara y completa, siempre y cuando las copias no sean usadas para fines comerciales. Los textos son responsabilidad del autor y no comprometen la opinión de UNIMINUTO. 
CONTENIDO

LAS AUTORAS

$\begin{array}{ll}\text { PRÓLOGO } & 10\end{array}$

$\begin{array}{ll}\text { INTRODUCCIÓN } & 16\end{array}$

\section{CAPÍTULO 1.}

Conceptualización de salud mental: consideraciones necesarias para la formación del talento humano en salud mental

1.1. Significado de salud mental como campo del conocimiento: una revisión del término desde las disciplinas y las instituciones

1.1.1. Aportes disciplinares al concepto de salud mental y sus aplicaciones 20

1.1.2. Conceptos institucionales de salud mental

1.2. Significados del término salud mental para la intervención

1.2.1. Conceptualización de salud mental desde la salud pública. Una propuesta conceptual integradora para facilitar las intervenciones

1.2.2. Reflexión sobre la intervención de la salud mental en Colombia 


\section{CAPÍTULO 2.}

Formación del talento humano en salud mental en Colombia: una mirada a los planes de estudios universitarios en Psicología, Trabajo Social, Medicina, Enfermería y Terapia Ocupacional

2.1. Talento humano en salud mental en Colombia

2.1.1. Talento humano en salud

2.1.2. Talento humano en salud mental

2.1.3. Temáticas a considerar en la formación del talento humano en salud mental

2.2. Formación en salud mental evidenciada en los planes de estudios de programas universitarios en Psicología, Trabajo Social, Medicina, Enfermería y Terapia Ocupacional

2.2.1. Características generales de los programas 68

2.2.2. Misión, visión y perfil del egresado 71

2.2.3. Presencia-ausencia del componente de salud mental de acuerdo a la revisión de mallas curriculares

2.2.4. Fortalezas y necesidades de la formación en salud mental que ofrecen los programas

\section{CAPÍTULO 3.}

Una propuesta de modelo de formación transdisciplinar en salud mental

3.1. Principales manifestaciones de la salud mental y características de su atención

3.1.1. Eventos en salud mental

3.1.2. Dimensión positiva de la salud mental

3.1.3. Principales características de la atención, desde la perspectiva de los actores de la investigación

3.2. Una perspectiva transdisciplinar para la propuesta de modelo de formación

3.3. Competencias de los profesionales en el campo de la salud mental: lecturas acordes a las necesidades de los contextos

3.4. Componentes de la propuesta de modelo de formación con visión transdisciplinar en salud mental: componentes temático y metodológico

3.4.1. Componente temático de la propuesta de modelo de formación con visión transdisciplinar

3.4.2. Componente metodológico 


\section{LISTA DE TABLAS}

Tabla 1. Número y proporción de documentos de salud mental en una compilación realizada entre 1999-2018 para estudios que contienen el concepto de salud mental

Tabla 2. Clasificación Internacional Uniforme de Ocupaciones cluo-88

Tabla 3. Clasificación Internacional Uniforme de Ocupaciones adaptada para Colombia

Tabla 4. Clasificación Nacional de Ocupaciones SENA 55

Tabla 5. Descripción de las profesiones según OIT, DANE y SENA 56

Tabla 6. Relación departamentos y programas ofertados 69

Tabla 7. Programas y rango de créditos, SNIES $2015 \quad 70$

Tabla 8. Programas y mallas curriculares $\quad 74$

Tabla 9. Cursos que sugieren el componente de salud mental (Cursos SM) y cursos que no sugieren componente de salud mental (Cursos no SM) $\quad 74$

Tabla 10. Frecuencia de cursos implícitos en salud mental por temáticas 75

Tabla 11. Cursos explícitos en salud mental 82

Tabla 12. Tasas por 100.000 habitantes de eventos en Antioquia y las subregiones más afectadas $2016 \quad 94$

Tabla 13. Tasas de muertes por causas externas en Colombia y en Antioquia, $2016 \quad 95$

Tabla 14. Frecuencia del consumo de alcohol para Antioquia en población general 96

Tabla 15. Reporte de trastornos mentales en consulta externa por municipio 98

Tabla 16. Reporte de trastornos mentales en hospitalización por municipio 98

Tabla 17. Componente metodológico de la propuesta de modelo de formación transdisciplinar en salud mental 


\section{LISTA DE FIGURAS}

Figura 1. Distribución porcentual de los documentos hallados de acuerdo a los componentes 44

Figura 2. Fuentes e información proporcionada

Figura 3. Número de programas participantes de acuerdo a cada fuente de información

Figura 4. Frecuencia de oferta de programas, SNIES 201569

Figura 5. Oferta de programas en universidades públicas y privadas SNIES, $2015 \quad 70$

Figura 6. Duración de programas en semestres, SNIES $2015 \quad 71$

Figura 7. Misión/visión/perfil del egresado programas en salud mental 71

Figura 8. Presencia de cursos en salud mental programa de Psicología 77

Figura 9. Presencia de cursos en salud mental programa de Trabajo social $\quad 78$

Figura 10. Presencia de cursos en salud mental programa de Medicina 79

Figura 11. Presencia de cursos en salud mental programa de Enfermería $\quad 80$

Figura 12. Presencia de cursos en salud mental programa de Terapia Ocupacional 81

Figura 13. Relación entrevistas, subregión, tipo de actor e instituciones 91

Figura 14. Relación inter y transdisciplinar entre Enfermería, Medicina, Trabajo Social y Psicología 


\section{DE LAS AUTORAS}

\section{Diana Marcela Bedoya Gallego}

Psicóloga, magíster en Ciencias del Matrimonio y la Familia. Estudiante de Doctorado en Psicología. Docente de la Corporación Universitaria Minuto de Dios - UNIMINUTO. Se ha desempeñado como docente universitaria y actualmente lidera el grupo de investigación Clínica Psicológica. Se interesa por la salud mental materna.

Correo electrónico: dbedoyagall@uniminuto.edu.co

\section{Diana CRistina Buitrago Duque}

Psicóloga, magíster en Salud Mental. Profesora Universidad de Antioquia. Ha trabajado en docencia, proyectos de investigación e intervención en salud mental desde una perspectiva de salud pública. Se interesa por la psicología social de la salud, salud pública y salud mental. Correo electrónico: dcristina.buitrago@udea.edu.co 


\section{María Vilma Restrepo Restrepo}

Médica-cirujana, magíster en Salud Pública. Profesora jubilada de la Universidad de Antioquia. Se ha desempeñado en el sector público y privado en investigación e intervención del consumo de sustancias psicoactivas. Se interesa por la salud mental desde una perspectiva de salud pública.

Correo electrónico: mariavilmarestrepo@gmail.com

\section{Alba Vanegas Arbeláez}

Psicóloga, magíster en Psicología. Docente y líder de prácticas en la Fundación Universitaria Católica del Norte. Se ha desempeñado como docente universitaria y ha trabajado como psicóloga clínica en entornos educativos. Se interesa por la relación clínica y sociedad.

Correo electrónico: aavanegasa@ucn.edu.co 


\section{PRÓLOGO}

La última década en Colombia ha sido particularmente prolífica para el desarrollo del campo de la salud mental, lo cual se evidencia no en solo los ámbitos académicos, científicos y profesionales, sino también en el contexto de las políticas públicas y sobre todo en su apropiación como objeto social.

Actualmente existen en Colombia 24 programas de especialización y maestría en salud mental, a los que se suman una amplia oferta de cursos, seminarios, diplomados, simposios y congresos que realizan las universidades y otras instituciones académico-profesionales. Así mismo, el número de grupos y líneas de investigación sobre salud mental que se encuentran registrados ante Colciencias ha venido en aumento, al igual que las publicaciones sobre el tema en revistas científicas nacionales e internacionales (Rojas-Bernal, Castaño-Pérez, Universidad CES, RestrepoBernal y Universidad CES, 2018). 
De otro lado, el avance en el ámbito de las políticas públicas en salud mental ha sido notable. En el año 2013 se proclamó la primera Ley de Salud Mental (Ley 1616 de 2013), en la que se consagra la salud mental como un asunto de interés y prioridad nacional para la República de Colombia, un derecho fundamental, un tema prioritario de salud pública, un bien de interés público y un componente esencial del bienestar y la calidad de vida de los colombianos (Congreso de Colombia, 2013). Si bien la implementación de esta ley ha sido bastante incipiente, su promulgación constituye un hito muy promisorio para hacer de la salud mental un tema de primer orden en la agenda pública, tal como quedó contemplado en la reciente política Nacional de Salud Mental (Resolución 4886 de 2018).

Finalmente, pero no menos importante, encontramos que la salud mental se ha convertido en un objeto social, esto es, un tema que circula en los escenarios cotidianos de las personas. Basta con revisar los medios de comunicación para darnos cuenta de que cada semana se publican noticias, informes y reportajes relacionados con salud mental, generando una popularización del concepto y de los fenómenos asociados a este. Dicho de otro modo, la salud mental no solo es un objeto de interés para los expertos, sino que es un tema que genera opiniones, informaciones, actitudes y representaciones entre las personas del común (Betancur Betancur, Restrepo Ochoa, Ossa Henao, Zuluaga Arboleda y Pineda Rodríguez, 2014).

Ahora bien, cuando contrastamos este creciente interés por la salud mental con la situación que reflejan los indicadores epidemiológicos, nos encontramos con un panorama preocupante. La encuesta Nacional de Salud Mental en Colombia del año 2015 ha mostrado una alta prevalencia de problemas de salud mental y trastornos mentales en los diferentes sectores de la población (Gómez-Restrepo et al., 2015), que se encuentra estrechamente vinculada con las condiciones de violencia, inequidad y vulneración de derechos que han caracterizado la historia del país en los últimos 60 años:

Asumir lo anterior implica considerar la salud mental desde el marco de los derechos y del desarrollo y trascender una visión estrictamente asistencial centrada en los trastornos. Supone aceptar que la salud mental es una 
fuerza transformadora que impulsa y coadyuva al desarrollo, ejercicio y garantía de los derechos, contribuye a la solución de los problemas del país 12 (conflicto armado y sus secuelas, desastres, pobreza extrema, etc.), mitiga el sufrimiento derivado de las vicisitudes de la vida cotidiana y de situaciones específicas (discapacidad, deterioro de las condiciones sociales, etc.) y posibilita la atención de los trastornos. La salud mental es una fuerza que opera con las potencialidades y recursos de los territorios y sus habitantes, y a partir de sus necesidades y expectativas (Asociación Colombiana de Psiquiatría, 2007).

Nos encontramos, entonces, ante un escenario complejo y paradójico; por un lado, un creciente interés por la salud mental como objeto académico, científico y social, y por otro lado, un panorama crítico en lo que respecta a la situación de salud mental de la población. Lo anterior, supone un llamado urgente a la acción que tiene como condición fundamental la formación de talento humano que, desde diferentes disciplinas y campos disciplinares, puedan aportar a la comprensión y a la intervención de los problemas de salud mental del país, a partir de una comprensión crítica del contexto, la historia y los determinantes sociales.

Y es precisamente este llamado a la acción el que da lugar al presente libro, el cual tiene como propósito presentar un ejercicio de revisión conceptual de la salud mental, analizar las condiciones actuales de la formación del talento humano en salud mental en Colombia y finalmente, proponer un modelo de formación en salud mental con perspectiva transdisciplinaria, que posibilite la articulación entre las acciones formativas y las necesidades en salud mental del país.

Al leer este texto, el lector podrá encontrar un interesante análisis construido en torno a cinco preguntas implícitas:

- ¿Cómo ha sido entendido el concepto de salud mental?

- ¿ ¿A quiénes se considera, o debería considerarse, "profesionales de la salud mental"? 
- ¿Cómo se forman dichos profesionales?

- ¿ ¿Cuáles son los fundamentos epistemológicos, conceptuales, políticos y éticos que subyacen a la formación en salud mental de los profesionales en Colombia?

- ¿ ¿De qué modo se pueden organizar los procesos de formación en salud mental para dar respuesta a las necesidades del país?

Los hallazgos resultan altamente sugerentes y dejan entrever cuatro lecciones de gran relevancia:

1. La salud mental no solo es un objeto de interés para las ciencias de la salud, sino para todas aquellas áreas del conocimiento que tienen que ver con los fenómenos biológicos, humanos y sociales que participan en la configuración de la vida y la experiencia humana.

2. El enfoque biomédico es necesario -pero no suficiente- para dar respuesta a las necesidades y problemáticas de salud mental que tiene el país. Se requiere un abordaje de la salud mental que permita comprenderla como un resultado de la relación dialógica y dialéctica del individuo con el contexto social y con las condiciones objetivas de existencia.

3. La formación en salud mental debe incorporar una perspectiva de derechos y de desarrollo humano, que permita la superación del individualismo y el reconocimiento de la salud mental como una construcción social, mediada por valores y ligada a los modos de vida.

4. Cualquier aproximación disciplinar a la salud mental resulta parcial e incompleta. Solo en la interdisciplinariedad y la transdisciplinariedad podemos aprehender su verdadera complejidad.

5. La formación en salud mental no se limita a la apropiación de una episteme o una techné; requiere la adopción de una posición ética y política de los profesionales frente a la vida humana, sus fines, propósitos y medios. 
Este texto constituye una invitación a las instituciones universitarias y a las comunidades académicas para repensar curricularmente la formación en salud mental de los profesionales de distintas áreas del conocimiento. La propuesta de un modelo de formación con perspectiva transdisciplinar que nos presentan las autoras constituye un aporte de gran relevancia para definir las competencias de los profesionales en salud mental, los componentes temáticos y los abordajes metodológicos.

No me resta más que reconocer y felicitar este esfuerzo que pone su atención en uno de los aspectos más importantes de cara a los nuevos retos y desafíos del país en materia de salud mental: la formación del talento humano desde una perspectiva transdisciplinar. 


\section{Referencias}

Asociación Colombiana de Psiquiatría. (2007). Política nacional del campo de la salud mental: Documento-Propuesta para discusión y acuerdos. Bogotá: Ministerio de la Protección Social República de Colombia. Recuperado de http://psiquiatria.org.co/web/wpcontent/uploads/2013/05/Pol\%C3\%ADtica-Nacional-del-Campode-la-Salud-Mental-versi\%C3\%B3n-final-2.pdf

Betancur Bentancur, C., Restrepo Ochoa, D. A., Ossa Henao, Y. de J., Zuluaga Arboleda, C. y Pineda Rodríguez, C. (2014). Representaciones Sociales sobe Salud Mental en un grupo de Profesionales en la Ciudad de Medellín: Análisis prototípico y categorial. Revista CES Psicología, 7(2), 96-107.

Congreso de la República de Colombia. (21 de enero de 2013). Ley 1616 de 2013. Por medio de la cual se expide la Ley de Salud Mental y se dictan otras disposiciones. DO: 48.680. Recuperado de http://www. secretariasenado.gov.co/senado/basedoc/ley_1616_2013.html

Gómez-Restrepo, C. et al. (2015). Encuesta Nacional de Salud Mental. Tomo I. Bogotá: Javegraf.

Rojas-Bernal, L. Á., Castaño-Pérez, G. A. y Restrepo-Bernal, D. P. (2018). Salud mental en Colombia. Un análisis crítico. CES Medicina, 32(2), 129-140. doi: https://doi.org/10.21615/cesmedicina.32.2.6

Diego Alveiro Restrepo Ochoa

Ph.D. en Salud Pública de la Universidad de Antioquia Decano Facultad de Psicología Universidad CES Presidente de la Asociación Colombiana de Facultades de Psicología - ASCOFAPSI 


\section{INTRODUCCIÓN}

La propuesta de un modelo de formación transdisciplinar en salud mental, en principio, parece una idea utópica si se considera la complejidad que conlleva ofrecer a las diferentes disciplinas que aportan en este campo del conocimiento unas líneas comunes o complementarias a la formación recibida en los programas universitarios. Sin embargo, la realidad colombiana, su sistema de salud y la normatividad que lo rige exigen que se conformen equipos interdisciplinarios, cuando no transdiciplinarios, que aporten a las intervenciones de salud mental en todo el espectro necesario, desde la promoción de la salud mental hasta la rehabilitación de los afectados por problemáticas relacionadas con esta, pasando por una visión integradora de la prevención de los trastornos mentales y otros problemas psicosociales, así como la implementación de tratamientos con enfoques clínicos, sociales y comunitarios efectivos y ajustados a los contextos poblacionales.

De acuerdo con la Organización Mundial de la Salud (OMS), se espera que la atención idónea en salud mental contemple características como disponibilidad, accesibilidad, aceptabilidad y calidad, características que requieren para su operacionalización de un ejercicio transdisciplinar e intersectorial; en ese sentido, la formación del talento humano en salud mental no es ajena a estas condiciones de la atención. 
Así las cosas, este texto desarrolla, en el capítulo 1, una exploración de los conceptos de salud mental de orden disciplinar e institucional, asunto que, por su diversidad y complejidad, ha llevado a las autoras a una clasificación del concepto de salud mental en una dimensión positiva y una negativa, en tanto asocian componentes tales como condicionantes de la salud mental, problemáticas psicosociales y trastornos mentales, que permiten hablar de la salud mental como un campo del conocimiento. La revisión mencionada evidenció la naturaleza diversa de este concepto y, por lo tanto, lo inapropiado de forzar un consenso unificado sobre "qué es salud mental", aspecto que debe ser entonces atendido para propiciar, desde los escenarios académicos y de intervención, mayores posibilidades de diálogo entre las disciplinas, y que permite, a su vez, salvar las brechas en la implementación y evaluación de programas y tratamientos.

Aun cuando el debate académico, científico y epistemológico alrededor de este tema es amplio y está en constante desarrollo, su aplicación se amarra a los contextos sociales, económicos y políticos, lo que justifica una revisión de orden normativo e institucional que reconozca el carácter público de la salud mental; en ese sentido, este texto propone un abordaje de la salud mental desde una perspectiva de salud pública. Bajo este enfoque se hizo también una lectura de los planes de formación universitaria y sus posibilidades de respuesta a los retos que plantea la Ley de Salud Mental colombiana, la Organización Mundial de la Salud y la Organización Panamericana de la Salud (OPS). Esta lectura se realizó a través de la ejecución del proyecto de investigación "Formación del talento humano en salud mental en seis programas de pregrado en Colombia", llevado a cabo en el periodo 2015-2016 y cuyos resultados y discusión se presentan en el capítulo 2 .

Esta investigación permitió reconocer que la formación en salud mental indicada en los programas universitarios de psicología, enfermería, medicina, trabajo social y terapia ocupacional, se ofrece principalmente como un contenido al interior de otros temas más generales, o bien, a través de cursos electivos o programas de formación posgradual. Igualmente, se identificaron las fortalezas y debilidades de estos planes universitarios en lo que respecta al desarrollo de competencias en los profesionales que se ocupan de la atención en salud mental. 
En consecuencia, y dando continuidad a la línea investigativa, se concibe la necesidad de diseñar un modelo de formación con perspectiva transdisciplinar en salud mental con el que se contribuya no solo a potenciar las fortalezas identificadas, sino, y fundamentalmente, a atender a las debilidades. Con miras a que fuera una propuesta que en efecto atendiera a las necesidades de los contextos, se construyó tomando como referente tanto documentos oficiales como la experiencia de empleadores, formadores y profesionales que se desempeñan en el campo de la salud mental en algunas subregiones antioqueñas. Atañe mencionar que el modelo de formación diseñado se construyó para el departamento de Antioquia y para los programas ofrecidos en este, a saber: Psicología, Enfermería, Medicina y Trabajo Social. Este modelo de formación es el resultado de la investigación "Propuesta de modelo de formación transdisciplinar en salud mental para cuatro programas de pregrado en Antioquia", presentada en el capítulo 3.

Lo mencionado en el párrafo anterior permite resaltar que el acercamiento a las diferentes subregiones del departamento de Antioquia arrojó como elemento emergente la necesidad de propiciar la articulación entre la academia y las instituciones, tanto públicas como privadas, que se ocupan de promover la salud mental y atender a la enfermedad mental, en tanto no solo basta contar con profesionales idóneamente formados, se requiere también de la disposición de recursos físicos y financieros que faciliten una adecuada operación de las políticas en salud mental.

Por último, es relevante mencionar que este texto es el resultado de esfuerzos investigativos gestados en los encuentros académicos de profesores y estudiantes de diferentes universidades ${ }^{1}$ que conforman el Grupo Académico en Salud Mental de Antioquia (GASMA), esfuerzos que a su vez fueron materializados por el Grupo Interdisciplinario de Estudios Sociales (GIES) de la Facultad de Ciencias Sociales y Humanas de la Corporación Universitaria Minuto de Dios - UNIMINUTO y el Grupo de Investigación en Salud Mental (GISAME) de la Facultad Nacional de Salud Pública de la Universidad de Antioquia.

\footnotetext{
${ }^{1}$ Universidad de Antioquia, Corporación Universitaria Minuto de Dios - UNIMINUTO, Universidad CES, Universidad Pontificia Bolivariana, Universidad Cooperativa de Colombia.
} 


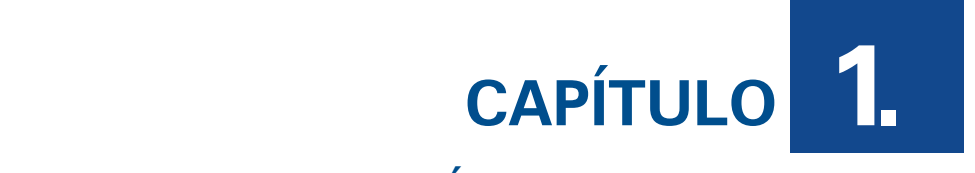
CONCEPTUALIZACIÓN DE SALUD MENTAL:

consideraciones necesarias para la formación del talento humano en salud mental

La intervención en salud mental ha sido objeto de diversas disciplinas de la salud y de las ciencias sociales, lo que la constituye en un elemento esencial para la atención en salud (Organización Mundial de la Salud, 2016) y el soporte social, así como para los programas de bienestar y desarrollo comunitario. Sin embargo, se presentan múltiples versiones del concepto salud mental y especialmente diversos usos del término.

Desde una perspectiva transcultural no es posible llegar a una definición que represente lo que significa salud mental en diversos contextos, pero se intenta, desde la oms alertar sobre la complejidad que subyace en el término, afirmando que "salud mental es más amplio que la simple ausencia de trastornos mentales" (oMs, 2001, p. 5) lo que revela que, en buena parte de la cultura occidental, el término salud mental se ha asociado como antítesis de las problemáticas psiquiátricas sin renunciar a una innegable relación entre ambos conceptos - salud mental y trastornos mentales-, de modo que parece estar representado por fenómenos no explicados suficientemente. 
Este capítulo revisa algunas de las conceptualizaciones de salud mental del orden disciplinar e institucional y propone luego un ejercicio de conceptualización desde la salud pública, disciplina que representa, para el caso de la salud mental, diversas propuestas multidisciplinares tendientes a la prestación de servicios integrados; posteriormente, intenta comprender a partir de la norma colombiana, cómo se constituye un punto de partida común para la formación del talento humano en salud mental en el país, dada la trascendencia que tiene el desempeño profesional y técnico en la ejecución de políticas y planes de salud mental. Este capítulo parte de una revisión documental, iniciada en el año 1999 hasta 2018 y de la que se seleccionaron 238 artículos sobre conceptos de salud mental disponibles en la internet, limitados a América Latina; su análisis se orienta hacia los abordajes disciplinares de medicina, enfermería, psicología, trabajo social y terapia ocupacional, y hacia los campos de acción en salud mental. Al revisar los conceptos de salud mental de las disciplinas seleccionadas para este texto, fue necesario ampliar la base de datos y agregar otros autores externos a América Latina y al periodo de tiempo descrito, esto permitió, incluso, hallar diferentes perspectivas y ramas disciplinares en la revisión documental: salud pública, sociología médica, etnopsiquiatría, antropología médica, enfermería psiquiátrica, epidemiología crítica, administración, derecho y sociología. Lo anterior revela que el concepto de salud mental en América Latina ha sido abordado por ramas o especializaciones de las diferentes disciplinas.

\subsection{Significado de salud mental como campo del conocimiento:} una revisión del término desde las disciplinas y las instituciones

\subsubsection{Aportes disciplinares al concepto de salud mental y sus aplicaciones}

Es importante aclarar que no todas las disciplinas expresan de manera explícita un concepto de salud mental; algunas de ellas reflexionan sobre el término, bien sea para diferenciarse o acercarse a las teorías de otras disciplinas o, para aclarar "qué tipo de salud mental" abordan desde sus propuestas disciplinares.

Desde el punto de vista histórico, se encuentra una primera mención de lo que podría asemejarse a salud mental en términos del bienestar en la filosofía griega, a partir de su interés por la búsqueda 
de la "excelencia del ser humano", representada por un sujeto que despliega sus potencialidades con moderación. En ese sentido, existe una aproximación a la salud mental como "salud del alma" o como "sabiduría práctica" llegando a un "despliegue armónico del ser" donde se unifica la salud mental con la física (Aristóteles, 1985, 1106b, p. 35, citado por Lopera Echavarría, 2012). Una aproximación histórica a la pérdida de la salud mental se encuentra en la obra de Foucault (1998) Historia de la locura en la época clásica, donde se plantea cómo ciertos saberes sobre la salud mental, o mejor sobre su ausencia, son usados como mediadores para intervenir en la vida de los sujetos que padecen un deterioro en esta, y terminan convirtiéndolos en objeto de marginación y verificación, ya que implica un ejercicio de poder sobre ellos. En la actualidad, esta situación de poder está representada en el manejo de la medicalización de una población vulnerable, tanto desde el punto de vista del suministro de fármacos como a través de la determinación de una conducta a seguir (confinamiento, restricción) y también, por medio de la clasificación nosológica, convirtiéndose esta en un dispositivo para controlar a un sector de la población en el ámbito de su vida privada y pública (Restrepo, 2012). La aceptación de este dispositivo de control ha sido institucionalizada por las prácticas médicas y psiquiátricas, así como por la salud pública, justificado en la necesidad de centrar la relación entre las facultades mentales y la conducta, con la estructura cerebral, cuyos orígenes se encuentran en la obra de Gall (1810) Sur les fonctions du cerveau et sur celles de chacune de ses parties (citado por Caponi, 2010).

A comienzos del siglo XX se inicia el Movimiento de Higiene Mental, tanto en los Estados Unidos como en Francia, cuyo objetivo fue mejorar la atención de las personas con trastornos mentales, pero también una mayor se centró en la preocupación por la prevención de dichos problemas (Klappenbach, 1999; Lopera Echavarría, 2012), basándose en la lógica de los factores de riesgo reconocidos por la psiquiatría y la salud pública.

Sin embargo, en la segunda mitad del siglo XX, comenzó un cambio de pensamiento representado en las obras de Canguilhem (citado por Caponi, 2010), donde se plantea el significado de "lo normal" y de lo "patológico" y su aplicabilidad en la sociedad. Esta línea de ideas incluye en el concepto de salud mental la capacidad del individuo de adaptarse 
a nuevas exigencias de la vida y de reconocer qué lo constituye como ser humano; esta idea se expresó más tarde en las definiciones de salud mental propuestas por la Organización Mundial de la Salud.

Según Bertolote (2008), los orígenes de una conceptualización más específica sobre salud mental se remontan a 1908; este autor sostiene que:

Más que una disciplina científica, la salud mental es un movimiento político e ideológico que involucra diversos sectores de la sociedad, interesados en la promoción de los derechos humanos de las personas con trastornos mentales y la calidad de su tratamiento. (p. 113).

Pero lo mental se refiere a una dimensión de la salud, definida también por la oMs y que, según esta, debía denominarse como "bienestar mental", no siendo una disciplina, sino como un término que sustituye el de higiene mental, refiriéndose no a un estado de salud, sino a un campo de la actividad sanitaria (Bertolote, 2008, p. 114).

No obstante, siendo comprensible la posición de Bertolote como psiquiatra, la discusión sobre el término salud mental en relación con lo que llamamos felicidad o bienestar subjetivo, como se prefiere llamar hoy a la eudaimonía, continúa siguiendo las bases grecorromanas de la cultura occidental, dada la trascendencia que tiene alcanzar un nivel óptimo de desarrollo para el ser humano; existe también en estas reflexiones una aspiración con connotación utilitarista que evoluciona, desde una concepción del ideal de ser humano propio de dicha filosofía, a una preocupación por el ser humano como instrumento de los sistemas, derivando en una suerte de ingeniería conductual. Al respecto, Canguilhem (2004, citado por Caponi, 2010), aunque admite la utilidad práctica de este conocimiento en pedagogía, medicina, psicología o control del crimen, también revela las innúmeras controversias sobre la precisión y efectividad de los estudios neurológicos por imágenes, al partir de una premisa cuestionable: que existe una equivalencia perfecta entre funciones mentales y mecanismos cerebrales identificables.

Gonzalo Miranda (2018), en su artículo “¿De qué hablamos cuando hablamos de salud mental?", señala la dificultad de definir la salud mental en tanto no sea la ausencia de enfermedad; pero propone de manera acertada que, es la salud mental lo que está en juego entre el 
individuo y la vida colectiva, lo que posibilita entrar en el lazo social y no solamente en razón de unas capacidades individuales o la ausencia de condiciones patológicas; en este último caso, la libertad se antepone a la alienación; la disfunción a la armonía y al equilibrio o funcionamiento correcto, incluso óptimo; la desadaptación a la adaptación. Si estar enfermo es no soportar las tensiones de la vida, la salud equivale a fortaleza de carácter. Ante estas dificultades en el concepto de salud mental, se señala que otras aproximaciones a la salud mental subrayan la cualidad silenciosa y privada de lo que significa la salud (Canguilhem, 2004, citado por Caponi, 2010).

Con el ánimo de ofrecer un contexto sobre la forma de abordar la salud mental desde las diferentes disciplinas que inspiran la propuesta de modelo de formación, a continuación, se presentan los hallazgos de la revisión documental en lo concerniente a las perspectivas disciplinares.

Medicina y psiquiatría: siguiendo las bases biológicas de la medicina, los profesionales de esta disciplina, y especialmente los psiquiatras, han sido actores importantes en la búsqueda de la causalidad de los trastornos mentales y de otros problemas del comportamiento. A partir de los avances en neurofisiología y la psicofarmacología, se han implementado los fármacos y otras intervenciones neurológicas como herramientas indispensables para el diagnóstico y tratamiento de los trastornos mentales y del manejo intra y extrainstitucional de estos. Sin embargo, algunos psiquiatras consideran que, así como la salud y la enfermedad no son polos opuestos, sino momentos de un proceso, la salud mental y el trastorno mental se encuentran en la misma situación, existiendo, otros elementos a considerar en este proceso, que no son necesariamente neurobiológicos, sino que cobran importancia: las condiciones sociales (económicas, políticas, culturales e ideológicas) que inciden en la manera de enfermar de la población (Madariaga, 1995).

El Movimiento de Higiene Mental, de principios del siglo XX se integró al modelo gubernamental de "estado de bienestar", no como calificación de un estado de salud mental individual, sino como un elemento en la organización social de la salud, por esta razón cobraron importancia, en ese entonces, los servicios que se desarrollaron para atender condiciones psiquiátricas, psicológicas y sociales de la población; es así como los servicios psiquiátricos han mantenido una estructura 
jerárquica, asignando la responsabilidad científica y administrativa en el psiquiatra; estas instituciones, entonces, han permanecido durante buena parte del siglo XX y XXI como estructuras con modelo biomédico; sin embargo, a medida que se han ido introduciendo otras formas de pensamiento sobre lo que significa la salud mental y el trastorno mental y, con ello la integración de diversas intervenciones desde otras disciplinas, se ha enriquecido el modelo biomédico con las posturas de la enfermería, la psicología, el trabajo social, la terapia ocupacional y la salud pública, lo que ha aportado nuevas consideraciones a las decisiones clínicas, institucionales y comunitarias (Ramalho, 2009).

Probablemente, el pensamiento centrado en la causalidad biológica sea una razón para que el término salud mental continúe siendo utilizado para nombrar fenómenos asociados a los trastornos mentales y otros problemas del comportamiento; es por ello que varias publicaciones de carácter psiquiátrico y psicológico continúan utilizando en su título y contenido el término salud mental como una forma de representar los fenómenos investigados, generalmente, problemas de salud mental. Se encuentran entonces estudios de salud mental que describen la situación epidemiológica de los trastornos mentales (OMS, 2001); los planes de acción para salud mental que se centran en los factores de riesgo para los trastornos mentales y otras problemáticas como el suicidio (OMS, 2013); y recursos en salud mental (OMS, 2006) que describen servicios, tanto psiquiátricos como comunitarios, dirigidos a poblaciones vulnerables con diversos problemas del comportamiento, de contenido tan amplio que van desde la depresión hasta violencia. Es así como Pilgrim (2009), en Key Concepts in Mental Health, realiza una recapitulación de conceptos claves en salud mental desde la perspectiva psiquiátrica, pero agregando una discusión crítica de muchos términos relacionados con los trastornos mentales, los servicios y su relación con la sociedad, develando que la causalidad biológica no tiene suficiente evidencia en algunos de ellos.

Existen algunos esfuerzos desde la psiquiatría por comprender los puntos de vista de otras disciplinas en el campo de la salud mental; por ejemplo, la Revista Vertex, de psiquiatría, es una publicación argentina dedicada al área de las disciplinas del campo de la salud mental; en el año 2012 se publicó un número dedicado a la comprensión del concepto de salud mental desde estas y en su editorial anota: 
El concepto de "salud mental" es utilizado por diversos autores y grupos para aludir a un movimiento, un campo disciplinar o un área de trabajo profesional, así como a una dimensión que forma parte de la salud (en general) y un estado o condición individual o grupal que se produce exclusivamente en un determinado contexto sociocultural (Alba, Agrest y Stagnaro, 2010, p. 17).

Enfermería: esta disciplina forma parte importante de los equipos de salud mental, no solo institucionales, sino además en los equipos de salud comunitaria. Estos profesionales han aportado sus teorías y conocimientos sobre "el cuidado del otro", y un modelo de intervención que actualmente se considera en estado de transición, puesto que ha debido reconfigurarse por las nuevas demandas de atención, asociadas principalmente a la necesidad de intervenir en toda la comunidad y no solo al enfermo mental en los centros hospitalarios; al reconocimiento de nuevos sufrimientos psiquiátricos y al incremento de las enfermedades crónicas como los trastornos mentales y aquellas propias del envejecimiento poblacional. El cambio en los roles sociales e individuales sitúan al cuidado de la enfermería más allá del ámbito individual y familiar y lo aproximan a la responsabilidad social compartida (Cruz-Ortiz et al., 2011).

Para la intervención en salud mental al interior de esta disciplina, se tienen diferentes especializaciones y modelos teóricos, que permiten inferir los aspectos en los cuales se hace énfasis en la prestación de los cuidados enfermeros. Revisaremos a continuación la definición de algunas especializaciones en enfermería que se orientan a la atención en salud mental, así como algunos de los modelos teóricos que fundamentan dicha práctica.

La primera definición a revisar corresponde a la especialización denominada Enfermería en Salud Mental, cuyas concepciones corresponden al momento en el cual la atención en salud mental, se realizaba desde la intervención de los trastornos mentales, así lo expone Esguerra (1991): "la Enfermería en Salud Mental es un área que emplea teoría del comportamiento humano, para prevenir y corregir los trastornos mentales y sus secuelas, y para fomentar una salud mental óptima en el individuo, la familia y la comunidad" (p. 28). 
Una concepción más amplia de los fenómenos a intervenir cuando se trata de salud mental, la propone la definición de enfermería en salud mental y psiquiátrica, que en palabras de Galvis (2015), se define como una

especialidad de las ciencias de la Salud y Antropológicas, [que estudia] no sólo las causalidades biológicas, sino también las motivaciones psicológicas, psicodinámicas y las condicionantes socioculturales de la enfermedad mental en sus múltiples formas, aplicando los cuidados y la atención pertinentes. (p. 1110).

Por su parte, la enfermería en salud mental comunitaria de acuerdo a Málvarez (2011) "se vincula a la comprensión de los procesos sociales (políticos, económicos, científicos, organizacionales, familiares) que intervienen en la producción de la salud mental y el sufrimiento psíquico" (p. 25). En palabras de la misma autora, en esta vertiente de la enfermería, su fundamento central, esto es, el cuidado del otro, se realiza a partir de concepciones humanas, sociales y familiares.

Desde la OPS (1990), en su texto Enfermería en salud comunitaria: un enfoque de sistemas, se señala la importancia de la práctica de enfermería distributiva, la cual se concibe como la prestación de cuidados en salud a poblaciones en riesgo, pero dentro del contexto de sus redes sociales significativas. Así entonces, esta práctica integraría la salud mental comunitaria, sin excluir el cuidado primario.

Lo que nos permiten concluir las definiciones expuestas es que la concepción de salud mental al interior de la enfermería no ha sido ajena a los cambios que se han dado en las conceptualizaciones institucionales de la salud y la salud mental. Por esta razón, las especializaciones en Salud Mental y Salud Mental Psiquiátrica retoman en su definición el concepto de enfermedad mental, como el foco hacía donde se dirigen los cuidados enfermeros. Por su parte, las especializaciones de Enfermería Distributiva y Enfermería en Salud Mental Comunitaria se fundamentan en la atención en salud, lo que da la idea de que esta se concibe más allá de la ausencia de enfermedad.

Otro aspecto a relevar, es que los postulados de las especializaciones proponen concepciones biomédicas, psicológicas y sociales, solo que esta triada que refleja el ser biopsicosocial ha quedado subsumida 
en la tradición imperante del modelo biomédico en esta disciplina, así lo considera Galvis (2015) a partir del análisis de producciones académicas realizado para la escritura de su texto "Teorías y modelos de enfermería usados en la enfermería psiquiátrica".

Así mismo, los desarrollos que anteceden a estas líneas, permiten apreciar la razón por la cual se considera que el modelo de intervención en salud mental desde la enfermería se encuentra en estado de transición, puesto que necesita pasar de la atención psiquiátrica biomédica a la atención comunitaria, y a la movilización política "relacionada con la transformación del modelo asistencial dominante" (Malvárez, 2011, párr. 1).

De otro lado, en la realidad de las intervenciones desde la enfermería, se considera la salud mental como parte esencial de la salud, y se expresa en las diferentes formas de cuidado: desde la Atención Primaria en Salud (APS) hasta la atención especializada en las instituciones psiquiátricas (Megías, Martínez y Pacheco, 2003), donde juega un papel esencial en el equipo de atención. Su papel en el trabajo de salud mental comunitaria está menos definido (García, 2004), pero no es menos importante, como se anota en la publicación de la OPS (1990), Enfermería en salud comunitaria: un enfoque de sistemas.

Por último, como lo señala Silvina Malvárez (2011), en América Latina la gran mayoría de enfermeras trabajan en hospitales psiquiátricos, en otros países es posible encontrar una proporción mayor de enfermeras de salud mental trabajando en las comunidades, enfrentando la gran distancia entre las propuestas conceptuales y las políticas que sustentan los modelos de atención y lo que efectivamente logra desarrollarse en los servicios de salud mental comunitario en el proceso de transición y cambio paradigmático; por lo tanto esta disciplina debe impulsar estos cambios aliándose a movimientos de transformación, con valores diferentes reconociendo los problemas prioritarios de salud mental incluyendo los emergentes, así como los propios de las políticas, conocimientos y servicios que también configuran el amplio campo del sufrimiento psíquico.

Psicología: por su parte, la conceptualización de salud mental desde la psicología implica el reconocimiento de los amplios debates que en esta disciplina se han dado alrededor del término, pues la naturaleza misma de su objeto de estudio gira en torno a asuntos relacionados con el 
sujeto y lo que significa "mental". Campos (2004) asevera que, lo indefinible del término salud mental muestra una cierta tolerancia ante la diversidad doctrinal que se da en este campo, tal como se ha expuesto en el caso de la psiquiatría y su apertura hacia otras consideraciones externas a la perspectiva neurofisiológica de los trastornos mentales.

En la psicología se encuentran diferentes escuelas de pensamiento -entre ellas, teorías de orientación humanista-existencial, psicoanalítica y cognitivo-conductual, así como propuestas de la psicología positiva y la psicología social- que permiten diversas perspectivas de aproximación a la conceptualización y aplicación de la salud mental. Carrazana (2002) realiza un ejercicio investigativo, a partir del cual reconoce en algunos postulados de la psicología humanista existencial, atributos que permiten definir la salud mental, entre ellos señala: la autorrealización, la libertad, la responsabilidad, la voluntad, la congruencia, la vivencia en el aquí y el ahora, la posibilidad de tomar contacto con las propias necesidades y orientar la satisfacción de las mismas, el reconocimiento de los propios límites y la valoración de la coexistencia con otros.

Por su parte, Ubilla (2009), en un esfuerzo por dilucidar el concepto de salud mental en la obra de Erik Fromm, hace referencia a las necesidades básicas resultantes de la condición humana y cuya satisfacción determina el grado de salud mental; estas necesidades son: de vínculo, de un marco de orientación, de poder entregarse a algo, de arraigo, de identidad y de trascendencia.

Por otro lado, Milagros Cubas (2006), desde una perspectiva psico-analítica, propone un modelo teórico que, en contraposición a lo patológico, propende por una visión de la salud mental en términos de la realización del potencial humano y una orientación hacia el bienestar del sujeto. Este modelo se estructura a partir de cuatro ejes: 1) representación integrada del sí mismo, específicamente la representación integrada del cuerpo y la integración de la identidad; 2) relaciones significativas con otros, entendidas como apego seguro, capacidad de amar y empatía; 3) funciones regulatorias efectivas y disponibles, las cuales comprenden el contacto con la realidad, el predominio de defensas secundarias y flexibles y la adaptación, la regulación de impulsos, demandas y afectos; 4. el crecimiento personal, incluyendo la capacidad de disfrutar sin culpa, la creatividad espontánea y la búsqueda de trascendencia. 
Milagros Cubas (2006), entonces, se reconoce en coincidencia con Klein (1959) y Winnicott (1965) (citados por Cubas, 2006), en tanto expresa que estar en equilibrio no hace referencia a evitar los conflictos sino a la capacidad de tolerar las emociones que genera el sufrimiento y afrontarlas de forma responsable en cuanto a la acción o la inacción.

En lo que respecta a psicología cognitivo-conductual, aun cuando sus bases epistemológicas son distintas a las que subyacen a las teorías psicoanalíticas, se encuentran coincidencias en su interés de presentar una conceptualización de salud mental que trascienda el modelo psicopatológico y se oriente más bien hacia el reconocimiento de las capacidades individuales. En este sentido, en Keegan (2012) se identifica que la salud mental es entendida como la capacidad de llevar a cabo conductas que permitan alcanzar las propias metas, a pesar de las emociones y pensamientos negativos. Según este autor, "el sufrimiento humano es ubicuo y, en gran medida, inevitable" (Keegan, 2012, p. 52) y forma parte de la normalidad, así como de la psicopatología; en consecuencia, la forma como se afronta el sufrimiento es un indicador de salud mental, haciendo referencia a la aceptación y al cambio como dos grandes principios considerados en la terapia cognitivo-conductual.

Adicionalmente, una visión salutogénica de la salud mental se enmarca en las propuestas de la psicología positiva; esta propuso un viraje del tratamiento y curación hacia la salud y el bienestar. De esta manera, dirige su interés hacia las fortalezas y virtudes del funcionamiento humano, buscando potenciar no solo el desarrollo individual sino también el desarrollo de las comunidades (Barrón y Sánchez, 2011). Los aspectos mencionados constituyen la dimensión positiva de la salud mental. Para Vázquez y Hervás (2009), esta perspectiva de la salud mental está referida a las emociones positivas, a la compasión con nosotros mismos y con los demás y a un modo adaptativo de comprender la realidad.

Los autores reconocen que el alcance y el mantenimiento de una buena vida es un objetivo común de la humanidad, y que, por lo tanto, se trata de una búsqueda que compete a diferentes sectores y actores con un interés de expandir los límites de la salud mental y el bienestar individual hacia lo político y lo poblacional; esto redunda en intervenciones que favorecen no solo el bienestar material, sino también el social y el emocional (Vázquez y Hervás, 2009). En ese sentido, la salud mental positiva hace énfasis en aspectos como desarrollo humano, capital social, 
capital humano, calidad de vida; como ejemplo de ello Vázquez y Hervás (2009) citan la invitación que hizo Amartya Sen (1999) a reorientar el análisis del desarrollo de las naciones: de uno centrado en el Producto Interno Bruto a otro centrado en las capacidades humanas.

No distante de la propuesta anterior, Ignacio Martín-Baró (1990), desde una perspectiva de la psicología social, insiste en la necesidad de entender la salud mental en términos más amplios y positivos, argumentando que el problema de los modos tradicionales no tiene que ver tanto con la utilización del modelo médico como sí con una concepción reduccionista del ser humano entendido como organismo individual y no como un ser histórico que se realiza en las relaciones sociales. En consecuencia, el autor en mención dimensiona el carácter social de la salud mental, el cual se expresa en las relaciones interpersonales e intergrupales y a su vez se enraíza en las particularidades del individuo. "Esta perspectiva permite apreciar en todo su sentido el impacto que sobre la salud mental de un pueblo pueden tener aquellos acontecimientos que afectan sustancialmente las relaciones humanas, como son las catástrofes naturales, las crisis socioeconómicas o las guerras" (Martín-Baró, 1984, párr. 10), indicando que es la guerra el fenómeno social que tiene mayores efectos tanto por la crisis económica que conlleva como por su carácter irracional y deshumanizante.

Trabajo social: respecto a la salud mental, el trabajo social como disciplina aportó en la primera mitad del siglo XX, su saber hacer respecto a la adaptación del enfermo mental al entorno familiar y social, bajo una lógica intervencionista subordinada al saber psiquiátrico, que reducía los problemas sociales a la presencia de dificultades familiares o económicas, por lo tanto, se desconocía la dimensión de lo social como agente incidente y/o causante de situaciones conflictivas. Por estas razones, Mendoza (2004) afirma que cumplir dicha función socializadora era una manera de "...responder a los intereses de las clases dominantes paliando e invisibilizando las manifestaciones de la cuestión social producto de las contradicciones inherentes al capitalismo" (p. 11).

Como se infiere del párrafo anterior, el trabajo social se vio abocado a realizar la intervención en salud mental desde los referentes teóricos de la psiquiatría y la psicología, efecto de ello surge lo que Mendoza (2004, p. 12) nombra como un profesional orientado a lo socioterapéutico, que establece una psicopatología de las relaciones familiares del paciente diagnosticado con alguna enfermedad mental. 
En la época actual y a raíz de los mismos giros que se han dado en la conceptualización de salud mental, se considera que el trabajo social aporta reflexiones que ayudan a comprender el concepto en el marco de la recuperación de una "noción del proceso histórico social", entendido este como análisis del contexto así como de los diferentes escenarios donde transcurre la vida cotidiana, su devenir y el impacto en la esfera de lo subjetivo; estos aspectos son esenciales para comprender a profundidad la complejidad del ámbito donde se expresan tanto el padecimiento subjetivo como las políticas sanitarias y sociales (Carballeda, 2012). Este autor explica cómo el trabajo en el sector de la salud y de la salud mental, incluye la atención de problemáticas sociales complejas y, al considerar las políticas sociales que entrelazan las metas de varios sectores, van reconfigurando lo barrial, comunitario y territorial. En sintonía con lo anterior, Mendoza (2009), desde una perspectiva sociológica, expresa que la relación entre los campos de la salud mental y las ciencias sociales puede ser muy valiosa, especialmente cuando se quiere lograr un enfoque más integral de los conceptos de salud y enfermedad mental; aunque históricamente ambos campos han tenido distancias al respecto, en la actualidad, y basándose en el reconocimiento de la multicausalidad de los trastornos psiquiátricos, el acercamiento de las propuestas de las ciencias sociales es necesario para el mantenimiento y recuperación de la salud mental (Mendoza, 2009).

Así, lo social en relación a la salud y la salud mental, ya no se piensa solamente a partir de lo familiar y lo económico, sino que abarca las tramas producto de la interrelación entre lo político, económico, demográfico, sociocultural y medioambiental (Carballeda, 2012).

En cuanto a la forma de proceder, Netto (1997, citado por Medoza, 2004) propone dos niveles que dan cuenta de un perfil del trabajador social muy diferente al construido en la primera mitad del siglo XX; en la actualidad se ve con más claridad su papel como intermediario entre las dinámicas de las relaciones sociales producto de la política social, y su implicación en el análisis de lo político a través de la socio-educación, funciones que transcurren de manera paralela a la asistencia de la población, labor que tradicionalmente ha desempeñado el trabajador social. 
Terapia ocupacional: esta disciplina parte del abordaje de la ocupación como una dimensión de lo humano, definida como "el hacer [que] da bienestar, propósito a la existencia de las personas y promueve el desarrollo social" (Santracruz, 2006, p. 35). Esta definición de lo que sería el objeto de intervención de la terapia ocupacional evoca algunos elementos de la concepción actual de salud mental promovida por la OMS (la cual podrá verse en el apartado Conceptos institucionales de salud mental, junto con las concepciones que le han precedido), donde se le define como "un estado de bienestar en el cual el individuo es consciente de sus propias capacidades, puede afrontar las tensiones normales de la vida, puede trabajar de forma productiva y fructifera y es capaz de hacer una contribución a su comunidad" (oMs, 2013, p. 42).

La evocación de la que se habla en el párrafo anterior se establece porque en ambas definiciones, es decir, la de ocupación y la de salud mental, se alude a:

- El bienestar, en la primera como efecto de lo que se hace, en la segunda como un estado del individuo, caracterizado por el trabajo productivo que puede desempeñar. En conclusión, en la dupla que se analiza, el bienestar se asocia al hacer.

- Una contribución por parte de las personas a la comunidad o al desarrollo social, que, de acuerdo al hilo de lo expuesto, puede darse como una capacidad derivada de su estado de bienestar; o como una consecuencia de lo que las personas hacen, en tanto "el comportamiento ocupacional siempre es un comportamiento medioambiental, ya que la ocupación es el diálogo del ser humano con su medio ambiente" (Iwama, 2008, citado por Méndez, 2016, p. 41).

- Por último, la referencia al hacer, que en el campo de la terapia ocupacional se propone de manera general, pero que, en el ámbito de salud mental desde la oMs, se concretiza en el trabajo productivo y fructífero.

A partir de lo anterior, se entiende la relación directa que tiene la salud mental con las múltiples ocupaciones humanas y con las acciones cotidianas. Por esta razón, se reconoce en los terapistas ocupacionales importantes actores de la intervención en el campo de la salud mental, tanto en sus aportes a la promoción de la salud, prevención de la 
enfermedad y al proceso de recuperación de la salud, considerando las diferencias entre los individuos que los hace responsables o no de acometer la cotidianidad según sus habilidades y la inclusión-exclusión de las personas con problemas de salud mental para la participación de la vida laboral y su significado en la construcción de una vida digna y de calidad (Sánchez, 2014).

Existe una deuda histórica con respecto a la atención psicosocial y ocupacional en salud mental, y esta disciplina se ha propuesto la construcción de espacios de participación comunitaria saludables y potenciadores de la recuperación de personas con trastornos mentales y con problemáticas psicosociales, ofreciendo herramientas para su inclusión social como dignificadora del vínculo social. Por ello, el terapista ocupacional en la intervención de la salud mental de la población, fomenta los roles ocupacionales asociados al sí mismo, como a la relación con los otros, es decir, propende para que las personas cuiden de sí mismas, se autoregulen, fortalezcan sus habilidades psicosociales, y construyan su pertenencia familiar, social y laboral (Santacruz, 2006).

Ahora bien, y dado que la responsabilidad en la construcción de un estado de bienestar en el ámbito mental, no puede recaer solamente en el individuo, Sánchez (2014) considera que la terapia ocupacional debe estar presente en aquellos espacios donde se construye el desarrollo psicosocial igualitario a lo largo de la vida teniendo como ámbito la participación comunitaria como fomentadora de los derechos fundamentales.

La multidisciplinariedad en la salud mental: es evidente, después de revisar las aproximaciones disciplinares al concepto de salud mental, que, aunque estas disciplinas aportan un conocimiento y unas prácticas, por sí mismas no dan respuesta total a la construcción de salud mental o a las propuestas para su recuperación y, probablemente, tampoco al concepto.

A partir de conceptos de salud mental como movimiento, como estado o como condición, Patricio Alba, Martín Agrest y Juan Carlos Stagnaro (2012) exponen en Salud mental, la polisemia de un concepto, que existe un componente esencialmente subjetivo que conlleva el uso del término salud mental: la enfermedad mental tendría un componente aparentemente objetivo e indiscutido y permitiría inscribir 
a las disciplinas que la estudian en el seno de la psicopatología, mientras que, el sufrimiento mental, carecería de límites precisos y todas las disciplinas que lo abordan merecerían un espacio discursivo y práctico. Aun así, Aníbal Goldchluk (2012), psiquiatra argentino, refiere que las dificultades al enfrentar las distintas formas clínicas en las que se expresa la pérdida de la de salud mental pueden llegar a desacuerdos importantes en campos como la legislación en salud mental, y no solamente en los espacios clínico-terapéuticos, lo que revela la dificultad para llegar a respuestas transdisciplinarias.

Sin embargo, el problema no se centra en los acuerdos disciplinares del orden teórico y terapéutico: desde el punto de vista de la salud pública, Gómez-Arias (2014) explica que, a partir de las crisis del capitalismo entre los años 1930 y 1950, los Estados de los países con este modelo gubernamental abandonaron la ideología liberal del libre mercado como reguladora del bienestar y adoptaron el modelo político y económico del estado de bienestar para gestionar desde allí los servicios; al desarrollarse la planificación en proyectos de salud, no siempre se tuvo conexión entre ellos, lo que muestra que no siempre se incorporaban las premisas de los modelos políticos y económicos a la planificación. Matus (1987) planteó que estas premisas incluían un mayor control de la población sobre su salud, como lo propone la estrategia de promoción de la salud en la Carta de Ottawa de 1986. En este punto, reaparece un modelo de desarrollo económico: el New Public Mangement, ajustado a los intereses del capital, donde la salud es considerada un gasto público adicional, iniciándose una era de amplios debates y reformas sanitarias.

En este escenario histórico, la salud mental como parte integrante de la salud, juega un papel preponderante en la construcción de la noción de bienestar, no solo considerando el acceso equitativo a bienes y servicios públicos, sino también en la forma como las sociedades favorecen la satisfacción y felicidad de sus miembros, lo cual depende de la noción de bienestar individual y social. Aparece entonces la preocupación por los indicadores de bienestar: no es solo la riqueza económica el indicador; otras circunstancias, como la consideración a la igualdad de género, el acceso universal a servicios y las libertades civiles, son importantes, además de algunos indicadores de tipo subjetivo, como la satisfacción vital, deben ser considerados en el diseño y evaluación de las políticas públicas y sus desarrollos (Vásquez, 2006). 
La economía es otra disciplina que ha aportado indicadores al reconocimiento del bienestar y de la salud mental como parte de este, incluyendo el ingreso colectivo e individual calculado en el Producto Interno Bruto (PIB) y el producto per cápita; la influencia de los problemas económicos en la pérdida de la salud mental ha sido estudiada en grupos de pacientes psiquiátricos y su relación con las crisis económicas de los Estados Unidos (Brenner, 1973, citado por Feldman, 1984). Pero no solamente el ingreso ha sido importante; desde esta perspectiva, se considera que una sociedad con mayor desigualdad económica y algunas creencias sobre atesorar bienes, sumado a una peor valoración y desprecio por el fracaso, pueden desarrollar una mayor prevalencia de enfermedades mentales (Pérez del Río, 2012).

En este punto es importante traer a colación los supuestos de la medicina social, también nombrada como salud colectiva (Casallas, 2017), sobre la salud mental y los trastornos mentales; existe una dificultad para establecer una línea divisoria entre estos dos términos, considerando las diferencias culturales y sociales sobre cada uno, ya que los trastornos mentales son vistos como "comportamientos socialmente inaceptables" en algunos ámbitos institucionales y sociales (McKeown y Lowe, 1989). La medicina social-salud colectiva propone entonces una visión integradora entre estos dos términos a través de medidas sanitarias o sociales donde puedan prevenirse, eliminar o aliviar las consecuencias de los trastornos mentales sobre las comunidades, enfatizando en la necesidad de ofrecer servicios diversos al alcance de las personas afectadas (Rosen, 2005). En América Latina, la medicina social-salud colectiva ha representado un movimiento de carácter político, que presenta el proceso salud/ enfermedad/cuidado del enfermo, desde una perspectiva de derechos, en contraste con la objetivación/medicalización del proceso de privatización y mercadeo de la salud que se ha propuesto desde otros modelos socioeconómicos. Ardila y Stolkiner (2012) consideran que se podría mejorar la salud mental poblacional si se incorpora el interés por esta dimensión a las prácticas sociales de salud/enfermedad/cuidado del enfermo; estas autoras piensan que "...el campo de la salud mental es un subcampo dentro del de la salud en general, pero que se ha configurado como el espacio paradigmático del límite a la concepción biologista-individual de la enfermedad (...)" (Ardila y Stolkiner, 2012, p. 3). Es importante anotar que, a pesar de los esfuerzos de las instituciones sanitarias por articular la promoción de la salud mental y la atención 
primaria en salud mental con las reformas de los sistemas de salud, es necesario aún enfrentar la medicalización extrema de los problemas de salud mental; en contraste, otros sistemas de salud ofrecen una atención integrada por instancias sociales, médicas y comunitarias que centran su interés en el sufrimiento emocional y en el bienestar, yendo más allá de la relación sujeto/objeto y dando lugar al ejercicio de derechos de los usuarios de servicios y de sus familias. Desde esta corriente médicosocial, el enfoque de derechos es central en las prácticas transformadoras en lo que a la salud mental respecta; ello ha llevado a que movimientos y organizaciones, basándose en esta visión de los derechos humanos, construyan una acción de alta relevancia que promueve la aparición de otros actores, como las organizaciones de familiares y las de usuarios de servicios de salud mental que son considerados actores indispensables para modificar la tendencia fuertemente corporativa de los actores tradicionales del campo de la salud mental y modificar su resistencia, al impulsar un nuevo ordenamiento jurídico, técnico y de gestión, ligado con la ética clínica (Ardila y Stolkiner, 2010).

Desde el punto de vista de la normatividad, Colombia ha propuesto reiteradamente políticas públicas de salud mental (1998, 2005, 2007, 2015 y 2018), pero estas no han sido implementadas con suficiencia. Con la Ley 1616 de 2013 o Ley de Salud Mental, se intentó dar respuesta a esta dificultad, sin embargo, aún está pendiente su reglamentación; se intenta una vez más, a través de la Resolución 1004886 de 2018 o Política Nacional de Salud Mental, reconocer, nuevamente, el derecho a la salud mental de la población colombiana, teniendo como norte cinco enfoques: derechos humanos, curso de vida, género, diferencial poblacional-territorial y psicosocial. Pueden influir diversos aspectos en la implementación de la normatividad y su efecto sobre la salud mental poblacional: asuntos del orden social, político, económico y cultural tienen injerencia no solamente en el contenido normativo sino a su vez, en la implementación, planeación y ejecución de los programas de las políticas y leyes que se deriven de estas normas.

Las anteriores reflexiones, que se engloban al interior de la disciplina de la salud pública, muestran cómo otras ciencias y corrientes de pensamiento influyen en el bienestar de la población y en su salud mental. Teniendo en cuenta que los problemas de salud mental son 
multifactoriales, el éxito de la planificación de su intervención depende de diversos asuntos que inciden en la investigación, la formación disciplinar, interdisciplinar y transdisciplinar además de la organización del sistema de salud; la preparación, desempeño y evaluación del talento humano es un elemento importante para el mantenimiento y recuperación de la salud mental de los individuos y comunidades y, en este punto, la conceptualización de salud mental propuesta por las instituciones contribuye de manera importante en esta formación profesional y en la orientación de las intervenciones que se desarrollen a partir de estas.

Como conclusión de los conceptos disciplinares de salud mental, puede destacarse que sus elementos se debaten entre la salud mental de los individuos y la pérdida de esta como objeto de intervención de las profesiones, las organizaciones y los Estados. Igualmente, se encuentran controversias entre los determinantes biológicos, psicológicos y sociales en la aparición de problemas de salud mental o en el mantenimiento de esta, siendo un punto importante para el diseño de las intervenciones y la relevancia de cada una de las profesiones en la recuperación de la salud mental y de la salud en general.

\subsubsection{Conceptos institucionales de salud mental}

La revisión de las propuestas conceptuales en salud mental desde las instituciones ofrece un panorama de la concepción de salud mental en el marco de los postulados políticos y programáticos planteados desde diferentes instituciones, con el fin de exponer sus significados y acercarse a las implicaciones que estos mismos tienen para las intervenciones que sobre la salud mental se realizan. Igualmente, este ejercicio presenta insumos para la reflexión sobre la formación del talento humano en salud mental desarrollada en el capítulo 2.

La literatura institucional sobre salud mental hallada luego de esta revisión documental, comprende principalmente las que publica la OMS/OPS; se hallan otros documentos institucionales, tanto del orden internacional, como nacional y local, que igualmente referencian la noción de salud mental que propone la OMS, o bien, presentan otros conceptos con elementos similares. La mayoría de las propuestas conceptuales 
explican qué es la salud mental de un individuo y pocas aluden al término en su significado colectivo, lo que plantea una dificultad para comprender la aplicación del concepto en los contenidos de los documentos, en tanto que, para algunas instituciones el objeto de su intervención es la colectividad y no solamente el sujeto.

La OMS precisa que no existe una definición oficial sobre lo que es salud mental y que cualquiera de ellas estará condicionada por particularidades culturales, subjetividades y diversas miradas disciplinares. Lo que no se encontró en este tipo de publicaciones es un respaldo teórico amplio que sustente los conceptos; el concepto de salud mental aparece como preámbulo del contenido de los documentos, pero en ellos el interés se centra en informar sobre problemáticas de salud mental, especialmente en trastornos mentales y problemas del comportamiento, pocos de ellos especifican qué significa ese estado de bienestar presentando un respaldo científico que relacione las características deseables con dicho estado. Al parecer, la adhesión institucional al concepto de la oMs es una forma de ratificar los convenios internacionales y la implementación y validación de las políticas y programas.

Desde el año 1946, la oms (2006) ubica la salud mental como un elemento integrante de la salud en general; esta última fue definida entonces como un "estado de completo bienestar físico, mental, y social, y no meramente la ausencia de enfermedad o dolencia" (OMS, 2006, p. 1). Posteriormente, el Dr. I. Levav (1992) propuso un concepto, enfatizando los aspectos esenciales que presenta un sujeto mentalmente sano:

La salud mental es un estado sujeto a fluctuaciones provenientes de los factores biológicos y sociales, en que el individuo, se encuentra en condiciones de seguir una síntesis satisfactoria de sus tendencias instintivas, potencialmente antagónicas, así como de formar y sostener relaciones armoniosas con los demás y participar constructivamente en los cambios que pueden introducirse en el medio ambiente físico y social (Levav, 1992, p. 107).

Más adelante, en el año 2001, en el Informe de Salud Mental, la oMs retoma esta definición sintetizándola en el bienestar subjetivo, la percepción de la propia eficacia, la autonomía, la competencia, la dependencia intergeneracional y la autorrealización y, en 2004, concluye 
que la salud mental es "un estado de bienestar en el cual el individuo se da cuenta de sus propias aptitudes, puede afrontar las presiones normales de la vida, puede trabajar productiva y fructíferamente y es capaz de hacer una contribución a su comunidad" (OMS, 2004, p. 14).

En esta última publicación, el objeto del informe ya no son los problemas de la salud mental, sino la promoción de esta y aparecen las condiciones ideales para mantenerla y mejorarla; estas condiciones tienen una relación directa con la cultura, las políticas públicas y el capital social, ya que consideran la salud mental un elemento con valores sustanciales e intrínsecos para el bienestar individual, social y cultural. Se enfatiza en la capacidad del sujeto de relacionarse armónicamente con otros, constituyéndose en la base de la seguridad y solidaridad de los pueblos.

El Ministerio de Salud de Canadá, en 1989, amplió la naturaleza del concepto identificando condiciones individuales y colectivas, así como aspectos éticos:

Salud mental es la capacidad de las personas y de los grupos para interactuar entre sí y con el medio ambiente; un modo de promover el bienestar subjetivo, el desarrollo y uso óptimo de las potencialidades psicológicas, ya sea cognitivas, afectivas o relacionales. Así mismo, el logro de metas individuales y colectivas, en concordancia con la justicia y el bien común (citado por Minsalud, 1998, p. 20).

Según la Federación Mundial para la Salud Mental (WFMH, por sus siglas en inglés) - organización pública y educativa en el tema-, la salud mental tiene que ver con la autopercepción construida en la relación con los demás y, con la forma como se responde a las demandas de la vida. Para esta federación, no existe una línea divisoria que indique con precisión cuál persona es mentalmente sana y cuál no lo está, nadie mantiene durante toda su vida las mismas condiciones de salud mental; así mismo, recomienda programas y recursos que contribuyan a la aproximación de promoción integral y holística que se ocupe de los aspectos de la salud mental y física que intervienen en el bienestar (Mebarak, De Castro, Del Pilar y Quintero, 2009). Lo anterior fue ratificado por los ministros de salud de la región europea de países miembros de la 
OMs (2005) en la Declaración de Salud Mental donde se acuerda que "el principal objetivo en materia de salud mental es mejorar el bienestar de las personas" (Ministerio de Sanidad, Consumo y Bienestar Social, 2005, p. 1), y se solicita a la oMs respaldo para el cumplimiento de políticas de salud mental con el fin de ofrecer servicios necesarios para la atención de los problemas en este tema.

La OMS, en el año 2008 se refiere a la salud mental como una prioridad mundial para la salud pública y propone tres objetivos básicos al respecto: 1 . reducir la carga humana, social y económica producida por los desórdenes psiquiátricos y neurológicos, incluyendo la inhabilidad intelectual y el abuso y dependencia a sustancias; 2 . promover la salud mental, y 3 . dar atención apropiada a los aspectos psicosociales del cuidado de la salud y mejorar la calidad de vida (OMS, 2008). En estos objetivos se denota la intención, derivada tal vez de su conceptualización, de intervenir no solamente los aspectos negativos (trastornos mentales y otros problemas), sino además centrarse en los aspectos positivos a través de la promoción de la salud mental.

En los Estados Unidos de América (EUA), el Instituto Nacional de Salud Mental (National Institute of Mental Health, 2017) ha aportado tanto a la investigación sobre el comportamiento humano como al mejoramiento de la atención a las personas afectadas por trastornos mentales, VIH/SIDA y adicciones. Esta institución admite que existen diferencias entre sus propios estamentos respecto a lo que es salud mental, por lo tanto, no se compromete con una sola definición sobre la misma (National Institute of Mental Health, 2017).

La mayoría de los sistemas de salud en el mundo ofrecen servicios de salud mental que en buena parte son de carácter psiquiátrico; paulatinamente, en ellos se han integrado otras actividades de carácter preventivo y de rehabilitación, así como de promoción de la salud mental, que han requerido equipos multidisciplinarios donde se atienden asuntos en conexión con los trastornos mentales y con situaciones generadoras de sufrimiento emocional. Algunas instituciones estatales y no gubernamentales han integrado tanto la atención a los problemas de la salud mental como la promoción de sus determinantes, incorporando las dimensiones negativas con las positivas. 
Para las organizaciones internacionales, en el constructo salud mental subyacen tanto sus aspectos positivos como negativos, aunque en la mayoría de los documentos institucionales los trastornos mentales y de los problemas de comportamiento y sus intervenciones adecuadas son el objeto de interés.

En Colombia, desde el punto de vista estatal, el concepto de salud mental está explícitamente contenido en la Ley 1616 de 2013 como:

un estado dinámico que se expresa en la vida cotidiana a través del comportamiento y la interacción de manera tal que permite a los sujetos individuales y colectivos desplegar sus recursos emocionales, cognitivos y mentales para transitar por la vida cotidiana, para trabajar, para establecer relaciones significativas y para contribuir a la comunidad. (Congreso de la República de Colombia, 2013, p. 1).

Esta definición es acogida por la Política Nacional de Salud Mental de 2018, expedida a partir de la Ley 1616, y presenta diferencias con la definición de salud mental citada en la anterior política colombiana (MinSalud, 1998, p. 20), la cual hacía alusión literal a la concepción de salud mental del Gobierno canadiense en 1989.

\subsection{Significados del término salud mental para la intervención}

\subsubsection{Conceptualización de salud mental desde la salud pública. Una propuesta conceptual integradora para facilitar las intervenciones}

Para la conceptualización de salud mental se realizó, como se dijo anteriormente, desde el año 1999 a 2018, una compilación documental no sistemática de literatura científica e institucional sobre el tema, en español, inglés y portugués; se sistematizaron 238 documentos que contenían las palabras "salud mental" y "concepto de salud mental" en el título; esta literatura se encontró disponible en las bases de datos electrónicas: Google Académico, Clinical Key, PubMed, Cambridge, Ebsco, Scielo y Oxford Journals y en algunos medios físicos. 
El material hallado se clasificó en dos dimensiones: 1. los aspectos referidos a problemas de salud mental, la gran mayoría sobre los trastornos mentales, así como sobre problemas psicosociales; esta primera dimensión se categorizó como "negativa". 2. Los aspectos referidos a los determinantes o condicionantes de la salud mental, su conceptualización como parte de la salud en general y las características individuales de lo que se denomina un sujeto mentalmente sano; esta segunda dimensión se denominó "positiva".

La propuesta conceptual que se muestra a continuación se construye en el contexto de una salud mental que, por ser parte integral de la salud, es un asunto central para la salud pública; en tal razón, no debe ser considerada solamente como un servicio más de los sistemas de salud, sino como una condición necesaria para la humanización de las intervenciones orientadas por políticas, normas y planes de salud. "No hay salud, sin salud mental" afirma la oMs (2004, p. 14), siendo este un principio globalmente aceptado por los países miembros. Con esta afirmación, la oMs reconoce que la salud mental es indispensable para alcanzar mejores niveles de salud, calidad de vida y bienestar (OMS, 2013).

Es necesario indicar que se ha estudiado el concepto de salud mental desde la salud pública en diversos documentos. En el realizado por Restrepo y Jaramillo (2012), se exponen los diferentes enfoques desde los que se aborda la conceptualización: biomédico, conductual, cognitivo y socioeconómico, así como los significados correspondientes (ausencia de trastornos mentales, adaptación como ajuste al contexto y al sistema productivo, capacidad del sujeto para adaptarse racionalmente a las demandas internas y externas y salud mental en términos de derechos y desarrollo humano). Igualmente, la relación entre salud pública y salud mental ha sido analizada por otros autores en Colombia, a partir de las dificultades en la legislación y la atención sanitaria en este tema (NovoaGómez, 2012; Arrivillaga, Collazos, Posada-Villa y Molina y González, 2009).

La literatura científica, institucional y política que incluye en su título y contenido el término "salud mental" es el producto de investigaciones, experiencias profesionales y representaciones sociales sobre el tema que, al analizarla, presenta un amplio panorama de asuntos relacionados con los trastornos mentales, problemáticas psicosociales y determinantes de 
salud mental que parecen conformar un campo de conocimiento al que aportan varias disciplinas, cuya integración es un proceso en construcción, como se ha expuesto anteriormente. Se justifica el contexto de la salud pública, en tanto es una disciplina que pretende integrar saberes sobre la salud y la enfermedad, así como sobre el bienestar físico, mental y social, siendo este un campo adecuado para articular los postulados o teorías disciplinares que aportan a la conceptualización de salud mental, partiendo de la necesidad de tener una orientación común para la multiplicidad de intervenciones que se realizan en este campo. Así mismo, desde el decenio de los sesenta del siglo pasado se ha identificado la necesidad de unificar los términos utilizados en la investigación y el abordaje de la salud mental. Aunque en un principio esta necesidad se orientaba principalmente hacia el diagnóstico y tratamiento psiquiátrico, se presentaba ya un interrogante sobre los diversos significados del término salud mental en las diversas culturas y disciplinas, así como en otros fenómenos relacionados (Horwitz y Marconi, 1966).

La comprensión holística de este campo del conocimiento tiene como objeto aportar al diseño, implementación y evaluación de las diversas intervenciones con enfoque biopsicosocial, de derechos, de desarrollo humano, diferencial, dirigidas a los trastornos mentales, los problemas del comportamiento, el sufrimiento emocional individual y social, a través del tratamiento y la prevención de los mismos, e igualmente a la promoción de la salud mental y del bienestar. Esta comprensión de la salud mental se considera central para la formación de talento humano, con un enfoque transdisciplinar con sentido humanista e integral.

Las temáticas tratadas por los documentos compilados, se analizaron bajo la categoría de dimensiones positiva y negativa, y al interior de estas, surgieron tres categorías que se denominaron componentes de la salud mental: condicionantes de la salud mental (referido a la dimensión positiva), problemas psicosociales y trastornos mentales (referidos a la dimensión negativa). Es necesario aclarar que en el análisis de los documentos, estos componentes y dimensiones aparecen entremezclados, quizá evidenciando la interrelación que se busca entre ellos en las diferentes investigaciones y ensayos, no necesariamente oponiéndose, sino configurando un proceso bidireccional. La distribución de estos componentes se ilustra en la figura 1. 
Figura 1. Distribución porcentual de los documentos hallados de acuerdo a los componentes

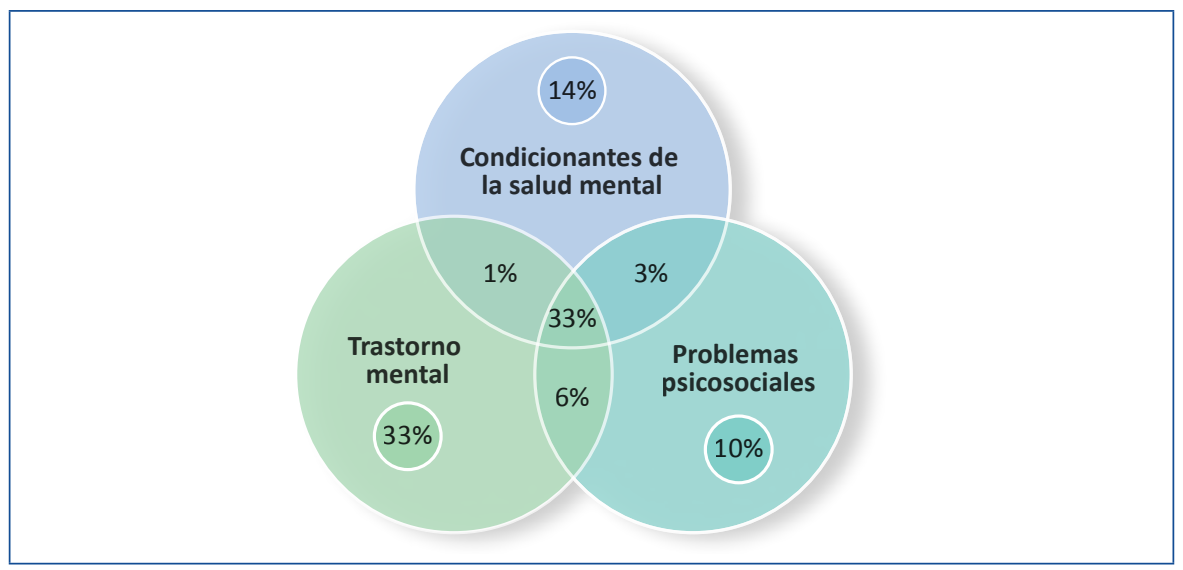

La distribución de esta información de acuerdo a sus fuentes, respecto a si es de carácter científico disciplinar o institucional, se esquematizan en la tabla 1.

Tabla 1. Número y proporción de documentos de salud mental en una compilación realizada entre 1999-2018 para estudios que contienen el concepto de salud mental

\begin{tabular}{|l|c|c|c|c|c|c|c|c|}
\cline { 2 - 9 } \multicolumn{1}{c|}{} & Positivo & F/R & Negativo & F/R & $\begin{array}{c}\text { Positivo/ } \\
\text { negativo }\end{array}$ & F/R & $\begin{array}{c}\text { Total } \\
\text { documentos }\end{array}$ & F/R \\
\hline Institucional & 2 & 3,0 & 37 & 56,9 & 26 & 40,0 & 65 & 27,3 \\
\hline Disciplinar & 28 & 16,1 & 75 & 43,3 & 70 & 40,6 & 173 & 72,6 \\
\hline Total & 30 & 12,6 & 112 & 47,0 & 96 & 40,3 & 238 & 100,0 \\
\hline
\end{tabular}

En esta tabla se evidencia como el sentido negativo de salud mental es la dimensión más frecuentemente abordada por los autores de los documentos compilados (47\%), tanto institucionales como disciplinares; por su parte, la dimensión positiva de la salud mental se refleja en el 12,6 \% de los documentos; sin embargo, esta dimensión aparece en mayor proporción en los textos disciplinares que en los institucionales; es relevante como ambas dimensiones se tratan conjuntamente en el $40 \%$ de los textos.

La dimensión negativa de la salud mental está comprendida, sumando las categorizaciones, en el $73 \%$ de estos; contienen aspectos sobre los trastornos mentales utilizando el término salud mental en relación con 
"servicios de salud mental" como sinónimo de servicios psiquiátricos (OMS, 2006), y "estudios de salud mental", refiriéndose a investigaciones epidemiológicas de trastornos mentales, entre otros (MinSalud, Colciencias, Pontificia Universidad Javeriana y Datos, Procesos y Tecnologías, SAS, 2015). También se categorizó en la dimensión negativa, otro grupo de documentos sobre "problemas de salud mental" refiriéndose a otras problemáticas de orden psicosocial (52\%): violencia (OMS, 2013), alienación (Jarne y Arch, 2009; Basabe y Páez, 2006), desafecto (Bowlby, 1968), uso de drogas (García, Ferreira, Tutus, De Almeida, Harvasi y Riveiro, 2015), sexualidad (Meyer, 2003) y malestar individual o social (Chávez, Macías y Klein, 2013).

La dimensión positiva de la salud mental resultó de categorizar aquellos documentos que se referían al concepto de salud mental desde perspectivas disciplinares (Restrepo y Jaramillo, 2012) e institucionales (OMS, 2013), así como ensayos e investigaciones sobre el significado de salud mental en diversas poblaciones (Betancur, Restrepo, Ossa, Zuluaga y Pineda, 2014; Barrón y Sánchez, 2001); se hallaron explicaciones sobre bienestar como sinónimo de salud mental (Oramas, Santana y Vergara, 2006; Blanco y Díaz, 2006 ) y características de sujetos mentalmente sanos de lo cual se ocupa, entre otras, la psicología positiva (Vázquez y Hervás, 2009).

En conclusión, salud mental es un campo del conocimiento, en tanto la revisión realizada reveló su complejidad y con ello la imposibilidad de reducirla a una única definición y a una única disciplina. Este campo comprende, como se dijo anteriormente, una dimensión positiva y otra negativa de la salud mental en las cuales cada uno de sus componentes presenta problemáticas o aspectos diversos que es necesario considerar si se quiere abarcar la mayoría de los temas relacionados con la salud mental y que son pertinentes para la investigación, la normatividad, la planeación de servicios y la formación del talento humano.

\subsubsection{Reflexión sobre la intervención de la salud mental en Colombia}

Si bien es preciso reconocer que no todas las intervenciones y acompañamientos en salud mental se realizan al interior del Sistema General de Seguridad Social en Salud (SGSSS), el Ministerio de Salud y Protección Social de Colombia de la mano con el Congreso de la República garantizan el ejercicio del pleno derecho a la salud y a la salud mental en el marco de las leyes, políticas y resoluciones que en esta materia se emiten y que 
se operan a través del mencionado SGSSS, entre ellas: Ley 1438 de 2011 (Reforma al Sistema General de Seguridad Social en Salud en el marco de la Atención Primaria en Salud), la Ley 1616 de 2013 (Ley de Salud Mental), la Resolución 1841 de 2013 (Plan Decenal de Salud Pública), la Ley 1751 de 2015 (ley para la regulación del derecho fundamental a la salud), la Resolución 429 de 2016 (Política de Atención Integral en Salud -PAIS-), la Resolución 4886 de 2018 (Política Nacional de Salud Mental), entre otras.

En la Ley 1616 de 2013, se establece que la atención en salud mental estará a cargo de los equipos interdisciplinarios conformados por psiquiatría, psicología, enfermería, trabajo social, terapia ocupacional, terapia psicosocial, medicina general, entre otros profesionales; el tipo de intervención se rige por el nivel de complejidad y especialización requerido según el esquema del SGSSS, reglamentado por la Ley 100 de 1993; desde ese año se han expedido otras leyes que reforman la anterior y numerosos decretos y acuerdos para precisar el tipo e intensidad de los servicios de salud mental. Ahora bien, la Ley 1616 de 2013 que pretendía subsanar algunas imprecisiones en materia de responsabilidad y derechos, no ha sido reglamentada y se sigue operando con decretos anteriores.

Desde el año 2003, se reconoció a través del Estudio Nacional de Salud Mental de Colombia que "solo una de cada 10 personas con un trastorno mental y solo una de cada cinco con dos o más trastornos mentales recibe algún tipo de tratamiento" (Ministerio de Protección Social, 2003, p. 9). Doce años después, se realizó la Encuesta Nacional de Salud Mental-2015 (MinSalud, 2015) en ella se reportó que existen barreras diversas en el acceso y oportunidad de los servicios de salud mental y que estas son de índole actitudinal, geográfico y económico; respecto a la atención, se destaca que entre el $94 \%$ y $88,5 \%$ de personas con problemas de salud mental (trastornos mentales) reciben atención después de solicitarla, siendo el recurso más utilizado las instituciones de salud y los profesionales de salud, particularmente la terapia más solicitada es la psicoterapia ( $58 \%$ a $72 \%$ ). Ahora, pese a que el requerimiento de uso de medicamentos oscila entre $0,8 \%$ y $3,7 \%$, el acceso a ellos no es completo pues, de acuerdo a lo que reporta la encuesta, la población que accede a los mismos varía entre $73 \%$ y $97 \%$; las principales razones de ello son la no disponibilidad del servicio, la espera para la entrega y la falta de recursos económicos. 
En este orden de ideas, se identifica un desajuste entre las necesidades de la población que demanda atención a estos problemas con diversos grados de complejidad en salud mental y la oportunidad de la atención. Se reconoce en la intervención que proporcionan médicos generales, un proceso complejo que le requiere indicar la gestión de medicamentos, interconsultas a otros niveles de complejidad del SGSSS y la activación de una red interinstitucional, en el marco de una estructura del mismo Sistema que condiciona la oferta a un portafolio delimitado de servicios en el plan de beneficios de cada EPS, el cual puede restringir las intervenciones requeridas para un tratamiento integral e integrado. Por otra parte, entendiendo que la atención del profesional de medicina se constituye en la puerta de entrada al Sistema, los diagnósticos en salud mental sin un adecuado entrenamiento técnico en el área, puede entorpecer el acceso a los servicios y una atención de calidad (Henao, Restrepo, Alzate y González, 2009; Novoa-Gómez, 2012). No obstante, es innegable la mejoría en el acceso a servicios institucionales de salud mental (MinSalud, 2015).

Ahora bien, en la Encuesta Nacional de Salud Mental (MinSalud, 2015) se recomienda el fortalecimiento de la salud mental comunitaria, la Atención Primaria en Salud Mental (APSM), la psicoeducación poblacional para disminuir las barreras actitudinales referidas entre otras cosas, a la desestigmatización de la enfermedad mental, al reconocimiento de los derechos y rutas de acceso a la atención, a la adherencia al tratamiento. En este orden de ideas, el reconocimiento de los recursos por fuera del SGSSS, generalmente de naturaleza comunitaria, es necesario para ofrecer una atención integral, no solamente a los individuos, sino también a las familias y grupos sociales de interacción. Lo anterior entra en sintonía con el objetivo planteado por la Política Nacional de Salud Mental (MinSalud, 2018), en tanto esta dirige sus acciones no solo a los individuos, sino también a las familias y a las comunidades, y proyecta la salud mental como un tema prioritario en la agenda pública, reconociendo que las comunidades son entornos y agentes fundamentales para el alcance de este propósito. Un aspecto a resaltar de la política en cuanto a su interés en la comunidad, es el planteamiento referido a la cualificación de los dispositivos comunitarios y la adaptación de los mismos a la medicina tradicional y a sus propias formas de organización. 
El contexto histórico y político colombiano, caracterizado por el conflicto armado, ha dejado una enorme necesidad de atención en aspectos psicológicos y sociales, derivados de las violencias, injusticias y abandono estatal, para lo cual se requieren profesionales y técnicos que acompañen, con un enfoque psicosocial, este tipo de problemas y tensiones que han generado en las personas malestar, pérdidas afectivas y económicas, sufrimiento psíquico e inequidad, entre otros. Los problemas de índole psicosocial o ambiental se presentan también en contextos externos a los que ha dejado el conflicto armado; en la Ley 1616 de 2013 se señala que estos problemas pueden ser:

un acontecimiento vital negativo, una dificultad o deficiencia ambiental, una situación de estrés familiar o interpersonal, una insuficiencia en el apoyo social o los recursos personales, u otro problema relacionado con el contexto en que se han desarrollado alteraciones experimentadas por una persona. (Ley 1616/2013, p. 3).

Tanto los trastornos mentales como las problemáticas psicosociales deben ser objeto de prevención mediante intervenciones dirigidas a los individuos, familias y colectivos, tendientes a disminuir o impactar los factores de riesgo relacionados con estos. En ese sentido, se encuentra que la Política de Salud Mental vigente, propone cinco enfoques desde los cuales orientar la prevención y asistencia a la enfermedad mental, la rehabilitación psicosocial, y la promoción de la salud mental; estos son: desarrollo basado en derechos humanos, curso de vida, género, diferencial poblacional-territorial, y psicosocial (MinSalud, 2018).

La construcción presentada hasta el momento da cuenta de los lineamientos políticos y normativos que circundan la atención en salud mental, atención que requiere profesionales y técnicos con conocimientos de los derechos en salud mental, las problemáticas y factores de riesgo y de protección, e igualmente con competencias en atención individual, familiar y comunitaria, transversalizando los diferentes niveles de atención (promoción de la salud mental, prevención de los problemas psicosociales y de los trastornos mentales, tratamiento oportuno y completo y rehabilitación psicosocial); esto contribuiría a que el alcance del derecho a la salud mental se garantice. 


\title{
FORMACIÓN DEL TALENTO HUMANO EN SALUD MENTAL EN COLOMBIA:
}

\author{
una mirada a los planes de estudios universitarios \\ en Psicología, Trabajo Social, Medicina, Enfermería \\ y Terapia Ocupacional
}

Después de realizar un recorrido por la conceptualización de salud mental, este capítulo se propone presentar un análisis de la formación del talento humano en salud mental en el contexto colombiano, a partir de las reflexiones e investigaciones del Grupo Académico en Salud Mental de Antioquia (GASMA) y del Grupo Interdisciplinario de Estudios Sociales (GIES) ${ }^{3}$, a propósito de la emisión de la Ley 1616 de enero 21 de 2013, Ley de Salud Mental. De esta manera, el capítulo desarrolla un contraste entre lo que podría considerarse un ideal en la formación profesional ${ }^{4}$ en

\footnotetext{
${ }^{2}$ GASMA es un grupo interuniversitario, interdisciplinario e intersectorial cuyo propósito es gestionar el conocimiento en salud mental desde una perspectiva de salud pública, en aras de aportar a la formación del talento humano en salud mental de acuerdo con las necesidades del contexto.

${ }^{3}$ GIES es un grupo de investigación interdisciplinar en ciencias sociales de la Facultad de Ciencias Humanas y Sociales de la Corporación Universitaria Minuto de Dios - UNIMINUTO Sede Bello.

${ }^{4}$ En el marco de los Niveles de la Educación Superior expuestos por el Ministerio de Educación Nacional de Colombia, el nivel profesional equivale a los programas universitarios; este es el tercer nivel de los otros dos posibles en la formación de pregrado (Nivel Técnico Profesional y Nivel Tecnológico, es decir, Niveles 1 y 2, respectivamente).
} 
salud mental - producto de las reflexiones de los grupos en mención-y aquello que para 2015 se halla como un aspecto de la realidad de dicha formación - producto de la investigación de estos mismos grupos-.

Para atender a este contraste, se presentan dos apartados: el primero delimita los constructos asociados a la expresión talento humano en salud mental, para luego exponer las temáticas en salud mental que deberían ser contempladas en la formación universitaria de este talento humano, según la orientación de lineamientos nacionales e internacionales; y el segundo presenta un panorama actual de dicha formación en el contexto colombiano, a partir de los resultados de la investigación "Formación del talento humano en salud mental en seis programas de pregrado en Colombia, 2015" .

Los temas tratados en este apartado tocan intereses del campo administrativo, educativo y de salud; el campo administrativo, permitirá comprender el término talento humano, el educativo propiciará un acercamiento al concepto de competencia/capacidad ${ }^{6}$, y el de salud delimitará el ámbito de aplicación de este talento humano. Igualmente, la presentación de este capítulo invita a recurrir a documentación normativa, legal e institucional en lo referente a talento humano en salud y en salud mental; esto es, a las orientaciones internacionales de organismos como la OMS, la Organización Internacional del Trabajo (OІт), y a publicaciones de entidades nacionales como el Ministerio de Educación, el Ministerio de Salud y Protección Social y del Congreso de la República de Colombia (específicamente, la Ley del Talento Humano en Salud y la Ley de Salud Mental) para listar las temáticas que de allí se infieren como relevantes en las formación del talento humano en salud mental. Finalmente, y en contraste con los retos de la Ley de Salud Mental, estos apartados deben traer a colación varios de los resultados de la investigación de 2015 mencionada anteriormente.

\footnotetext{
${ }^{5}$ Esta investigación fue desarrollada por el Grupo Académico en Salud Mental de Antioquia y el Grupo Interdisciplinario de Estudios Sociales con el apoyo financiero del Sistema de Investigación de UNIMINUTO; este ejercicio investigativo, se acercó al análisis de los planes de estudios universitarios de seis disciplinas, no obstante, en este capítulo se ofrecen los resultados del análisis de cinco de ellas.

${ }^{6}$ Aunque en este capítulo no se hará mayor desarrollo del concepto de competencia, se hace alusión a la misma, toda vez que dentro de sus componentes está el referido a conocimientos o saber.
} 
Es necesario aclarar tres cosas: primero, que, tanto en el ámbito administrativo-empresarial como en el ámbito académico, se hace referencia al desarrollo de competencias; ambas estrechamente relacionadas, en tanto la academia - entre otras cosas - debe formar para el trabajo. Segundo, que el acercamiento a la formación en salud mental que se hace en el segundo apartado de este capítulo, se centra en los contenidos temáticos inferidos de la Ley de Salud Mental (y demás documentos mencionados en el párrafo anterior) y posteriormente analizados en las mallas curriculares de los programas universitarios que para 2015 estaban activos en el Sistema Nacional de Información de la Educación Superior (SNIES), y no se trata propiamente de un análisis del desarrollo de competencias en salud mental; ahora bien, en el capítulo 3 de este libro, en aras de presentar la propuesta de modelo de formación transdiciplinar en salud mental, se retomará tanto la conceptualización de competencia como las competencias que, a partir de la propuesta en mención, se esperan desarrollar en el talento humano en salud mental.

Finalmente, la tercera claridad es que la elección de los planes de estudios universitarios que se presentarán en este libo para los programas de Psicología, Trabajo Social, Medicina, Enfermería y Terapia Ocupacional, se hizo a partir de aspectos de la Ley de Salud Mental de Colombia y del interés de los investigadores en los planes de formación de pregrado universitario (no así, en planes técnicos, tecnológicos, ni en los planes especializados).

\subsection{Talento humano en salud mental en Colombia}

Con el propósito de delimitar los constructos asociados a la expresión talento humano en salud mental, se responderá a dos preguntas: ¿qué es talento humano en salud? y ¿quiénes son el talento humano en salud mental en Colombia?

\subsubsection{Talento humano en salud}

Aun cuando la OMS y la OPS se refieren a las personas que trabajan en el campo de la salud como recurso, las reflexiones hechas para el desarrollo de las investigaciones y la escritura de este texto, concluyeron la pertinencia de hacer referencia a estas personas en términos de talento; aspecto que además se justifica en que así son también nombradas en las 
leyes colombianas de salud mental y de talento humano. Así, el término "talento humano" se diferencia del de "recurso humano" en su intención de privilegiar las capacidades de los colaboradores, otorgándoles un papel protagónico en el ejercicio de sus funciones y propiciando su participación en la planeación de las mismas; el segundo término, se enfoca en la capacidad productiva del trabajador, situándolo como una pieza sustituible de la organización cuyo papel es pasivo (Aktouf, 1998).

Ahora, en lo que respecta al talento humano que se desempeña específicamente en el campo de la salud, la oms lo nombra como trabajador sanitario y lo define en términos de "toda persona que lleva a cabo tareas que tienen por principal finalidad promover la salud" (OMS, 2006. p. 1). Esta definición, de acuerdo a lo planteado por la misma OMs, es consecuente con su visión de sistema sanitario, según la cual, dicho sistema tiene como principal objetivo el mejoramiento de la salud; definición que abarcaría estrictamente a toda persona que de una u otra forma se ocupe del cuidado de la salud de otros, aun cuando su trabajo no sea formal ni remunerado. Este hecho, es también reconocido por la OMS como una contribución importante y esencial para el funcionamiento de los sistemas de salud, no obstante, complejiza la posibilidad de hacer seguimiento y estudio de las funciones, en cuanto al cuidado de la salud, que diversas personas realizan en el marco de la informalidad y la no remuneración (OMS, 2006).

En el informe sobre la salud en el mundo de 2006 Colaboremos por la salud, la oms ofrece una clasificación de los trabajadores sanitarios en términos de: quienes se desempeñan en el sector salud y tienen funciones administrativas en salud o bien funciones de dispensar servicios de salud; y quienes se desempeñan en otros sectores con funciones de dispensar servicios de salud $u$ otros servicios que incluyen a todas las demás ocupaciones (OMS, 2006).

Igualmente, la OPS se refiere a los recursos humanos en salud como ...todas las personas que realizan acciones cuya finalidad fundamental es mejorar la salud. Son personas con distintas profesiones y ocupaciones que se forman y trabajan en la salud, y que pertenecen a diversas categorías de formación, ámbito laboral y situación de empleo. 
Se incluye en este grupo a quienes trabajan como asalariados o como voluntarios en el sector público y privado, ya sea a tiempo completo o con jornada parcial, e independientemente de si prestan servicios de salud, gestionan los servicios del sistema o abordan los determinantes sociales de salud. Los recursos humanos para la salud forman parte de un campo intersectorial complejo y mantienen un compromiso con la salud y con las poblaciones a las que sirven. (OPS, 2012, párr. 2).

Como puede apreciarse en esta referencia al recurso humano que hace la OMS, no solo los profesionales de campos del conocimiento asociados a la salud hacen parte de este recurso humano, aquí también se incluyen todas las personas que de una u otra forma emiten acciones encaminadas al cuidado de la salud, es decir, aquí se incluyen también la gestión y las acciones comunitarias, muchas de ellas sin remuneración. Este último aspecto explicaría por qué, aun cuando estas personas pueden desarrollar actividades en torno a la promoción de la salud, no están consideradas en las clasificaciones del trabajo que a continuación se presentan. Ahora bien, la pesquisa del talento humano se hizo sobre los profesionales de la salud mental supuestos en la Ley 1616, dado el interés del presente ejercicio.

La OIT, entonces, dispone de la Clasificación Internacional Uniforme de Ocupaciones (cluo-88), en la cual, las ocupaciones se distribuyen en 10 grandes grupos ${ }^{7}$; a partir de esta clasificación, los profesionales del área de la salud explicitados en el título de este capítulo están categorizados en el segundo gran grupo de los 10 que allí se describen; los subgrupos principales en los que se enmarcan estas disciplinas son el 22, correspondiente a "Profesionales de las ciencias biológicas, la medicina y la salud" y el 24 , correspondiente a "Otros profesionales científicos e intelectuales".

\footnotetext{
7 Gran grupo 0: Fuerzas Militares / Gran grupo 1: Directores y gerentes / Gran grupo 2: Profesionales, científicos e intelectuales / Gran grupo 3: Técnicos y profesionales del nivel medio / Gran grupo 4: Personal de apoyo administrativo / Gran grupo 5: Trabajadores de los servicios y vendedores de comercios mercados / Gran grupo 6: Agricultores y trabajadores calificados agropecuarios, forestales y pesqueros / Gran grupo 7: Oficiales, operarios, artesanos y oficios relacionados / Gran grupo 8: Operadores de instalaciones y máquinas y ensambladores / Gran grupo 9: Ocupaciones elementales (OIT, 2010. p. 3).
} 
Tabla 2. Clasificación Internacional Uniforme de Ocupaciones cIUo-88

\begin{tabular}{|c|c|c|c|c|}
\hline $\begin{array}{l}\text { Gran } \\
\text { grupo }\end{array}$ & $\begin{array}{l}\text { Subgrupo } \\
\text { principal }\end{array}$ & Subgrupo & Grupo primario & $\begin{array}{c}\text { Disciplina en la } \\
\text { que se interesa } \\
\text { este capítulo }\end{array}$ \\
\hline \multirow{5}{*}{ 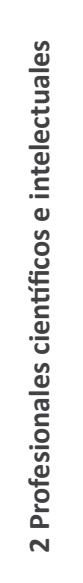 } & \multirow{3}{*}{$\begin{array}{l}22 \text { Profesionales } \\
\text { de las ciencias } \\
\text { biológicas, la } \\
\text { medicina y la } \\
\text { salud }\end{array}$} & \multirow{2}{*}{$\begin{array}{l}222 \\
\text { Médicos y } \\
\text { profesionales } \\
\text { afines }\end{array}$} & 2221 Médicos & Medicina \\
\hline & & & $\begin{array}{l}2229 \text { Este grupo primario } \\
\text { abarca a los médicos } \\
\text { y profesionales afines } \\
\text { (excepto el personal de } \\
\text { enfermería y partería) } \\
\text { no clasificados en otros } \\
\text { epígrafes }\end{array}$ & $\begin{array}{l}\text { Terapia } \\
\text { ocupacional }\end{array}$ \\
\hline & & $\begin{array}{l}223 \text { Profesional } \\
\text { de enfermería y } \\
\text { partería de nivel } \\
\text { superior }\end{array}$ & $\begin{array}{l}2230 \text { Profesional de } \\
\text { enfermería y partería de } \\
\text { nivel superior }\end{array}$ & Enfermería \\
\hline & \multirow{2}{*}{$\begin{array}{l}24 \text { Otros } \\
\text { profesionales } \\
\text { científicos e } \\
\text { intelectuales }\end{array}$} & \multirow{2}{*}{$\begin{array}{l}244 \text { Especialistas } \\
\text { en ciencias } \\
\text { sociales y } \\
\text { humanas }\end{array}$} & 2445 Psicólogos & Psicología \\
\hline & & & $\begin{array}{l}2446 \text { Profesionales del } \\
\text { trabajo social }\end{array}$ & Trabajo social \\
\hline
\end{tabular}

Fuente: tabla adaptada por las autoras, con base en información de la Clasificación Internacional Uniforme de Ocupaciones CIUO-88 (OIT, 2010).

En la versión de la CIUo-88, adaptada en 2005 por el Departamento Administrativo Nacional de Estadística (DANE) para Colombia, se encuentra una clasificación similar (CIUo Colombia, 2005).

Tabla 3. Clasificación Internacional Uniforme de Ocupaciones adaptada para Colombia

\begin{tabular}{|c|c|c|c|c|}
\hline $\begin{array}{l}\text { Gran } \\
\text { Grupo }\end{array}$ & $\begin{array}{l}\text { Subgrupo } \\
\text { principal }\end{array}$ & Subgrupo & Grupo primario & $\begin{array}{l}\text { Disciplina en la } \\
\text { que se interesa } \\
\text { este capítulo }\end{array}$ \\
\hline \multirow{5}{*}{ 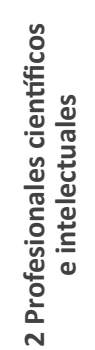 } & \multirow{3}{*}{$\begin{array}{l}22 \text { Profesionales } \\
\text { de las ciencias } \\
\text { biológicas, la } \\
\text { medicina y la } \\
\text { salud }\end{array}$} & \multirow{3}{*}{$\begin{array}{l}222 \text { Médicos, } \\
\text { profesionales } \\
\text { en ciencias de la } \\
\text { salud y afines }\end{array}$} & 2221 Médicos & Medicina \\
\hline & & & $\begin{array}{l}2225 \text { Fonoaudiólogos, } \\
\text { fisioterapeutas y afines }\end{array}$ & $\begin{array}{l}\text { Terapia } \\
\text { ocupacional }\end{array}$ \\
\hline & & & $\begin{array}{l}2226 \text { Enfermeros(as) } \\
\text { profesionales }\end{array}$ & Enfermería \\
\hline & \multirow{2}{*}{$\begin{array}{l}24 \text { Otros } \\
\text { profesionales } \\
\text { científicos e } \\
\text { intelectuales }\end{array}$} & \multirow{2}{*}{$\begin{array}{l}244 \text { Profesionales } \\
\text { en ciencias } \\
\text { económicas, } \\
\text { sociales y humanas }\end{array}$} & 2445 Psicólogos & Psicología \\
\hline & & & $\begin{array}{l}2446 \text { Trabajadores } \\
\text { sociales y afines }\end{array}$ & Trabajo social \\
\hline
\end{tabular}

Fuente: tabla adaptada por las autoras, con base en información de la Clasificación Internacional Uniforme de Ocupaciones adaptada para Colombia (DANE, 2005). 
La clasificación más reciente con la que se cuenta en Colombia es la realizada por el Servicio Nacional de Aprendizaje (SENA), a través de la Dirección de Empleo y Trabajo del Observatorio Laboral y Ocupacional Colombiano; esta Clasificación Nacional de Ocupaciones (CNO) describe diez áreas de desempeño, dos de las cuales, incorporan las disciplinas de interés: el campo 3, denominado "ocupaciones en salud" y el campo 4, denominado "ocupaciones en ciencias sociales, educación, servicios gubernamentales y religión".

Tabla 4. Clasificación Nacional de Ocupaciones SENA

\begin{tabular}{|c|c|c|c|c|}
\hline $\begin{array}{c}\text { Área de } \\
\text { desempeño }\end{array}$ & $\begin{array}{c}\text { Área } \\
\text { ocupacionales }\end{array}$ & $\begin{array}{c}\text { Campos } \\
\text { ocupacionales }\end{array}$ & Ocupaciones & $\begin{array}{l}\text { Disciplina en la } \\
\text { que se interesa } \\
\text { este capítulo }\end{array}$ \\
\hline \multirow[t]{4}{*}{$\begin{array}{l}3 \text { Ocupaciones } \\
\text { en Salud }\end{array}$} & \multirow[t]{4}{*}{$\begin{array}{l}31 \text { Ocupaciones } \\
\text { profesionales en } \\
\text { salud }\end{array}$} & $\begin{array}{l}311 \text { Médicos, } \\
\text { odontólogos y } \\
\text { veterinarios }\end{array}$ & $\begin{array}{l}3112 \text { Médicos } \\
\text { generales }\end{array}$ & Medicina \\
\hline & & $\begin{array}{l}314 \text { Profesionales } \\
\text { en terapia y } \\
\text { valoración }\end{array}$ & $\begin{array}{l}3143 \text { Terapeutas } \\
\text { ocupacionales }\end{array}$ & $\begin{array}{l}\text { Terapia } \\
\text { ocupacional }\end{array}$ \\
\hline & & $\begin{array}{l}315 \text { Profesionales } \\
\text { en enfermería }\end{array}$ & 3151 Enfermeros & Enfermería \\
\hline & & 316 Psicólogos & 3161 Psicólogos & Psicología \\
\hline $\begin{array}{l}4 \text { Ocupaciones } \\
\text { en ciencias } \\
\text { sociales, } \\
\text { educación, } \\
\text { servicios guber- } \\
\text { namentales } \\
\text { y religión }\end{array}$ & $\begin{array}{l}41 \text { ocupaciones } \\
\text { profesionales en } \\
\text { ciencias sociales, } \\
\text { educación, } \\
\text { servicios guber- } \\
\text { namentales y } \\
\text { religión }\end{array}$ & $\begin{array}{l}415 \text { Trabajadores } \\
\text { sociales y clérigos }\end{array}$ & $\begin{array}{l}4152 \\
\text { Trabajadores } \\
\text { sociales y } \\
\text { consultores de } \\
\text { familia }\end{array}$ & Trabajo social \\
\hline
\end{tabular}

Fuente: tabla adaptada por las autoras, con base en información de la Clasificación Nacional de Ocupaciones (SENA, 2014).

En la descripción que estas clasificaciones realizan sobre el quehacer de los profesionales en mención, se encuentra que el DANE (2005) expone de forma más completa las funciones en comparación con la OIT (2010) y el SENA (2014). En la tabla 5 se contrastan estas descripciones de acuerdo al organismo que las clasifica. 
Tabla 5. Descripción de las profesiones según OIT, DANE y SENA

\begin{tabular}{|c|c|c|c|}
\hline & OIT, 2010 & DANE, 2005 & SENA, 2014 \\
\hline & $\begin{array}{l}\text { Se ocupan } \\
\text { esencialmente de la } \\
\text { prevención y cura } \\
\text { de enfermedades; } \\
\text { este aspecto, lo } \\
\text { abordan desde la } \\
\text { conceptualización, } \\
\text { teorización, } \\
\text { investigación, diseño de } \\
\text { métodos y estrategias } \\
\text { de intervención y } \\
\text { participación en } \\
\text { políticas públicas. }\end{array}$ & $\begin{array}{l}\text { Investigan, perfeccionan o desarrollan } \\
\text { conceptos, teorías y métodos que } \\
\text { aplican en la prevención, diagnóstico } \\
\text { y tratamiento de enfermedades y } \\
\text { prevención de secuelas, trastornos } \\
\text { y lesiones físicas, psicológicas y } \\
\text { psiquiátricas de los humanos; } \\
\text { estudian su naturaleza, causa } \\
\text { y desarrollo, y practican } \\
\text { intervenciones quirúrgicas. }\end{array}$ & $\begin{array}{l}\text { Previenen, } \\
\text { diagnostican } \\
\text { y tratan } \\
\text { enfermedades, } \\
\text { trastornos físicos } \\
\text { y lesiones de } \\
\text { pacientes. }\end{array}$ \\
\hline 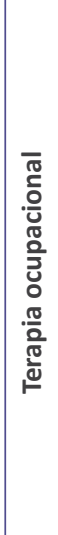 & $\begin{array}{l}\text { No se describe } \\
\text { específicamente } \\
\text { terapia ocupacional, } \\
\text { solo se hace referencia } \\
\text { a otras profesiones } \\
\text { afines no especificadas } \\
\text { en la CIUO. }\end{array}$ & $\begin{array}{l}\text { Diseñan, dirigen y ejecutan } \\
\text { programas terapéuticos orientados } \\
\text { a la audición, habla, lenguaje, voz } \\
\text { y aprendizaje relacionados con la } \\
\text { comunicación humana; aplican } \\
\text { métodos manuales, especiales u otras } \\
\text { técnicas similares, encaminados a la } \\
\text { valoración, prevención, tratamiento, } \\
\text { rehabilitación y control de pacientes } \\
\text { con afecciones óseas, musculares, } \\
\text { respiratorias, cardiorrespiratorias } \\
\text { y cardiopulmonares; promueven, } \\
\text { conservan y rehabilitan el desempeño } \\
\text { ocupacional de personas con } \\
\text { disfunciones psicosociales, } \\
\text { sensoriales y mentales. }\end{array}$ & $\begin{array}{l}\text { Planean y llevan } \\
\text { a cabo programas } \\
\text { diseñados } \\
\text { individualmente, } \\
\text { de actividades } \\
\text { para pacientes } \\
\text { con problemas } \\
\text { físicos o mentales } \\
\text { y los incentivan } \\
\text { para que cuiden } \\
\text { de sí mismos y } \\
\text { los comprometen } \\
\text { en actividades } \\
\text { laborales y } \\
\text { recreativas. }\end{array}$ \\
\hline & $\begin{array}{l}\text { Sus funciones son } \\
\text { relativas al apoyo del } \\
\text { trabajo de los médicos. }\end{array}$ & $\begin{array}{l}\text { Participan en investigaciones, } \\
\text { asesorías y consultorías relacionadas } \\
\text { con el cuidado de la salud de } \\
\text { las personas, familias y grupos } \\
\text { comunitarios; asisten a médicos } \\
\text { y cirujanos en el ejercicio de sus } \\
\text { funciones, se ocupan de las urgencias } \\
\text { en ausencia de estos; proporcionan } \\
\text { cuidados profesionales de enfermería } \\
\text { a heridos, enfermos, personas con } \\
\text { discapacidad y otras personas que } \\
\text { necesitan tal asistencia; ayudan, } \\
\text { planean y participan en programas } \\
\text { de prevención y rehabilitación; } \\
\text { implementan y valoran el cuidado } \\
\text { del paciente velando por la } \\
\text { calidad de la atención. }\end{array}$ & $\begin{array}{l}\text { Supervisan y } \\
\text { coordinan las } \\
\text { actividades } \\
\text { del personal } \\
\text { de enfermería } \\
\text { en el cuidado } \\
\text { y atención } \\
\text { de pacientes. } \\
\text { Proveen cuidado } \\
\text { directo a los } \\
\text { pacientes. }\end{array}$ \\
\hline
\end{tabular}




\begin{tabular}{|c|c|c|c|}
\hline & OIT, 2010 & DANE, 2005 & SENA, 2014 \\
\hline $\begin{array}{l}\frac{\pi}{00} \\
\frac{0}{0} \\
\frac{0}{0} \\
\frac{0}{0}\end{array}$ & $\begin{array}{l}\text { Se ocupan de los } \\
\text { procesos mentales y } \\
\text { del comportamiento } \\
\text { de los seres humanos, } \\
\text { buscando favorecer la } \\
\text { adaptación y desarrollo } \\
\text { de las personas. }\end{array}$ & $\begin{array}{l}\text { Investigan y diagnostican a los } \\
\text { seres humanos en cuanto a su } \\
\text { comportamiento, desórdenes } \\
\text { psicológicos, emocionales y mentales; } \\
\text { aconsejan a los pacientes y les } \\
\text { recomiendan terapias o tratamientos } \\
\text { según el tipo de problema que } \\
\text { presenten; asesoran sobre estos } \\
\text { conocimientos o los aplican con } \\
\text { el fin de promover la adaptación } \\
\text { y desarrollo tanto individual } \\
\text { como social, educativo o } \\
\text { profesional de las personas. }\end{array}$ & $\begin{array}{l}\text { Diagnostican } \\
\text { trastornos } \\
\text { emocionales } \\
\text { y psicológicos, } \\
\text { asesoran al } \\
\text { paciente, } \\
\text { suministran } \\
\text { terapias e } \\
\text { investigan y } \\
\text { aplican teorías } \\
\text { relacionadas } \\
\text { con el } \\
\text { comportamiento } \\
\text { y los procesos } \\
\text { mentales. }\end{array}$ \\
\hline $\begin{array}{l}\bar{\pi} \\
\frac{\pi}{4} \\
0 \\
. \frac{0}{\pi} \\
\frac{0}{\pi} \\
\frac{1}{2}\end{array}$ & $\begin{array}{l}\text { Orientan a las personas } \\
\text { en la identificación y la } \\
\text { utilización de recursos y } \\
\text { medios necesarios para } \\
\text { superar sus dificultades } \\
\text { de índole social. }\end{array}$ & $\begin{array}{l}\text { Formulan, orientan, administran } \\
\text { y evalúan proyectos de desarrollo } \\
\text { relacionados con el bienestar social } \\
\text { de las personas, básicamente } \\
\text { con dificultades de adaptación y } \\
\text { funcionamiento social; aconsejan y } \\
\text { prestan ayuda a individuos y familias } \\
\text { para que comprendan con más } \\
\text { claridad sus problemas y procuran } \\
\text { obtener su colaboración en la } \\
\text { resolución de los mismos; realizan } \\
\text { actividades tendientes a evitar la } \\
\text { delincuencia; realizan terapias y } \\
\text { remiten a otros especialistas. }\end{array}$ & $\begin{array}{l}\text { Orientan a } \\
\text { personas, tratan } \\
\text { dificultades de } \\
\text { adaptación y } \\
\text { funcionamiento } \\
\text { social, brindan } \\
\text { consejería, } \\
\text { terapia y remiten } \\
\text { a otros servicios } \\
\text { sociales de apoyo } \\
\text { a personas, } \\
\text { grupos y familias. }\end{array}$ \\
\hline
\end{tabular}

Fuente: tabla adaptada por las autoras con base en información de la Clasificación Internacional Uniforme de Ocupaciones CIUO-88 de la OIT (2010), Clasificación Internacional Uniforme de Ocupaciones adaptada para Colombia del DANE (2005), y la Clasificación Nacional de Ocupaciones del SENA (2014).

Finalmente, el Congreso de la República a través de la Ley 1164 de octubre 3 de 2007, Ley del Talento Humano en Salud, expresa funciones para el personal de la salud que están contempladas en las clasificaciones del trabajo retomadas anteriormente:

Por talento humano en salud se entiende todo el personal que interviene en la promoción, educación, información de la salud, prevención, diagnóstico, tratamiento, rehabilitación y paliación de la enfermedad de todos los habitantes del territorio nacional dentro de la estructura organizacional de la prestación de los servicios de salud. (Congreso de la República de Colombia, 2007, p. 1). 
En la perspectiva de la anterior definición y de las clasificaciones ocupacionales a las que se hizo referencia, los profesionales de psicología, trabajo social, medicina, enfermería y terapia ocupacional, se constituyen en talento humano en salud. El apartado siguiente intentará explicar en qué sentido estos profesionales son, además, talento humano en salud mental.

\subsubsection{Talento humano en salud mental}

Para efectos de la reflexión y análisis que presenta este libro, el talento humano en salud mental se identifica a partir de diferentes referencias que en la Ley 1616 de enero de 2013 (Ley de Salud Mental colombiana) se hace al respecto; allí, se mencionan disciplinas como psicología, medicina, enfermería, terapia ocupacional, psiquiatría, entre otras, para conformar los equipos básicos de atención prehospitalaria en salud mental, equipos interdisciplinarios, e incluso, para hacer parte del Consejo Nacional de Salud Mental (Congreso de la República de Colombia, 2013). Sin embargo, es importante señalar que la atención en salud mental no se limita a los profesionales del área de la salud, y como bien lo retoma la Política Nacional de Salud Mental del Informe del Relator Especial sobre el derecho de toda persona al disfrute del más alto nivel posible de salud física y mental (ONU, 2017) "la atención integral e integrada deriva el involucramiento interdisciplinar del talento humano conformado tanto por los profesionales de la salud, como por los profesionales de otras áreas del conocimiento" (Política de salud mental. Anexo técnico, 2018, p. 20).

Retomando lo expuesto en el primer capítulo acerca de las conceptualizaciones disciplinares que se hallaron luego de la revisión documental, puede identificarse que tanto medicina, como enfermería, psicología, terapia ocupacional y trabajo social se interesan por comprender e intervenir en temas relacionados con la promoción de la salud mental, la prevención y la asistencia a la enfermedad mental, la rehabilitación psicosocial; igualmente, por el desarrollo de investigaciones en este ámbito y por la participación en políticas públicas que garanticen el disfrute de individuos, familias y comunidades del derecho a la salud mental. Algunas disciplinas más desde el cuidado, otras 
desde la medicación, otras desde los psicoterapéutico, otras desde la rehabilitación y otras desde el empoderamiento y restablecimiento de los derechos en salud; ninguna de estas funciones es exclusiva de una sola disciplina, ellas mismas se encuentran en el trabajo interdisciplinario, tanto de intervención como de investigación.

Reconociendo, entonces, que en el nivel de pregrado existen, además del universitario, niveles técnicos y tecnológicos que bien pueden estar al servicio de la salud mental, y que en el nivel de posgrado existen un sinnúmero de especializaciones, maestrías y doctorados que orientan formación en salud mental, se ha focalizado este análisis al nivel universitario ${ }^{8}$, toda vez que el grueso de las atenciones en salud mental la realizan profesionales no necesariamente especializados; los análisis a otros niveles de formación se han considerado para futuras investigaciones. Es así que por talento humano en salud mental -en el nivel de pregrado- se hace alusión a profesionales de psicología, trabajo social, medicina, enfermería y terapia ocupacional, y en ese sentido, el análisis que aquí se presenta sobre la formación en salud mental, se hace sobre las ofertas curriculares que existen en el país para formar en estas disciplinas y sobre las expectativas que se tienen frente a dicha formación, es decir, aquello que se considera como importante para incluir en estos planes curriculares.

Estas cinco disciplinas, con objetos propios de estudio e intervención, se encuentran en el interés de acompañar la salud mental de personas y grupos poblacionales, a partir de acciones de promoción de la salud mental, prevención de la enfermedad mental, asistencia a la enfermedad mental, rehabilitación psicosocial, participación en la construcción de políticas públicas; igualmente, desde las acciones que se realizan en otros sectores - diferentes al de salud- como el de bienestar, protección, trabajo, cultura, deporte, entre otros.

\footnotetext{
${ }^{8}$ En el marco de los niveles de la Educación Superior expuestos por el Ministerio de Educación colombiano, según el cual, la educación superior se imparte en dos niveles: pregrado y posgrado; en el nivel de pregrado están los niveles técnico profesional (relativo a programas técnicos profesionales), tecnológico (relativo a programas tecnológicos), y profesional (relativo a programas profesionales universitarios); la educación de posgrado comprende los niveles de especializaciones (relativas a programas de especialización técnica profesional, especialización tecnológica y especializaciones profesionales), maestrías, y doctorados (Ministerio de Educación Nacional, 2010).
} 


\subsubsection{Temáticas a considerar en la formación del talento humano en salud mental}

Tal como se mencionó en el capítulo 1, la oms define la salud mental como "un estado de bienestar en el cual el individuo es consciente de sus propias capacidades, puede afrontar las tensiones normales de la vida, puede trabajar de forma productiva y fructífera y es capaz de hacer una contribución a su comunidad" (2004, p. 14); definición ampliada por el Congreso Colombiano en la Ley 1616 de enero de 2013, donde se describe como

...un estado dinámico que se expresa en la vida cotidiana a través del comportamiento y la interacción, de manera que permite a los sujetos individuales y colectivos desplegar sus recursos emocionales, cognitivos y mentales para transitar por la vida cotidiana, trabajar, establecer relaciones significativas y contribuir a la comunidad. (Congreso de la República de Colombia, 2013).

La salud mental, entonces, es de interés y prioridad nacional, es un derecho fundamental que tiene todo ser humano, a través del cual se le garantiza un bienestar emocional, mental y físico, procurando el mejoramiento de su calidad de vida (Congreso de la República de Colombia, 2013).

Esta ley propone la atención integrada e integral en salud mental, señalando la importancia de capacitar y actualizar al talento humano que atiende en servicios de salud mental; dichas capacitaciones están referidas a la implementación de nuevos métodos, técnicas y tecnologías pertinentes y aplicables en promoción de la salud mental, prevención de la enfermedad mental, tratamiento a la enfermedad mental y rehabilitación psicosocial. Retomando la referencia que la Ley 1616 hace de las disciplinas en el nivel universitario, encargadas de atender la salud mental (entre ellas psicología, enfermería, trabajo social, medicina y terapia ocupacional), la academia debe reflexionar acerca del estado de la formación de estos profesionales, surge así la necesidad de revisar en los currículos de pregrado la presencia de temáticas relacionadas con la psicopatología, la evaluación y diagnóstico en salud mental, la intervención de los trastornos mentales, la prevención, promoción y rehabilitación en salud mental, la atención primaria en salud mental, acerca de las 
intervenciones sociales/comunitarias en salud mental, la evaluación de programas y proyectos en salud mental, la salud mental positiva, la salud mental basada en la evidencia, los determinantes sociales de la salud mental, las teorías del desarrollo humano, el sistema de salud y los servicios en salud mental, la salud mental comunitaria, la salud mental en los contextos clínico, hospitalario, educativo y organizacional, la salud mental y la estigmatización, la sexualidad, las violencias, los consumos, entre otros.

Ahora bien, la OPS (2009) expone en la Estrategia y plan de acción sobre salud mental, una serie de lineamientos para la formación del talento humano en salud mental que deben considerar las instituciones que se ocupan de esta formación; desde allí se llama la atención sobre la necesidad de dejar a un lado los métodos que tradicionalmente se han usado para la formación del personal, donde ha primado un modelo vertical que separa a los diferentes prestadores de servicios en salud mental. Tomando en cuenta lo expuesto, la ops sugiere implementar métodos de formación que respondan a las siguientes dimensiones:

- Servicios basados en la competencia: se deben definir las competencias fundamentales y las competencias particulares para todos los proveedores de los servicios de salud mental.

- Neutralidad profesional: se refiere a la necesidad de ofertar programas de formación en las competencias de salud mental, a todos los proveedores de salud, con lo cual se evita que la formación quede circunscrita única y exclusivamente a los llamados profesionales de salud mental, y que se perpetúe la falta de interdisciplinariedad.

- Información basada en la evidencia: como su nombre lo indica, esta dimensión se refiere a que el conocimiento impartido debe estar sustentado en la evidencia científica y, por ende, la práctica que de allí se derive.

- Integración en los sistemas de salud existentes: los programas de formación deben ajustarse a los sistemas de salud existentes, de tal manera que el proveedor de salud en el ejercicio de sus funciones, sienta que hace parte del sistema y que tiene la posibilidad de adaptarse a los cambios que en este se generan. 
- Promoción de la equidad y accesibilidad: la formación debe sustentarse en los valores fundamentales que orientan la protección de los derechos humanos de los pacientes.

- Sostenibilidad: los programas "deben ser sostenibles dentro del contexto del sistema de salud en el que han sido desarrollados" (OMS, 2007, citado por OPS, 2009).

- Desarrollo de la capacidad del sistema: los programas deben orientarse de tal manera que todos los proveedores de salud estén en la posibilidad de mejorar la capacidad del sistema de ofrecer atención apropiada (OPS, 2009).

Retomando lo dicho en párrafos anteriores respecto al término talento humano, a partir del cual se privilegian las capacidades de los colaboradores, se reconoce en él una característica que le suma valor a la fuerza de trabajo o al conjunto de empleados de una organización, y es esa característica la que puede ser gestionada; Alles (2007) se refiere a esta gestión en términos de selección, evaluación del desempeño y desarrollo de las competencias. Es a una parte de este último aspecto, desarrollo de las competencias, al que se hace alusión en el ejercicio de reflexionar sobre la formación del talento humano en salud mental, toda vez que dicha formación está referida al desarrollo de competencias para la atención en salud mental.

El desarrollo de una competencia, a grandes rasgos, se traduce en la posibilidad de saber hacer, invitando a la aplicación creativa, responsable, crítica y reflexiva de conocimientos, habilidades y actitudes. En ese sentido, y en el marco del análisis que aquí se presenta, una de las tareas que debe trazarse en los comités de currículo de los diferentes programas universitarios está asociada al análisis temático que debe incorporarse en dicha formación; las otras tareas, muy importantes por cierto, están relacionadas con las distintas reflexiones y acciones que deben emprenderse en función de transmitir ese conocimiento de tal manera que los profesionales en formación lo incorporen crítica y reflexivamente, esto es, la articulación de las diferentes dimensiones de la competencia (ser, saber y hacer). 
En el sentido de lo planteado por la OMS, la OPS y el Congreso de la República de Colombia, y del saber o conocimiento como un componente importante del desarrollo de las competencias específicas de los profesionales que acompañan en salud mental, este equipo de investigación identifica como temáticas a considerar en los planes de formación universitario las siguientes:

\section{Niveles de atención y acompañamiento en salud mental}

1. Promoción del bienestar y de la salud mental

2. Prevención de la enfermedad mental

3. Atención a la enfermedad mental/intervención de los trastornos mentales

4. Rehabilitación psicosocial

5. Estrategias de evaluación y diagnóstico de problemáticas psicosociales y trastornos mentales

\section{Diferentes enfoques y modelos de atención}

6. Atención primaria en salud mental

7. Atención basada en enfoque de derechos

8. Atención basada en enfoque diferencial

9. Modelo biopsicosocial

10. Teorías de desarrollo a escala humana

11. Determinantes sociales de la salud (mental)

Eventos en salud mental asociados a problemáticas psicosociales y a enfermedades mentales tales como

12. Problemas relacionados con suicidio

13. Consumos

14. Sexualidad

15. Violencias

16. Psicopatología 


\section{Salud mental en diferentes contextos}

17. Salud mental comunitaria

18. Salud mental en el contexto educativo

19. Salud mental en las organizaciones

20. Salud mental y familia

21. Salud mental en el contexto clínico

\section{Temas asociados a salud pública}

22. Salud pública

23. Sistema de salud y servicios de salud mental

24. Legislación y políticas públicas en salud

25. Estrategias de intervención sociales/comunitarias en salud mental

26. Evaluación de programas y proyectos en salud mental

\section{Otros}

27. Resiliencia

28. Calidad de vida

29. Inclusión

30. Discapacidad

31. Salud mental positiva

32. Investigación en salud mental

33. Psicología y salud

34. Psicología basada en la evidencia

Este inventario de temas, al que se ha llegado como una guía que permita el análisis de los cursos indicados en los planes universitarios de los programas de interés, y que desde la perspectiva de las reflexiones de GASMA y GIES, atiende en términos de contenidos a varios de los retos que como país se tienen para acompañar la salud mental de los colombianos; esto es, un conjunto de temas necesarios para desarrollar en las clases con las personas que se están formando en estas profesiones de tal forma que puedan trabajar desde una perspectiva interdisciplinar e intersectorial en la promoción de la salud mental y del bienestar, desde todos los sectores que esta puede trabajarse, en la prevención de la enfermedad mental y las problemáticas psicosociales, en la evaluación, 
diagnóstico e intervención integral de las enfermedades mentales y los problemas psicosociales, en la participación de la planificación y transformación de políticas públicas y en la investigación. Todo lo anterior, desde los enfoques de derechos, diferenciales y de desarrollo humano.

Luego de la investigación que dio lugar a la propuesta de modelo de formación con perspectiva transdisciplinar que se presenta en el tercer capítulo, el equipo investigador identificó otras temáticas importantes para considerar en la formación de los profesionales en mención; estas y la propuesta metodológica se expondrán al final del libro.

\subsection{Formación en salud mental evidenciada en los planes de estudios de programas universitarios en Psicología, Trabajo Social, Medicina, Enfermería y Terapia Ocupacional}

La OMS, en su informe de 2006, hace referencia a un ciclo de vida laboral que comprende tres momentos: entrada, vida laboral y salida. En el momento "entrada" al ciclo de vida laboral, se encuentra la formación o preparación de los trabajadores sanitarios, y al respecto, la OMS plantea -entre otras cosas - la importancia de desarrollar instituciones docentes sólidas y garantizar la calidad de la formación (OMS, 2006). Igualmente, enumera una serie de principios necesarios para un Sistema de Salud, en los cuales explicita algunas consideraciones respecto al talento humano: 1. los trabajadores de la salud son la base del sistema de salud; 2 . la salud es un servicio público y una responsabilidad social y 3 . los trabajadores de la salud son protagonistas de su propio desarrollo (citado por Ortiz, Cubides y Restrepo, 2013).

Sin embargo, en algunos campos de la salud, como la salud mental, no todos los profesionales del sector están capacitados suficientemente para actuar en todo el proceso de intervención y esto, no está relacionado solo con el tiempo de formación, sino también con las competencias que se requieren para cada etapa de este proceso; es posible que un psiquiatra no esté preparado suficientemente para coordinar programas comunitarios de promoción de la salud mental pero sí para el tratamiento de trastornos mentales; por el contrario, un trabajador social puede estar limitado para el diagnóstico de este tipo de problemas pero es idóneo para preparar una comunidad y coordinar un programa de promoción de la salud mental. 
Cada profesional de la salud tiene unas competencias determinadas que al complementarse estructuran programas, intervenciones e investigaciones en salud mental; pero no solamente se requiere la suma de conocimientos: la integralidad en el enfoque permite visualizar al ser humano y a los colectivos desde una óptica biopsicosocial que permita intervenciones adaptadas de manera técnica y ética a los contextos donde se vive, teniendo como referencia los derechos humanos, asunto que ha sido orientado desde la OMS para todas las naciones, y que impulsa a establecer políticas y legislación en salud mental coherente con estos derechos (OMS, 2006).

En salud y especialmente en salud mental, para prevenir e intervenir de manera integral los problemas propios del sector se requiere, no solamente la confluencia de diferentes profesionales y otros agentes, sino también que estos deben actuar como un equipo, cuyo producto sea una respuesta adecuada a las necesidades de los individuos y de las comunidades en razón de las situaciones del contexto y de las posibilidades del sistema de salud donde laboran u operan. Para ello se requiere una educación interprofesional que mejore la comunicación, colaboración y cooperación en estos equipos tal como lo proponen diversos autores (Reeves et al., 2008; Barnsteiner et al., 2007; Soto Fuentes, 2017).

Con el propósito de trabajar por una salud universal, la ops presenta una estrategia enfocada en los recursos humanos que incluye, en uno de sus retos, la planificación de la formación de los profesionales de acuerdo a las necesidades de las comunidades, e implica específicamente una trasformación en su educación de tal forma que aprendan trabajando activamente con las comunidades; y la definición de acuerdos entre el sector salud y el sector educación, que aseguren estándares de alta calidad en la educación de estos profesionales (OPS, 2017).

Por su parte, la Organización de las Naciones Unidas para la Educación, la Ciencia y la Cultura (Unesco) plantea que "el desarrollo en los estudiantes de las competencias o capacidades ampliamente definidas, como la reflexión crítica y creativa, depende de la integración de tres grandes ámbitos de aprendizaje: conocimientos, capacidades y valores" (Unesco, 2006). Pero ¿qué tipo de competencias requieren los psicólogos, trabajadores sociales, médicos, enfermeros y terapeutas ocupacionales para responder a las necesidades de salud mental de los 
individuos y comunidades que acompañan? Esta es una respuesta que se ha intentado bordear desde lo que se infiere de los documentos legales e institucionales que se han revisado y de los cuales ya se ha hablado, y a la que en el capítulo 3, se intentará dar mayor desarrollo. Por lo pronto, este capítulo se acerca a un análisis de los contenidos temáticos en salud mental que sugiere la Ley 1616 y que se espera, estén incorporados en los planes de formación universitarios de los programas que la misma ley cita.

Este apartado, entonces, ofrece un panorama de la formación en salud mental, construido a partir de la revisión de los planes de estudios universitarios de interés. Esta revisión buscó específicamente acercarse a las características generales de los programas, a los componentes implícitos/explícitos relacionados con la salud mental y sus componentes constitutivos, a los enfoques desde los que se fundamenta la formación en salud mental, a las estrategias de formación curricular y extracurricular que se implementan en los programas, al componente interdisciplinar de la formación en salud mental y finalmente, a las fortalezas y necesidades de la formación en salud mental (Buitrago y Bedoya, 2016). Para este propósito, la investigación se sirvió de la revisión de fuentes como el SNIES, las páginas web de los diferentes programas y sus mallas curriculares, así como de un ejercicio cualitativo de panel de expertos. Estas fuentes, proporcionaron información de interés a la investigación, tal como se esquematiza en la figura 2.

Figura 2. Fuentes e información proporcionada

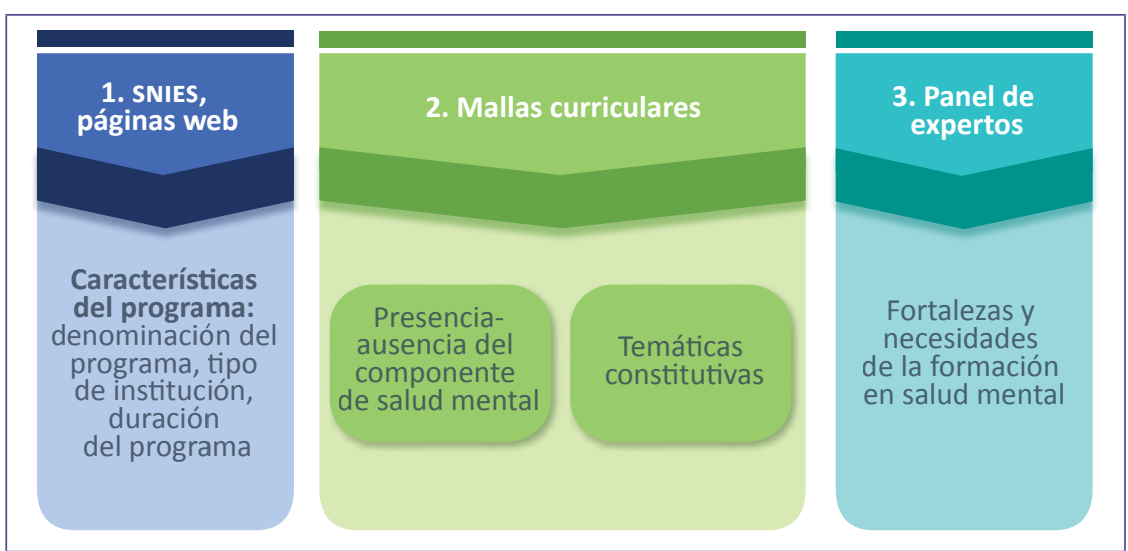


EI SNIES y el análisis de las páginas web (específicamente misión/ visión/perfil del egresado) permitieron caracterizar los programas; las mallas curriculares propiciaron la identificación de los componentes implícitos o explícitos relacionados con la salud mental dentro de los currículos de formación, así como las temáticas constitutivas de los componentes de formación en salud mental en estos programas (mallas curriculares); el panel de expertos permitió identificar las fortalezas y necesidades de la formación en salud mental. La figura 3 presenta lo hallado en las fuentes consultadas.

Figura 3. Número de programas participantes de acuerdo a cada fuente de información

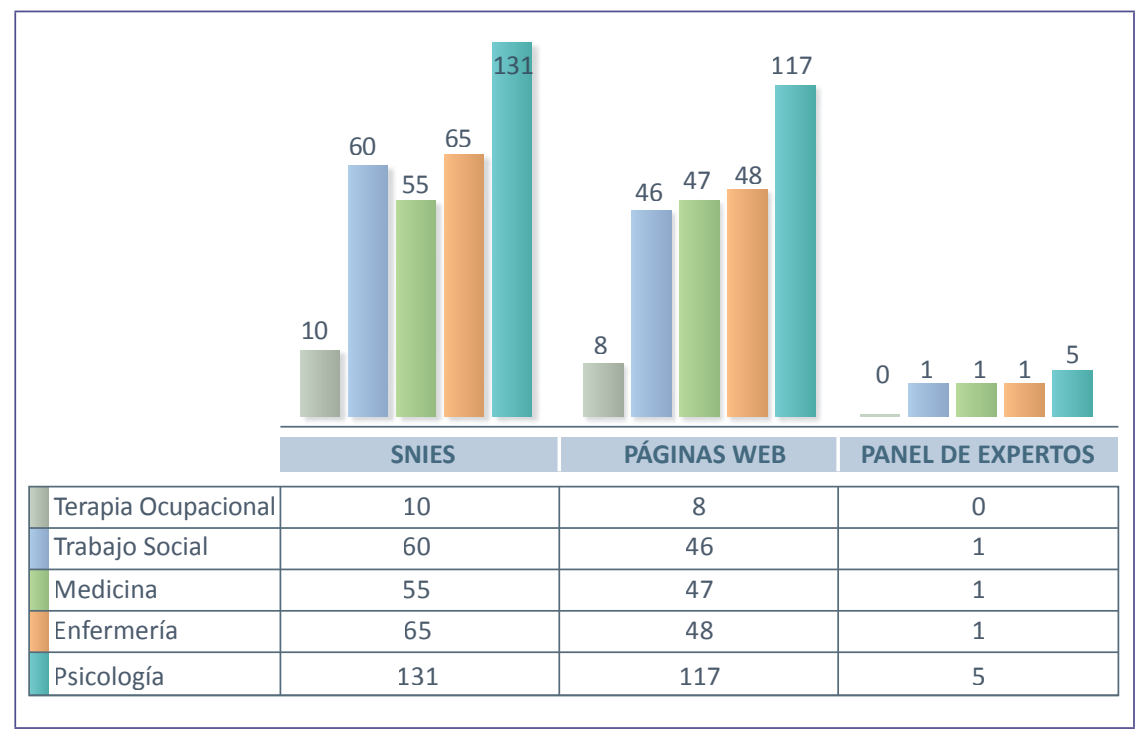

\subsubsection{Características generales de los programas}

Esta caracterización relaciona información correspondiente a la denominación del programa, duración del mismo y el tipo de institución a la cual pertenece. Para el año 2015, según el SNIES, en Colombia se ofertaron 321 programas que forman en las disciplinas de interés. El programa que presenta mayor oferta en el país, es Psicología con 131 programas; le sigue Enfermería con 65, Trabajo Social con 60, Medicina con 55 y, finalmente, Terapia Ocupacional es el de menor frecuencia, con 10 programas. 
Figura 4. Frecuencia de oferta de programas activos en SNIES 2015

Terapia Ocupacional

Medicina

Trabajo Social

Enfermería

Psicología

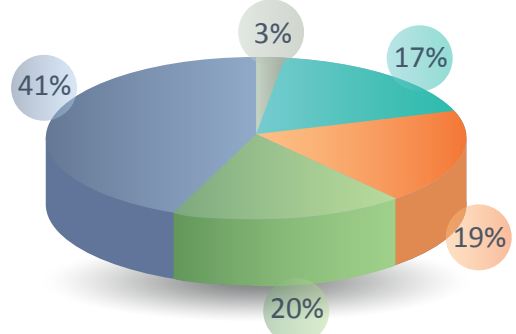

Los 321 programas se distribuyen en 114 universidades -de las cuales, 36 son públicas y 78 privadas (32\% y 68\%, respectivamente)- que, a su vez, se encuentran en 24 departamentos del país. La siguiente tabla, relaciona el departamento y el número de programas que allí se ofertan, siendo Cundinamarca, Antioquia y Valle del Cauca, los departamentos en los que se encuentra mayor oferta de programas académicos.

Tabla 6. Relación departamentos y programas ofertados

\begin{tabular}{|l|c|l|c|}
\hline \multicolumn{1}{|c|}{ Departamento } & $\begin{array}{c}\text { Número de } \\
\text { programas }\end{array}$ & \multicolumn{1}{|c|}{ Departamento } & $\begin{array}{c}\text { Número de } \\
\text { programas }\end{array}$ \\
\hline Cundinamarca & 74 & Huila & 7 \\
\hline Antioquia & 53 & Cauca & 6 \\
\hline Valle del Cauca & 35 & Magdalena & 6 \\
\hline Santander & 21 & Tolima & 6 \\
\hline Atlántico & 17 & Cesar & 5 \\
\hline Bolívar & 13 & Meta & 5 \\
\hline Norte de Santander & 12 & Chocó & 4 \\
\hline Nariño & 10 & Sucre & 2 \\
\hline Caldas & 9 & Arauca & 2 \\
\hline Quindío & 8 & Guajira & 1 \\
\hline Risaralda & 8 & Casanare & 1 \\
\hline Córdoba & 7 & Putumayo & 4 \\
\hline
\end{tabular}


La mayoría de los programas (68\%) pertenecen a universidades privadas, y se encuentra que el programa de Psicología - el cual representa el $40 \%$ de la oferta formativa de interés en esta investigación- presenta una marcada diferencia, dado que el $81 \%$ de los programas hace parte de universidades privadas.

Figura 5. Oferta de programas en universidades públicas y privadas SNIES, 2015

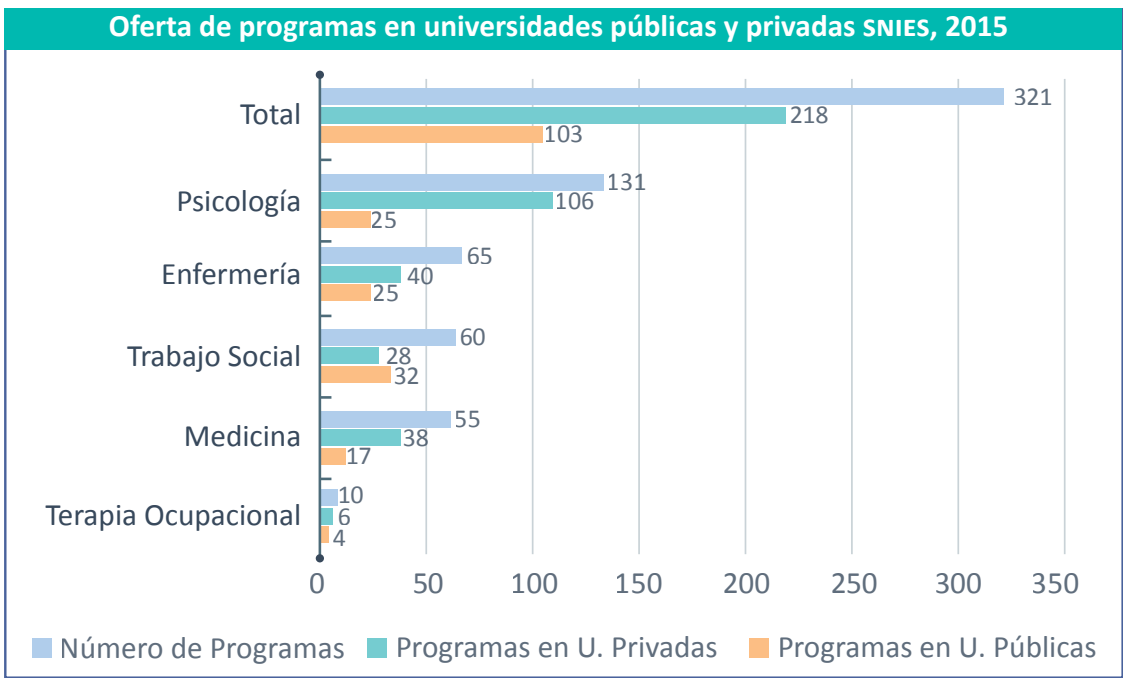

En lo que respecta a la duración de los programas y la destinación de créditos, se observa que los programas de medicina requieren mayor número de semestres para obtener la titulación (de 12 a 14), lo que a su vez guarda relación con el número de créditos expresados en los planes de formación (entre 209 y 382 créditos); por su parte, Trabajo Social, Psicología, Enfermería y Terapia Ocupacional pueden desarrollarse entre 8 y 12 semestres, oscilando su destinación de créditos entre 89 y 174 (ver tabla 7 y figura 6).

Tabla 7. Programas y rango de créditos, SNIES 2015

\begin{tabular}{|l|c|c|c|c|c|}
\cline { 2 - 6 } \multicolumn{1}{c|}{} & $\begin{array}{c}\text { Terapia } \\
\text { Ocupacional }\end{array}$ & Medicina & Trabajo Social & Enfermería & Psicología \\
\hline $\begin{array}{l}\text { Rango de } \\
\text { créditos }\end{array}$ & $160-171$ & $209-382$ & $89-179$ & $144-198$ & $130-196$ \\
\hline
\end{tabular}


Figura 6. Duración de programas en semestres, SNIES 2015

\begin{tabular}{|c|c|c|c|c|c|c|c|}
\hline \multicolumn{8}{|l|}{120} \\
\hline \multicolumn{8}{|l|}{100} \\
\hline \multicolumn{8}{|l|}{80} \\
\hline \multicolumn{8}{|l|}{60} \\
\hline \multicolumn{8}{|l|}{40} \\
\hline \multicolumn{8}{|l|}{20} \\
\hline \multirow[t]{2}{*}{0} & 是 & 酒 & a & & $=$ & 且 & 是 \\
\hline & $\begin{array}{c}08 \\
\text { Semestres }\end{array}$ & $\begin{array}{c}09 \\
\text { Semestres }\end{array}$ & Semestres & Semestres & Semestres & Semestres & Semestres \\
\hline Terapia Ocupacional & 2 & 3 & 5 & 0 & 0 & 0 & 0 \\
\hline Medicina & 0 & 0 & 3 & 0 & 40 & 9 & 3 \\
\hline Trabajo Social & 21 & 5 & 33 & 0 & 1 & 0 & 0 \\
\hline Enfermería & 28 & 11 & 26 & 0 & 0 & 0 & 0 \\
\hline Psicología & 6 & 19 & 106 & 0 & 0 & 0 & 0 \\
\hline
\end{tabular}

\subsubsection{Misión, visión y perfil del egresado}

El análisis de la misión, visión y perfil del egresado se realizó con base en la información hallada en las diferentes páginas web de los programas. En dicho análisis se identificó información relacionada con los enfoques de formación; así por cada programa se relacionó información concerniente a: determinantes sociales de la salud, desarrollo humano, salud mental positiva, enfoque de derechos, enfoque biomédico, enfoque biopsicosocial, enfoque diferencial, referencia a la interdisciplinariedad y transdisciplinariedad, promoción y prevención, así como, referencias explícitas a la formación en salud mental, tal como se observa en la figura 7.

Figura 7. Misión/visión/perfil del egresado programas en salud mental

\section{Trabajo Social}

La misión de estos programas se sintetiza en formar trabajadores sociales de alta calidad, autónomos, con sentido ético y crítico frente a las diferentes realidades sociales, comprometidos con las problemáticas del entorno local, regional y nacional; profesionales que son agentes de cambio en la vida de las personas, familias y comunidades en las que intervienen; que además tienen capacidades para investigar la realidad social y los procesos humanos, para proponer planes y proyectos de desarrollo, participación social y desarrollo comunitario. 


\section{Terapia Ocupacional}

Todas coinciden en su misión de educar profesionales con sentido social y espíritu investigativo. Así mismo concuerdan en su visión, en tanto se proyectan graduando terapeutas ocupacionales que sean seres humanos íntegros con una alta capacidad de innovación y producción de conocimientos, líderes en el estudio de la ocupación humana y profesionales autónomos en el servicio a la comunidad.

\section{Medicina}

Los programas de Medicina, propenden por formar estudiantes quegeneren procesos de trasformación social encaminados al bienestar individual y colectivo, que promuevan la promoción, conservación y recuperación integral de la salud y que sean profesionales éticos y socialmente responsables. Señalan como características de sus egresados, ser profesionales integrales que asumen un compromiso ético con la vida, están en capacidad de prevenir, detectar, aportar al diagnóstico y tratamiento de los problemas de salud; trabajar en la promoción, conservación y recuperación de la salud del individuo y de la comunidad, comprometidos con el mejoramiento de su calidad de vida. Esperan formar médicos con actitud crítica e investigativa y con las herramientas teóricas y prácticas necesarias para aportar soluciones efectivas a las problemáticas de salud de la población colombiana, desde una visión integral de la vida contemplando sus aspectos biológicos, psicológicos, sociales y culturales.

\section{Enfermería}

Los diferentes pregrados de Enfermería convergen en su misión al interesarse por la formación integral de enfermeros caracterizados por ejercer un cuidado de calidad, basados en valores éticos y principios científicos, permitiéndoles emplear métodos de investigación para poner en práctica los conocimientos adquiridos; una formación con sentido de responsabilidad profesional y social, desde un enfoque que contempla la perspectiva biopsicosocial, buscando incidir en la calidad de vida del individuo, la familia y la comunidad. De esta forma, están capacitados para trabajar en la promoción de la salud y la prevención de la enfermedad, a la vez que pueden participar en procesos de rehabilitación y reincorporación de las personas a sus diferentes escenarios sociales.

\section{Psicología}

Respecto a la misión, visión y perfiles, las diferentes universidades se ajustan al interés de formar psicólogos con conciencia crítica, ética y social, con espíritu humanista y criterio investigativo, con capacidad de evaluar y diagnosticar las realidades a partir del dominio de la teorías y técnicas de la psicología; de esta forma, exponen su interés por responder a las necesidades y problemáticas del país con el fin de promover el bienestar psicológico y la calidad de vida del individuo, contribuyendo al desarrollo integral de éste y de la sociedad. Finalmente, se expresa en los perfiles del egresado, que este profesional estará en capacidad de desempeñarse en diferentes áreas, tales como psicología organizacional, psicología clínica y de la salud, psicología social y psicología educativa. 
Con base en el análisis de esta información, se identifica que los diferentes programas incluyen la formación en salud mental como un componente implícito que se relaciona con temas de abordaje más amplio, calidad de vida, conservación de los derechos humanos, reconocimiento y respeto por la diferencia, atención e intervención a las necesidades del contexto, participación en la formulación de políticas; y de manera más explícita en los programas de Psicología. Así mismo, se hace interesante resaltar que en las diferentes descripciones se enuncia el desarrollo de competencias para el trabajo interdisciplinario; ahora, tal como se ha venido observando en la presentación de resultados, lo expuesto en las misiones, visiones y perfiles del egresado no logra traducirse efectivamente en los planes y estrategias de formación.

\subsubsection{Presencia-ausencia del componente de salud mental de acuerdo a la revisión de mallas curriculares}

El análisis de la presencia/ausencia del componente de salud mental en las mallas curriculares, se realizó a partir de la identificación de cursos que en su denominación explicitaban el término salud mental (cursos explícitos), o bien denominaciones que guardaran relación con temas asociados a salud mental (cursos implícitos); ahora bien, dicho análisis contempló los cursos obligatorios, dado que los cursos electivos eran nombrados, la mayoría de las veces, de forma genérica en los planes de formación (por ejemplo, Electiva 1, Electiva 2...). La identificación de cursos implícitos, se hizo a partir de la lista de temáticas presentada en el apartado anterior, de tal forma que permitiera reconocer denominaciones relacionadas con temas de salud mental.

Las mallas curriculares fueron recabadas a través de las páginas web de las universidades que ofrecen estos programas, y aquellas cuya tramitación no fue posible por este medio se obtuvieron a través de comunicación electrónica con sus respectivos directivos. De los 321 programas que para 2015 estaban activos en el SNIES, se obtuvieron 266 mallas curriculares, 117 de Psicología, 48 de Enfermería, 47 de Medicina, 46 de Trabajo Social y 8 de Terapia Ocupacional. En total, se obtuvo un $83 \%$ de las mallas curriculares de estos programas activos; la tabla 8 , esquematiza la participación de los programas con sus respectivas mallas curriculares. 
Tabla 8. Programas y mallas curriculares

\begin{tabular}{|l|c|c|c|}
\cline { 2 - 4 } \multicolumn{1}{c|}{} & Programas activos SNIES & \multicolumn{2}{c|}{ Mallas curriculares } \\
\hline Terapia Ocupacional & 10 & 8 & $80 \%$ \\
\hline Trabajo Social & 60 & 46 & $77 \%$ \\
\hline Medicina & 55 & 47 & $85 \%$ \\
\hline Enfermería & 65 & 48 & $74 \%$ \\
\hline Psicología & 131 & 117 & $89 \%$ \\
\hline Total & 321 & 266 & $83 \%$ \\
\hline
\end{tabular}

Fueron sistematizados 14.067 cursos, de los cuales 65 se indicaron como explícitos y 2.058 como implícitos; es decir, de los 14.067 cursos, 65 presentaban en su denominación el término salud mental y 2.058 , términos asociados a salud mental. La tabla 9 muestra la relación entre los cursos que sugerían contenidos de salud mental -implícitos y explícitos-y aquellos que no.

Tabla 9. Cursos que sugieren el componente de salud mental (Cursos SM) y cursos que no sugieren componente de salud mental (Cursos no SM) ${ }^{9}$

\begin{tabular}{|c|c|c|c|c|c|c|c|c|c|c|}
\hline \multirow[b]{3}{*}{ Psicología } & \multicolumn{4}{|c|}{ Cursos SM } & \multirow{2}{*}{\multicolumn{2}{|c|}{$\begin{array}{l}\text { Total cursos } \\
\text { SM }\end{array}$}} & \multirow{2}{*}{\multicolumn{2}{|c|}{ Cursos no SM }} & \multirow{2}{*}{\multicolumn{2}{|c|}{$\begin{array}{c}\text { Total cursos } \\
\text { sistematizados } \\
\text { mallas } \\
\text { curriculares }\end{array}$}} \\
\hline & \multicolumn{2}{|c|}{$\begin{array}{l}\text { Cursos } \\
\text { implícitos } \\
\text { en SM }\end{array}$} & \multicolumn{2}{|c|}{$\begin{array}{l}\text { Cursos } \\
\text { explícitos } \\
\text { en SM }\end{array}$} & & & & & & \\
\hline & 998 & $15,94 \%$ & 8 & $0,13 \%$ & 1.006 & $16,07 \%$ & 5.256 & $83,93 \%$ & 6.262 & $100 \%$ \\
\hline Medicina & 424 & $14,34 \%$ & 20 & $0,68 \%$ & 444 & $15,02 \%$ & 2.513 & $84,98 \%$ & 2.957 & $100 \%$ \\
\hline $\begin{array}{l}\text { Trabajo } \\
\text { Social }\end{array}$ & 324 & $14,52 \%$ & 2 & $0,09 \%$ & 326 & $14,61 \%$ & 1.905 & $85,39 \%$ & 2.231 & $100 \%$ \\
\hline Enfermería & 257 & $11,95 \%$ & 28 & $1,30 \%$ & 285 & $13,26 \%$ & 1.865 & $86,74 \%$ & 2.150 & $100 \%$ \\
\hline $\begin{array}{l}\text { Terapia } \\
\text { Ocupacional }\end{array}$ & 55 & $11,78 \%$ & 7 & $1,50 \%$ & 62 & $13,28 \%$ & 405 & $86,72 \%$ & 467 & $100 \%$ \\
\hline Totales & 2.058 & $14,63 \%$ & 65 & $0,46 \%$ & 2.123 & $15,09 \%$ & 11.944 & $84,91 \%$ & 14.067 & $100 \%$ \\
\hline
\end{tabular}

\footnotetext{
${ }^{9}$ Las frecuencias relativas en esta tabla, se presentan en relación al total de cursos sistematizados por cada programa.
} 
2.2.3.1 Cursos que implícitamente contemplan el componente de salud mental

La pesquisa de los cursos implícitos se realizó a partir de 31 temáticas que tuvieron como referencia lo descrito en el apartado anterior. Estas temáticas se encontraron relacionadas en 2.058 cursos (cursos implícitos en salud mental) y se distribuyeron como se muestra en la tabla 10.

\section{Tabla 10. Frecuencia de cursos implícitos en salud mental por temáticas}

\begin{tabular}{|c|c|c|}
\hline Temáticas & Frecuenci & asociados \\
\hline Evaluación y diagnóstico en salud mental & 326 & $15,84 \%$ \\
\hline Salud mental en el contexto clínico & 268 & $13,02 \%$ \\
\hline Salud mental comunitaria & 222 & $10,79 \%$ \\
\hline Psicopatología & 185 & $8,99 \%$ \\
\hline Salud pública & 130 & $6,32 \%$ \\
\hline Intervención de los trastornos mentales & 120 & $5,83 \%$ \\
\hline Determinantes sociales en salud mental & 87 & $4,23 \%$ \\
\hline Prevención en salud mental & 84 & $4,08 \%$ \\
\hline Salud y familia & 81 & $3,94 \%$ \\
\hline $\begin{array}{l}\text { Intervenciones sociales/comunitarias en salud } \\
\text { mental }\end{array}$ & 65 & $3,16 \%$ \\
\hline Sistemas de salud y servicios en salud mental & 65 & $3,16 \%$ \\
\hline Salud mental en el contexto de las organizaciones & 65 & $3,16 \%$ \\
\hline Evaluación de programas y proyectos & 56 & $2,72 \%$ \\
\hline Atención primaria en salud mental & 46 & $2,24 \%$ \\
\hline Teorías del desarrollo humano & 37 & $1,80 \%$ \\
\hline Salud mental en el contexto educativo & 35 & $1,70 \%$ \\
\hline Problemas relacionados con la sexualidad & 31 & $1,51 \%$ \\
\hline Problemas relacionados con violencias & 30 & $1,46 \%$ \\
\hline Atención basada en enfoque de derechos & 24 & $1,17 \%$ \\
\hline Atención basada en enfoque diferencial & 24 & $1,17 \%$ \\
\hline Legislación y políticas en salud mental & 18 & $0,87 \%$ \\
\hline Calidad de vida & 17 & $0,83 \%$ \\
\hline Psicología y salud & 13 & $0,63 \%$ \\
\hline Rehabilitación en salud mental & 12 & $0,58 \%$ \\
\hline
\end{tabular}




\begin{tabular}{|l|c|c|}
\hline \multicolumn{1}{|c|}{ Temáticas } & \multicolumn{2}{c|}{ Frecuencia de cursos asociados } \\
\hline Discapacidad & 5 & $0,24 \%$ \\
\hline Problemas relacionados con consumos & 3 & $0,15 \%$ \\
\hline Inclusión & 3 & $0,15 \%$ \\
\hline Salud mental positiva & 2 & $0,10 \%$ \\
\hline Resiliencia & 2 & $0,10 \%$ \\
\hline Salud mental en el contexto hospitalario & 1 & $0,05 \%$ \\
\hline Salud mental y estigmatización & 1 & $0,05 \%$ \\
\hline Suicidio & 0 & $0,00 \%$ \\
\hline Total cursos implícitos & 2.058 & $100 \%$ \\
\hline
\end{tabular}

Los 2.058 cursos están distribuidos entre los cinco programas así: 998 cursos correspondieron a las mallas curriculares de Psicología, 424 a las de Medicina, 324 a las de Trabajo Social, 257 a las de Enfermería y 55 a las de Terapia Ocupacional. Dado que en el país existe un número diferente de ofertas respecto de estos cinco programas, la lectura de la proporción de los cursos en salud mental, debe hacerse con relación al número de cursos sistematizados por programa, no al total de ellos; en este sentido, los programas que mayor formación en salud mental revelan en sus mallas curriculares son Psicología, Medicina y Trabajo Social con $15,94 \%, 14,52 \%$ y $14,34 \%$ respectivamente. Ahora bien, solo Psicología reporta una proporción un poco por encima de la media de los programas, es decir, por encima de $14,63 \%$ que es el porcentaje de cursos en salud mental que se hallaron del total de cursos sistematizados. Este hecho, se considera, está respaldado en que el objeto de estudio e intervención de los profesionales de psicología está asociado directamente a la salud mental, sin embargo, llama la atención que este porcentaje en Psicología no sea significativamente mayor que en los otros programas; ahora bien, no hay parámetros que permitan delimitar un porcentaje ideal de formación en salud mental para ninguno de los programas.

Para el programa de Psicología (figura 8), se encuentra que la temática más recurrente en las mallas curriculares corresponde a "Evaluación y diagnóstico en salud mental" con una frecuencia del $33 \%$, seguida de "Salud mental en el contexto clínico" con $14 \%$ y "Psicopatología" con 
$14 \%$. Por su parte, las temáticas de "Atención primaria en salud mental", "Salud mental positiva", "Salud mental en el contexto hospitalario", "Salud mental y estigmatización", "Suicidio" y "Discapacidad" no se hallaron en estas mallas curriculares.

Figura 8. Presencia de cursos en salud mental programa de Psicología

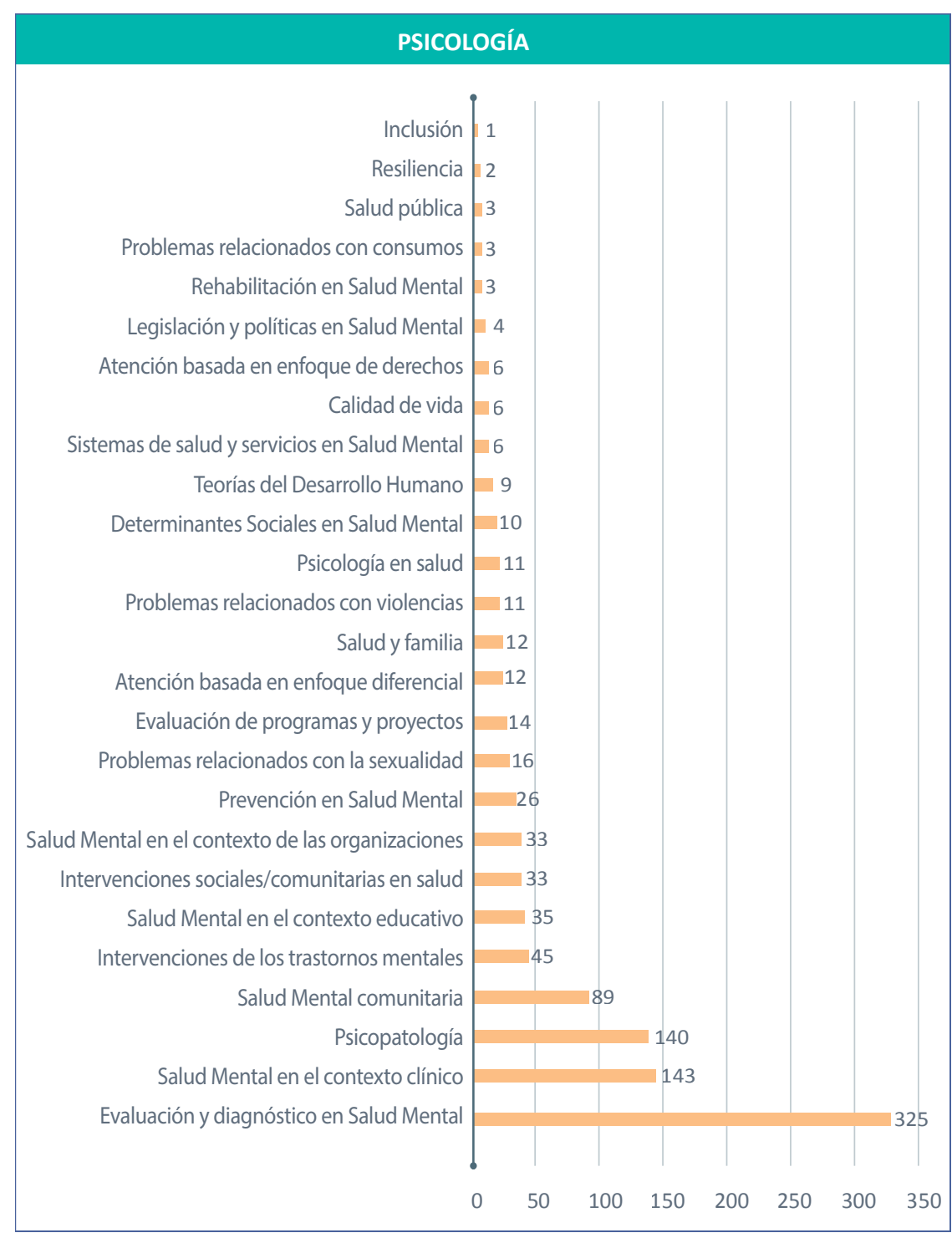


En las mallas curriculares de Trabajo Social (figura 9), se encuentra una frecuencia del $15 \%$ en cursos asociados a "salud pública" e igualmente para "Determinantes sociales de la salud mental"; cursos como "Evaluación y diagnóstico en salud mental", "Intervención de los trastornos mentales", "Atención primaria en salud mental", "Prevención en salud mental", "Rehabilitación en salud mental", "Problemas relacionados con la sexualidad", "Problemas relacionados con consumos", "Salud mental positiva", "Salud mental en el contexto hospitalario", "Salud mental en el contexto educativo", "Salud mental y estigmatización", "Suicidio", Discapacidad", "Resiliencia", "Inclusión" y "Psicología y salud" no se hallaron en las mallas curriculares de Trabajo Social.

Figura 9. Presencia de cursos en salud mental programa de Trabajo Social

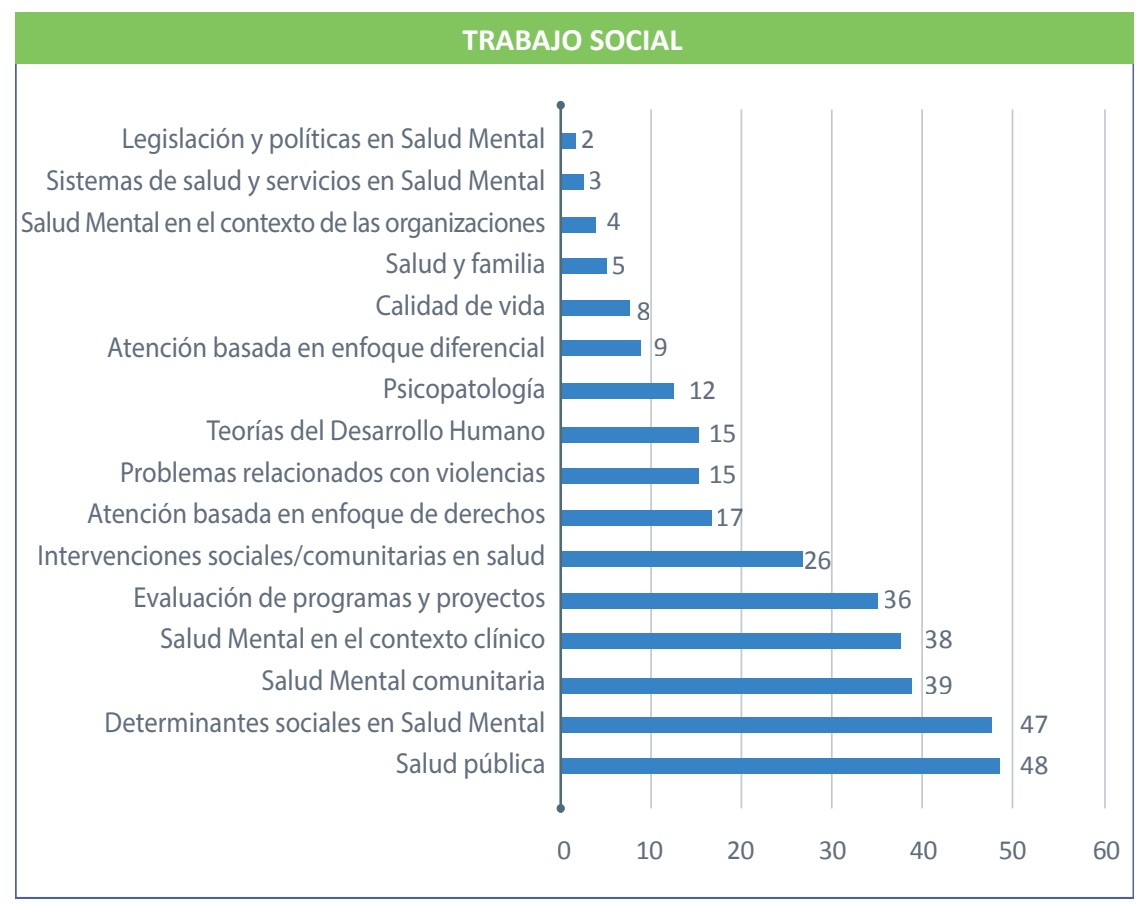

En las mallas curriculares de Medicina (figura 10), se encuentra mayor frecuencia de cursos asociados a "Salud mental comunitaria" e "Intervención de los trastornos mentales"; no se encontraron cursos relacionados con "Evaluación y diagnóstico en salud mental", "Intervenciones 
sociales/comunitarias en salud mental", "Problemas relacionados con consumos", "Salud mental basada en la evidencia", "Salud mental en el contexto educativo", "Salud mental y estigmatización", "Calidad de vida", "Suicidio", "Discapacidad", "Atención basada en enfoque de derechos", "Atención basada en enfoque diferencial", "Resiliencia", e "Inclusión".

Figura 10. Presencia de cursos en salud mental programa de Medicina

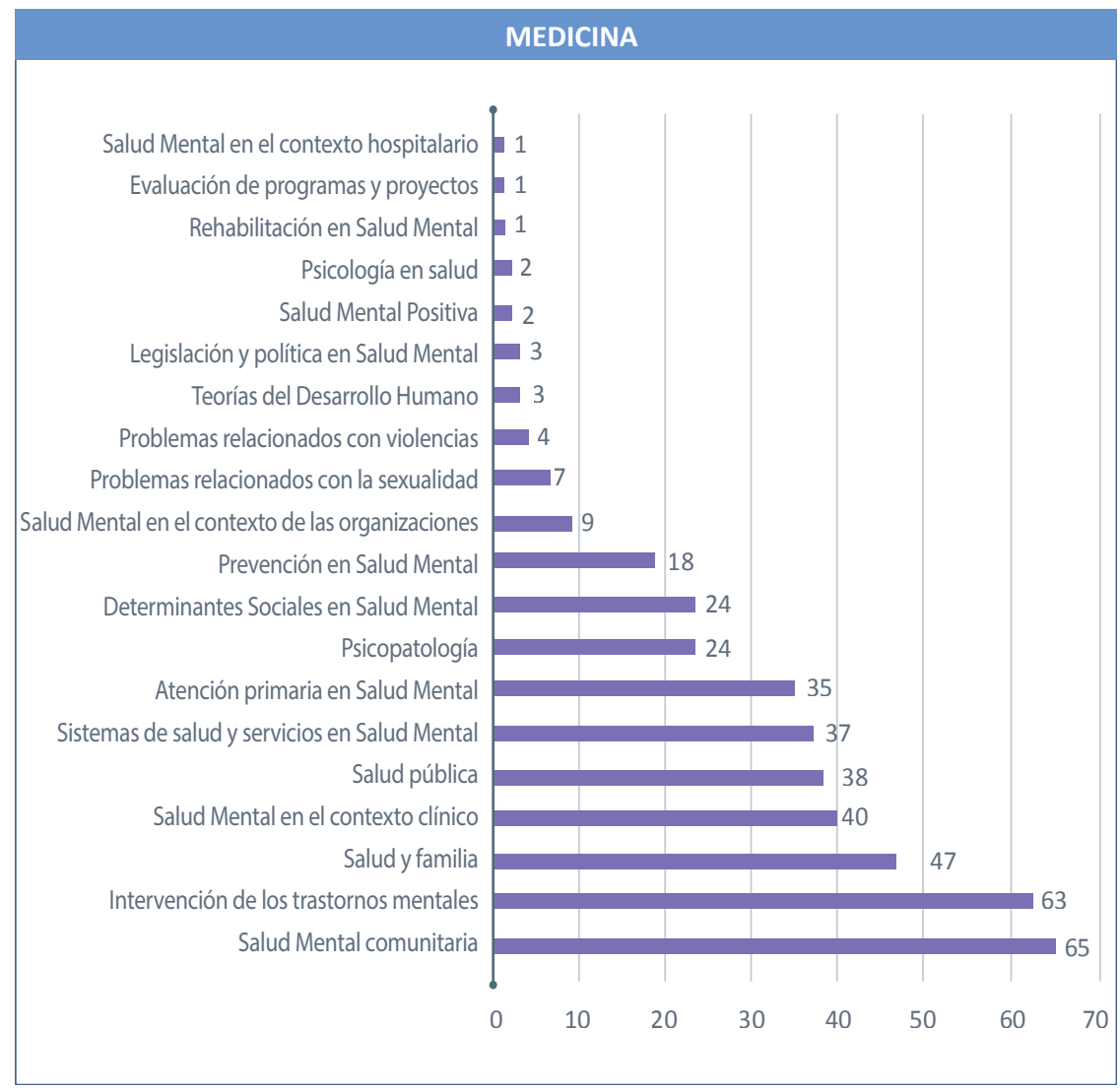

Para el caso del programa de Enfermería (figura 11), en las mallas curriculares se evidenció mayor frecuencia de cursos de "Salud mental en el contexto clínico", "Salud pública" y "Prevención en salud mental", cada uno con $15 \%$ de frecuencia respecto a los demás cursos implícitos encontrados para este programa. No se encontraron cursos que 
relacionaran las temáticas de "Evaluación y diagnóstico en salud mental", "Intervenciones sociales/comunitarias en salud mental", "Problemas relacionados con consumos", "Problemas relacionados con violencias", "Salud mental positiva", "Salud mental en el contexto hospitalario", "Salud mental en el contexto educativo", "Salud mental y estigmatización", "Suicidio", "Discapacidad", "Atención basada en enfoque de derechos", "Atención basada en enfoque diferencial", "Resiliencia", "Inclusión", y "Psicología y salud".

Figura 11. Presencia de cursos en salud mental programa de Enfermería

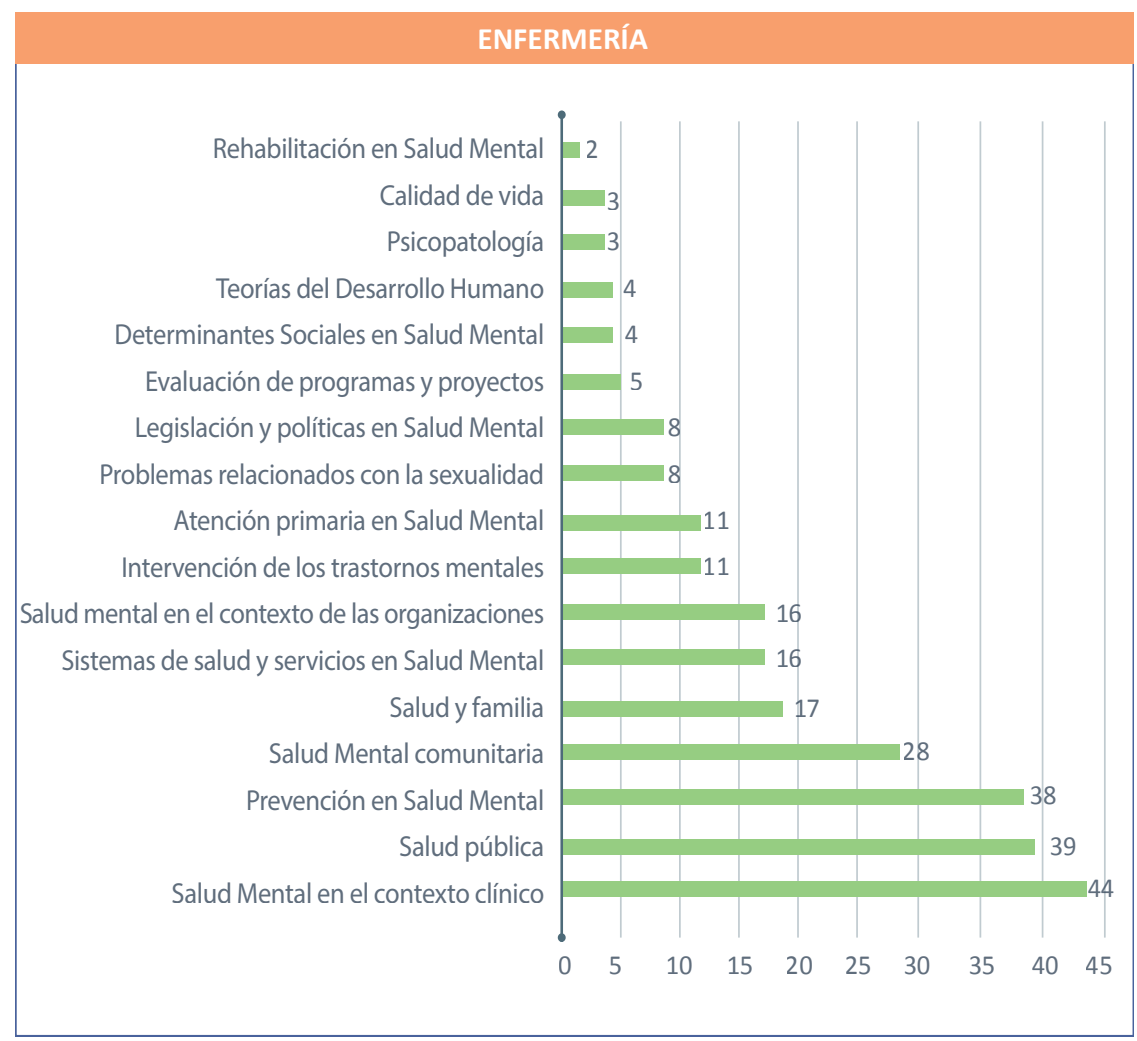

En las mallas curriculares de los programas de Terapia Ocupacional (figura 12), se encuentra que los cursos asociados a "Psicopatología", "Rehabilitación en salud mental", "Intervenciones sociales/comunitarias en salud mental" y "Teorías del desarrollo humano" presentan la mayor 
frecuencia, $11 \%$ cada uno de ellos. No se hallaron cursos asociados a "Atención primaria en salud mental", "Evaluación de programas y proyectos", "Problemas relacionados con la sexualidad", "Problemas relacionados con consumos", "Problemas relacionados con violencias", "Salud mental positiva", "Salud mental en el contexto hospitalario", "Salud mental en el contexto educativo", "Calidad de vida", "Suicidio", "Resiliencia", "Salud y familia", y "Psicología y salud".

Figura 12. Presencia de cursos en salud mental programa de Terapia Ocupacional

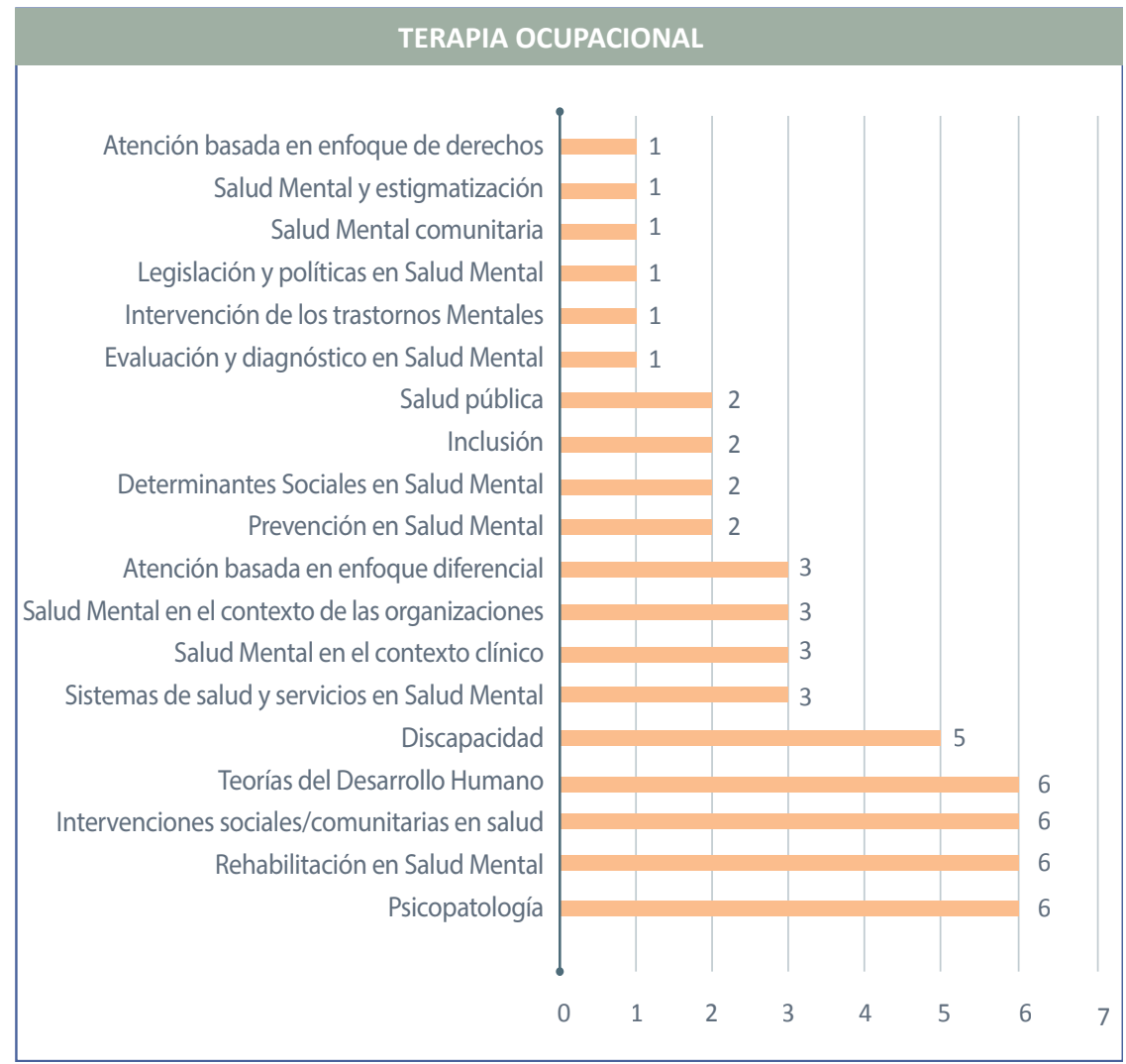

De las 31 temáticas pesquisadas, 30 se encontraron, como se señaló anteriormente, en las diferentes mallas curriculares. Las temáticas a través de las cuales se trabaja implícitamente el componente de salud mental, es decir, los cursos implícitos estuvieron relacionados mayormente con 
temáticas como "Evaluación y diagnóstico en salud mental" y "Salud mental en el contexto clínico"; por el contrario, la temática "Suicidio" no se identificó en las mallas curriculares analizadas.

\subsubsection{Cursos que explicitan el componente de salud mental}

El análisis de las mallas curriculares permitió identificar 65 cursos que en su nominación explicitan el término "salud mental", tal como aparece en la tabla 11. De ellos, 28 corresponden al programa de Enfermería; 20 al programa de Medicina; 8 al programa de Psicología; 7 cursos al programa de Terapia Ocupacional; y 2 al programa de Trabajo Social.

Tabla 11. Cursos explícitos en salud mental

\begin{tabular}{|c|l|l|}
\cline { 2 - 4 } \multicolumn{1}{c|}{} & \multicolumn{1}{|c|}{ Programa } & \multicolumn{1}{c|}{ Nombre del curso } \\
\hline $\mathbf{1}$ & Enfermería & Salud mental y sexualidad humana \\
\hline $\mathbf{2}$ & Enfermería & Cuidado de enfermería en salud mental \\
\hline $\mathbf{3}$ & Enfermería & Práctica de enfermería al adulto mayor y salud mental \\
\hline $\mathbf{4}$ & Enfermería & Cuidado de enfermería al adulto mayor y salud mental \\
\hline $\mathbf{5}$ & Enfermería & Práctica cuidado en salud mental del niño, adolescente y familia \\
\hline $\mathbf{6}$ & Enfermería & Práctica cuidado en salud mental del niño, adolescente y familia \\
\hline $\mathbf{7}$ & Enfermería & Cuidado en salud mental del niño, adolescente y familia \\
\hline $\mathbf{8}$ & Enfermería & Salud mental \\
\hline $\mathbf{9}$ & Enfermería & Proceso de enfermería en cuidado básico y salud mental \\
\hline $\mathbf{1 0}$ & Enfermería & Salud mental \\
\hline $\mathbf{1 1}$ & Enfermería & Salud mental \\
\hline $\mathbf{1 2}$ & Enfermería & $\begin{array}{l}\text { Cuidado de enfermería a las personas y grupos comunitarios } \\
\text { en salud mental }\end{array}$ \\
\hline $\mathbf{1 3}$ & Enfermería & Salud mental en personas \\
\hline $\mathbf{1 4}$ & Enfermería & $\begin{array}{l}\text { Cuidado a la persona con alteraciones de la salud mental y } \\
\text { cuidado a la persona en urgencias }\end{array}$ \\
\hline $\mathbf{1 5}$ & Enfermería & Salud mental \\
\hline $\mathbf{1 6}$ & Enfermería & Cuidado de enfermería a la persona con enfermedad mental \\
\hline $\mathbf{1 7}$ & Enfermería & Salud mental y sexualidad humana \\
\hline $\mathbf{1 8}$ & Enfermería & $\begin{array}{l}\text { Cuidado de enfermería en salud mental a individuos y grupos } \\
\text { de la comunidad }\end{array}$ \\
\hline $\mathbf{1 9}$ & Enfermería & $\begin{array}{l}\text { Cuidado de enfermería en salud mental a individuos y grupos } \\
\text { de la comunidad }\end{array}$ \\
\hline
\end{tabular}




\begin{tabular}{|c|c|c|}
\hline & Programa & Nombre del curso \\
\hline 20 & Enfermería & Cuidado en salud mental del adulto, adulto mayor y familia \\
\hline 21 & Enfermería & Práctica en salud mental del adulto, adulto mayor y familia \\
\hline 22 & Enfermería & Cuidado de la salud mental y psiquiatría \\
\hline 23 & Enfermería & Cuidado de enfermería en salud mental y psiquiatría \\
\hline 24 & Enfermería & Salud mental \\
\hline 25 & Enfermería & Cuidado de enfermería en psiquiatría y salud mental \\
\hline 26 & Enfermería & Enfermería en salud mental \\
\hline 27 & Enfermería & Salud mental \\
\hline 28 & Enfermería & Enfermería en salud mental \\
\hline 29 & Medicina & Salud mental \\
\hline 30 & Medicina & Salud mental \\
\hline 31 & Medicina & Salud mental comunitaria \\
\hline 32 & Medicina & Salud mental \\
\hline 33 & Medicina & Salud mental \\
\hline 34 & Medicina & Salud mental del niño y el adulto \\
\hline 35 & Medicina & Salud mental y comunitaria \\
\hline 36 & Medicina & Salud mental 1 \\
\hline 37 & Medicina & Salud mental 2 \\
\hline 38 & Medicina & Salud mental 3 \\
\hline 39 & Medicina & Salud mental \\
\hline 40 & Medicina & Salud mental, medicina interna \\
\hline 41 & Medicina & Salud mental, pediatría \\
\hline 42 & Medicina & Salud mental, ginecología y obstetricia \\
\hline 43 & Medicina & Introducción a clínica salud mental \\
\hline 44 & Medicina & Salud mental \\
\hline 45 & Medicina & Salud mental \\
\hline 46 & Medicina & Salud mental \\
\hline 47 & Medicina & Salud mental \\
\hline 48 & Medicina & Salud mental \\
\hline 49 & Psicología & Promoción y prevención en la salud mental \\
\hline 50 & Psicología & Promoción y prevención en la salud mental \\
\hline 51 & Psicología & Seminario psicología social 3 (psicología y salud mental) \\
\hline
\end{tabular}




\begin{tabular}{|c|c|c|}
\hline & Programa & Nombre del curso \\
\hline 52 & Psicología & Seminario psicología social 3 (psicología y salud mental) \\
\hline 53 & Psicología & Seminario psicología social 3 (psicología y salud mental) \\
\hline 54 & Psicología & Seminario psicología y salud mental \\
\hline 55 & Psicología & $\begin{array}{l}\text { Promoción de la salud mental y prevención de los problemas } \\
\text { sociales en la comunidad }\end{array}$ \\
\hline 56 & Psicología & $\begin{array}{l}\text { Promoción de la salud mental y prevención de los problemas } \\
\text { sociales en la familia }\end{array}$ \\
\hline 57 & $\begin{array}{l}\text { Terapia } \\
\text { Ocupacional }\end{array}$ & Bienestar mental \\
\hline 58 & $\begin{array}{l}\text { Terapia } \\
\text { Ocupacional }\end{array}$ & Terapia ocupacional en salud mental \\
\hline 59 & $\begin{array}{l}\text { Terapia } \\
\text { Ocupacional }\end{array}$ & Acción profesional en salud mental \\
\hline 60 & $\begin{array}{l}\text { Terapia } \\
\text { Ocupacional }\end{array}$ & Salud mental y disfunciones psicosociales \\
\hline 61 & $\begin{array}{l}\text { Terapia } \\
\text { Ocupacional }\end{array}$ & Terapia ocupacional en salud mental y disfunciones sociales \\
\hline 62 & $\begin{array}{l}\text { Terapia } \\
\text { Ocupacional }\end{array}$ & Práctica en salud mental \\
\hline 63 & $\begin{array}{l}\text { Terapia } \\
\text { Ocupacional }\end{array}$ & Terapia ocupacional y salud mental \\
\hline 64 & Trabajo Social & Salud mental \\
\hline 65 & Trabajo Social & Salud mental \\
\hline
\end{tabular}

\subsubsection{Fortalezas y necesidades de la formación en salud mental que ofrecen los programas}

El análisis de las fortalezas y necesidades de la formación en salud mental para las disciplinas objeto de estudio se realizó en el marco de un panel desarrollado con profesores y directores de varios de estos programas en Colombia. El panel de expertos entonces - tratándose de un ejercicio cualitativo al que se invitó a representantes de todos los programas-, contó con la participación de 10 personas (9 panelistas y una moderadora) que representaron a psicología, trabajo social, medicina y enfermería. 
El encuentro se propuso reflexionar acerca de las fortalezas y debilidades reconocidas con relación a la formación - de acuerdo a cada área sustantiva universitaria (docencia, investigación, extensión/ proyección social)-; así como, propiciar la identificación de estrategias para la potenciación de lo encontrado como fortalezas en la formación y la generación de propuestas para atender a las debilidades de la misma formación en salud mental.

Los panelistas identificaron como fortalezas en el área sustantiva de docencia de sus programas, la posibilidad de contar con profesores posgraduados en disciplinas afines a la salud mental, lo que a su vez -según ellos mismos-, los convierte en profesionales idóneos para acompañar dicha formación; sin embargo, señalaron que el hecho de que los espacios de formación estén sujetos a la permanencia del docente en el programa se constituye en una dificultad de carácter administrativo y no necesariamente del área de docencia, frente a la cual revelan dos elementos que sí representan una significativa debilidad, a saber, que los planes de formación no incluyen como componente explícito cursos que atiendan a la formación en salud mental, siendo por tanto competencia del docente quien por intereses particulares lo sirva a través de cursos electivos, hecho que redunda en procesos sin continuidad.

A lo mencionado en el párrafo anterior, e incluso como consecuencia de lo allí expuesto, se suma que al no ser una temática relevante en los planes de formación no se disponen los recursos necesarios para atender a las exigencias de ser abordada de manera interdisciplinaria. En ese sentido, se encuentra una tendencia particular a realizar lecturas desde el modelo biomédico, en exclusión de las necesidades del contexto, en otros términos, se identifica una tendencia marcada a presentar la formación en salud mental desde modelos patológicos. Atañe mencionar que, desde la perspectiva de los panelistas, para el caso del programa de psicología, por las exigencias particulares de la disciplina llega a presentarse una mayor referencia a cursos que introducen implícitamente temas relacionados con la salud mental, cuestión que se hace más compleja en el programa de Trabajo Social, pues, como ya se había mencionado, son cursos que se ofrecen como electivos, y en ese caso el interés del estudiante será decisivo en el acceso a los mismos. 
Por otro lado, se reconoce como condición favorable, específicamente para el programa de Psicología, la apertura que se ha venido desarrollando hacia otros campos ocupacionales diferentes de la clínica, en particular, se hace énfasis en la aplicación del saber en el campo comunitario; este elemento se relaciona como fortaleza en el área de extensión y proyección social al contar con centros de atención psicológica a través de los cuales se acompaña la salud mental de las comunidades; en ese aspecto se hallan relaciones con los demás programas. En el programa de Enfermería, se observa interés por el trabajo con comunidades, en el desarrollo de temáticas relacionadas con el acceso a los servicios de salud, salud y familia, y salud y comunidad, así como la disposición de centros de atención a la comunidad. Se trata de una fortaleza que reconoce en las prácticas profesionales escenarios propicios para aplicar el conocimiento de carácter teórico, mediante procesos de evaluación, intervención y comprensión de las realidades que están relacionadas con la salud mental de las poblaciones.

Ahora bien, en lo que a investigación respecta, se observa que algunos programas cuentan con grupos de investigación reconocidos por Colciencias, lo que fomenta, además, la participación de estudiantes en semilleros de investigación, dado que se reconoce el desempeño de estos como líderes de procesos, así como, los productos que pueden surgir a partir de dicha participación. En particular, el programa de Enfermería expone su participación en proyectos de investigación relacionados con violencia intrafamiliar y sexualidad, este último programa plantea que al establecer convenios con instituciones hospitalarias y con el Instituto Colombiano de Bienestar Familiar (ICBF), ha sido posible transmitir de forma práctica temas abordados en investigaciones, en relación con consumo de sustancias psicoactivas, sexualidad y primera infancia. No obstante, surgen, tal como ya se expuso en docencia, dificultades para realizar trabajos en red y, por lo tanto, de carácter interdisciplinario, puesto que, por condiciones administrativas no se disponen los recursos necesarios para fortalecer este tipo de procesos.

Se señala entonces en el panel, que la salud mental no es una temática incluida como campo obligatorio en las mallas curriculares, sino que se plantea, fundamentalmente, como tema abordado al interior de otros cursos más generales, o bien, como aspecto de formación complementaria a la que el profesional debe acceder. Ello implica limitaciones en la 
disposición de recursos que favorezcan la formación del talento humano encargado de acompañar la salud mental, y a consecuencia de ello, no se alcance un trabajo interdisciplinario e intersectorial.

Los panelistas coincidieron en plantear, a propósito del área sustantiva de docencia - bien para potenciar las fortalezas, o bien, para generar acciones de mejora a las debilidades-, que ha de propenderse por la unificación de criterios al interior de las mallas curriculares, de forma que, la formación en salud mental se incluya como componente explícito. Dicha formación, desde la perspectiva del panel, deberá propiciar espacios de diálogos disciplinares con el propósito, no solo de atender a las exigencias interdisciplinarias e intersectoriales propias de la formación en salud mental, sino también, para garantizar que haya un abordaje que trascienda los modelos tradicionales. Ahora bien, llama la atención de manera relevante que pese al interés de incluir en las mallas curriculares dichos componentes explícitos, el mayor énfasis está puesto en la formación posgradual; cada uno de los representantes de programas asistentes al panel de expertos, reconoció en las especializaciones y maestrías el espacio propicio para la cualificación del talento humano encargado de acompañar la salud mental. Exponen que dicha formación posgradual suscita el encuentro con otros saberes, así como la profundización en temáticas específicas; razones por la que ha de velarse que sectores que no tienen fácil acceso a la misma encuentren, por oferta de las mismas universidades, mayores posibilidades de dar continuidad a su proceso de formación.

En lo que respecta al área investigativa se reconoce que es preciso fortalecer el trabajo en red y, por lo tanto, generar acciones articuladas en las que el profesional en formación tenga lugar a una participación activa que, a su vez, contribuya a la emergencia de competencias que les permita abordar y comprender de forma más crítica la realidad, y con ello, las situaciones que afectan o promueven la salud mental. Se incentiva, entonces, la creación de semilleros de investigación y la participación en proyectos del sector público, pues se considera que esto contribuirá a acciones de carácter interdisciplinario.

A propósito de programas de extensión y proyección social, se sugiere generar estrategias pedagógicas que permitan, por un lado, atender a las necesidades del contexto, y por otro, lograr una mayor difusión de las mismas. Este elemento se relaciona con las propuestas 
realizadas al área docente, en tanto, se retoma la idea de activar espacios de formación complementaria, para el caso, mediante diplomados, seminarios, entre otros. Así mismo, se reconoce que, dado que la formación en atención a las comunidades es una de las temáticas más abordadas desde los diferentes programas, deberá seguirse fortaleciendo, no solo en términos de la formación misma, sino también a través de la creación de centros que permitan que la población pueda acceder a un acompañamiento real, y con ello, contribuir a las transformaciones del tejido social.

En última instancia, se plantea una idea que cobra relevancia por lo que propicia en términos de la formación del talento humano y en términos del acceso a los servicios por parte de la comunidad. Es decir, se llega a la conclusión de que la Ley 1616 de 2013, debe convertirse en un recurso a través de cual se logre una inclusión más clara del componente de salud mental en los planes de formación, toda vez que, invita a la lectura en contexto; esto último, propiciando un mecanismo mediante el cual la población tenga conocimiento de los servicios a los que puede acceder a través del sistema de salud. Lo anterior redunda en la idea de que la formación en salud mental es también una acción política.

A partir de los resultados expuestos en este capítulo, emergen interrogantes como: ¿ंes la formación posgradual el recurso que permitirá atender a las falencias de la formación profesional en salud mental?, o, ¿dichas falencias pueden ser atendidas desde el pregrado mismo? Siendo afirmativa la respuesta a la última pregunta, se hace relevante adelantar ejercicios investigativos que permitan responder a ¿cómo diseñar un modelo de formación transdisciplinar en salud mental para estos programas?

El establecimiento de un panorama de la formación en salud mental ofrecida por estos programas propició la construcción de una propuesta de modelo de formación transdisciplinar en salud mental y plantear así cambios académicos en la formación del talento humano necesarios para el cumplimiento de la Ley 1616 de enero de 2013. Esta propuesta de modelo, bien será desarrollada en el tercer capítulo de este libro. 


\section{CAPÍTULO

\section{UNA PROPUESTA DE MODELO DE FORMACIÓN TRANSDISCIPLINAR EN SALUD MENTAL ${ }^{10}$}

Lo expuesto en el capítulo anterior deja como conclusión dos ideas concretas, a saber, 1.) la salud mental no es tema de interés explícito en los planes de formación curricular, más bien, 2.) se marca una importante tendencia a ser abordada como parte de temas o cursos más generales. Ideas que luego se expresaron en interrogantes respecto a los mecanismos que favorecerían la formación del profesional encargado de atender la salud mental de las poblaciones.

Es así como, pensar en una propuesta de modelo de formación transdisciplinar en salud mental se convierte en el esfuerzo, no solo de contribuir al fortalecimiento de los procesos de formación de los estudiantes de programas universitarios relacionados con el equipo básico de atención en salud mental, sino también de atender a los retos que, de acuerdo con lo que se infiere de la Ley 1616 de 2013, se presentan para esta formación en el territorio colombiano, entre ellos, la articulación

\footnotetext{
${ }^{10}$ Parte de este capítulo ha sido utilizado para la publicación de un artículo en la revista interdisciplinaria Revista de Psicología y Ciencias Afines. Puede hallarse con la siguiente citación: Bedoya-Gallego, D., Buitrago-Duque, D. y Vanegas-Arbeláez, A. (2019). Transdisciplinariedad en salud mental: una propuesta de modelo de formación. Interdisciplinaria, 36(1), 119-132.
} 
de la academia con los entes encargados de ofrecer atención, la capacidad de reconocer las necesidades específicas de cada población, el trabajo interdisciplinario e intersectorial, y la participación social y comunitaria, entre otros.

Londoño, Valencia y Vinaccia (2006) plantean que es labor del psicólogo legitimar su participación en procesos relativos a la salud, tales como, la práctica, la investigación y la educación, involucrando los distintos aspectos asociados a la salud pública, las iniciativas de salud rurales, la salud ocupacional, la genética y los avances tecnológicos en medicina y en la calidad de vida; planteamiento que deberá extenderse a los demás profesionales afines al área de la salud, sirviéndose de argumentos como el que plantea Sierra (2010) al señalar que, mejorar la formación de los médicos en salud integral y mental abrirá las posibilidades de una atención más efectiva, y por consiguiente una reducción de los costos derivados de la mala calidad en los servicios de salud mental. Lo anterior, redunda en la expectativa de una articulación que procure la transdisciplinariedad.

Ahora bien, es claro que las conclusiones expuestas en el capítulo 2 emergen tras la revisión de las mallas curriculares, lo que permite una aproximación solo a uno de los actores implicados en atender la salud mental de los individuos y poblaciones, es decir, la academia; de ahí entonces que aparezca el cuestionamiento acerca de lo que puede hallarse en el acercamiento a una realidad más concreta en lo relativo a las experiencias de las comunidades.

De esta manera, la propuesta del modelo de formación se diseñó tras la realización de un ejercicio aplicado, en el que se buscó la participación de las nueve subregiones del departamento de Antioquia, a saber: Magdalena Medio, Occidente, Suroeste, Urabá, Bajo Cauca, Nordeste, Norte, Oriente y Valle de Aburrá; esta participación se realizó a través del acercamiento a los municipios centrales de estas subregiones, en tanto allí fue posible encontrar las instituciones que congregan la atención a los demás municipios que las componen. Así las cosas, en cada una de las visitas se realizaron entrevistas a funcionarios de las secretarías de salud, los hospitales, las comisarías de familia, los centros zonales del Instituto Colombiano de Bienestar Familiar (ICBF), entre otros. Estos informantes, de acuerdo a su naturaleza, se clasificaron en: empleadores, formadores y profesionales en salud mental. De esta manera, el trabajo de campo 
dejó como resultado 38 entrevistas, 17 de ellas correspondientes a empleadores, 19 a profesionales y 2 a formadores. La figura 13 permite relacionar las entrevistas realizadas de acuerdo a la región visitada, la institución y el tipo de actor.

Figura 13. Relación entrevistas, subregión, tipo de actor e instituciones

\begin{tabular}{|c|c|c|c|}
\hline & & Instituciones & $\begin{array}{l}\text { Número de } \\
\text { entrevistas }\end{array}$ \\
\hline Subregión & $\begin{array}{l}\text { Número de } \\
\text { entrevistas }\end{array}$ & \multirow{3}{*}{$\begin{array}{l}\text { Secretarías de Salud } \\
\text { Otras Secretarías } \\
\text { Comisarías de Familia e ICBF } \\
\text { Instituciones universitarias } \\
\text { Fundaciones } \\
\text { Hospitales }\end{array}$} & $\begin{array}{c}13 \\
3\end{array}$ \\
\hline \multirow{5}{*}{$\begin{array}{r}\text { Urabá } \\
\text { Occidente } \\
\text { Oriente } \\
\text { Suroeste } \\
\text { Magdalena Medio } \\
\text { Valle de Aburrá } \\
\text { Norte } \\
\text { Nordeste } \\
\text { Bajo Cauca }\end{array}$} & $\begin{array}{l}8 \\
6 \\
6\end{array}$ & & $\begin{array}{c}2 \\
1 \\
13\end{array}$ \\
\hline & $\begin{array}{l}4 \\
4\end{array}$ & & 38 \\
\hline & $\begin{array}{l}4 \\
3 \\
2\end{array}$ & Tipo de actor & $\begin{array}{l}\text { Número de } \\
\text { entrevistas }\end{array}$ \\
\hline & 1 & \multirow{3}{*}{$\begin{array}{l}\text { Empleadores } \\
\text { Profesionales } \\
\text { Formadores }\end{array}$} & 17 \\
\hline & 38 & & $\begin{array}{c}19 \\
2\end{array}$ \\
\hline & & & 38 \\
\hline
\end{tabular}

Fuente: figura construida a partir de la información recabada en el trabajo de campo de la investigación.

Una vez transcritas las entrevistas, estas fueron codificadas y categorizadas a través del software Nvivo (versión 11), y de ello emergieron 285 códigos usados 651 veces, los que, a su vez, tributaban a las 6 categorías de análisis, a saber: contexto, eventos en salud mental, atención, formación (se subdividió en fortalezas y falencias en la formación), competencias del profesional en salud mental y metodología para la aplicación de la propuesta de modelo de formación.

Por otro lado, se realizó un ejercicio de carácter documental que permitió identificar los principales eventos en salud mental reportados en el departamento de Antioquia, según fuentes oficiales; este ejercicio se realizó a través de la revisión de los datos suministrados por el Sistema Nacional de Vigilancia en Salud Pública (SIVIGILA, 2014), el Tamizaje de Salud Mental del Departamento de Antioquia 2009-2010 y la Encuesta Nacional de Salud Mental 2015, así como de los diferentes documentos 
de Análisis de Situación de Salud (ASIS, 2013) de cada uno de los municipios que componen las nueve subregiones, y las estadísticas de morbilidad (Secretaría Seccional de Salud y Protección Social de Antioquia -SSSPSA-, 2016) y mortalidad del departamento (SSSPSA, 2017).

Ambos procesos, el aplicado y el documental, permitieron construir una propuesta inicial para el modelo de formación en salud mental, integrando en ella un componente temático y uno metodológico; esta primera versión de la propuesta fue llevada al III Encuentro Grupo Académico en Salud Mental de Antioquia, GASMA: necesidades y retos de la formación del recurso humano en salud mental-2016 ${ }^{11}$, evento que contó con la participación de algunos de los informantes que se identificaron en la fase de recolección de la información, a quienes se les socializó la construcción alcanzada al momento. Posteriormente, los invitados se reunieron en mesas de trabajo y entregaron sus respectivas devoluciones, realizando con este ejercicio una validación de la construcción que se les presentó; de esta forma, las devoluciones entregadas fueron consideradas para la formulación final de la propuesta de modelo de formación.

En consideración de lo anterior, el presente capítulo se propone, inicialmente, presentar los principales eventos en salud mental que fueron identificados, tanto a partir de la revisión documental como del trabajo de campo, y con ello las características de la atención a dichos eventos, pues con base en estos y en las temáticas presentadas en el capítulo 2, se construyó el componente temático.

Posteriormente, se presenta un desarrollo de la perspectiva transdisciplinar del modelo, teniendo como base la conceptualización realizada en el primer capítulo acerca de la salud mental como campo del conocimiento; aspecto que se relaciona con el siguiente apartado, el cual expone una reflexión acerca de las competencias de los profesionales en salud mental, puntualizando que el reto para la formación está

\footnotetext{
${ }^{11}$ Desde su creación en 2013, GASMA se ha propuesto gestionar el conocimiento en salud mental desde una perspectiva de salud pública, en aras de aportar a la formación del talento humano en salud mental de acuerdo con las necesidades del contexto. En ese sentido, anualmente realiza el Encuentro GASMA, como propuesta abierta a diferentes sectores e instituciones para reflexionar sobre temas relativos a la salud mental de la población colombiana. De manera puntual, el III Encuentro se llevó a cabo el 25 de mayo de 2016 en la Sede de Investigación Universitaria (SIU) de la Universidad de Antioquia.
} 
en favorecer el desarrollo de competencias a través de las cuales los profesionales estén en capacidad de hacer lecturas críticas acordes a las necesidades de los contextos.

En consecuencia, el apartado final expone los componentes temático y metodológico, de la propuesta de modelo de formación con visión transdisciplinar en salud mental.

\subsection{Principales manifestaciones de la salud mental y características de su atención}

La conceptualización presentada en el primer capítulo permite precisar que la salud mental puede ser entendida como un campo del conocimiento en el que convergen dos dimensiones (negativa y positiva) y tres componentes (trastornos mentales, problemas psicosociales y condicionantes de la salud mental).

Así las cosas, los eventos en salud mental identificados en la fase aplicada de la investigación se presentan atendiendo -en el marco de la dimensión negativa - a los trastornos mentales y a los problemas psicosociales, y de manera específica en este último componente, se abordan las violencias y el consumo de sustancias psicoactivas (SPA); se hace relevante aclarar que los participantes de la investigación no hicieron alusiones a la dimensión positiva de la salud mental. Sin embargo, la información se contrasta con los hallazgos de la fase documental, pues de manera particular, la Encuesta Nacional de Salud Mental-2015 (MinSalud, 2015), en comparación con los estudios anteriores, por primera vez trasciende una visión centrada en los problemas y trastornos mentales, incluyendo información relativa al bienestar individual y colectivo, a la promoción de la salud mental, a la convivencia ciudadana y a la calidad de vida.

Ahora bien, inicialmente se hace una relación de la información hallada de manera documental y posteriormente esta información se contrasta con la obtenida en el trabajo de campo, evidenciando las coincidencias y diferencias observadas en ambas fuentes. Una vez establecido este panorama, se hace referencia a las condiciones en las que se ofrece la atención institucional a los problemas documentados, que fue posible identificar tras el acercamiento a las subregiones. 
Al respecto, es importante mencionar que la evaluación de la atención en salud mental en Antioquia ha tenido pocos acercamientos que permitan dar cuenta de la efectividad del sistema de salud y otros sectores que ofrecen respuestas y programas para problemáticas en salud mental. En el año 2010, Berbesi y Bareño concluyeron que "sin contar con la voluntad política plasmada a través de programas para la intervención de problemáticas latentes y aplazadas se estará creando una agenda inconclusa e intratable por los entes territoriales" (p.41). Planteamiento que cobra relevancia en tanto es preciso considerar que en lo que respecta a la salud mental, no solo basta con que se cuente con profesionales idóneamente formados, sino también que sean favorables las condiciones sociales en las que es ofrecida la atención.

\subsubsection{Eventos en salud mental}

\subsubsection{Problemas psicosociales: violencias}

La revisión documental permitió hallar que la violencia se presenta como un fenómeno relevante asociado a otros problemas de salud mental. De acuerdo con la oms (2002), esta se clasifica en términos de su origen (autoinflingida, interpersonal y colectiva) y tipo (física, sexual, psicológica, privación o desatención). Por su parte, el SIVIGILA - Antioquia (2016) orienta los reportes en función de privación y negligencia, violencia física, violencia psicológica, violencia sexual, violencia intrafamiliar e intento de suicidio. Como se observa en la tabla 12, el evento con tasas más elevadas es la violencia intrafamiliar (que implica varios tipos de violencia) y la región más afectada es Oriente; aunque vale señalar que esto puede estar influenciado por el reporte organizado que desde cada una de las subregiones se realiza respecto de los eventos, así como por el acceso a dicho reporte.

Tabla 12. Tasas por 100.000 habitantes de eventos en Antioquia y las subregiones más afectadas 2016

\begin{tabular}{|l|c|l|}
\hline \multicolumn{1}{|c|}{ Tipo de violencia } & Tasa por $\mathbf{1 0 0 . 0 0 0}$ habitantes & Subregión más afectada \\
\hline Violencia intrafamiliar & 170,9 & Oriente $(269,2)$ \\
\hline Violencia física & 90,4 & Oriente $(155,6)$ \\
\hline Intento de suicidio & 64,7 & Oriente $(84,9)$ \\
\hline Violencia sexual & 54,6 & Valle de Aburrá $(61,7)$ \\
\hline Violencia psicológica & 19,1 & Oriente $(58,3)$ \\
\hline Privación y negligencia & 6,9 & Suroeste $(13,0)$ \\
\hline
\end{tabular}

Fuente: SIVIGILA Antioquia, 2016. 
En Colombia, las muertes violentas se clasifican por su origen (homicidios de origen social o político; por suicidio y por accidentes). La tasa más alta de eventos de causa externa tiene que ver con los homicidios, particularmente, en lo que respecta a Antioquia, se encuentra que esta supera en todos los eventos los datos a nivel Colombia, como lo muestra la tabla 13.

Tabla 13. Tasas de muertes por causas externas en Colombia y en Antioquia, 2016

\begin{tabular}{|l|c|c|}
\hline \multicolumn{1}{|c|}{ Muerte por causa externa } & $\begin{array}{c}\text { Tasa por } \mathbf{1 0 0 . 0 0} \\
\text { habitantes Colombia }\end{array}$ & $\begin{array}{c}\text { Tasa por } \mathbf{1 0 0 . 0 0} \\
\text { habitantes Antioquia }\end{array}$ \\
\hline Homicidios & 23,66 & 24,65 \\
\hline Accidentes de transporte & 14,93 & 15,7 \\
\hline Otros accidentes & 6,03 & 6,93 \\
\hline Suicidios & 5,2 & 6,47 \\
\hline
\end{tabular}

Fuente: Forensis - Instituto Nacional de Medicina Legal y Ciencias Forenses, 2016.

Al contrastar la información hallada en la revisión documental con la información referida por los actores entrevistados en el trabajo de campo, se encontró que con relación al evento violencias los informantes hacen referencia a elementos que pueden clasificarse en: suicidio e intentos de suicidio, violencias domésticas, violencias de género, abuso sexual, violencias escolares y conductas violentas en jóvenes, y finalmente, violencia por conflicto armado. Los resultados muestran que, la violencia es el evento que mayor impacto tiene en la salud mental de las poblaciones, desde la perspectiva de los participantes de la investigación. Por un lado, porque se trata de un evento que se halla relacionado con los otros reportados, por ejemplo, en el caso de los trastornos mentales se halla relación entre violencias y depresión, estrés postraumático, y trastornos de la ansiedad; por otro lado, por la relación que se manifiesta entre la violencia y los problemas sociales que afectan la salud, tales como, la pobreza, la inequidad, la escasez de recursos y/o mala disposición de recursos.

\subsubsection{Problemas psicosociales: consumo de sustancias psicoactivas}

El reporte entregado por el Tamizaje de Salud Mental de Antioquia (SSSPSA, 2010) informa que las drogas más consumidas por la población general en edades entre 9 y 79 años son el alcohol y el tabaco. En el año 2010 para Antioquia el consumo de alcohol se manifestó como se muestra en la tabla 14. 
Tabla 14. Frecuencia del consumo de alcohol para Antioquia en población general

\begin{tabular}{|l|c|}
\hline \multicolumn{1}{|c|}{ Frecuencia del consumo } & Porcentaje poblacional \\
\hline Último mes & $70,70 \%$ \\
\hline Diariamente & $17,20 \%$ \\
\hline Bebedor de riesgo ${ }^{12}$ & $12,1 \%$ \\
\hline
\end{tabular}

Fuente: Tamizaje - Dirección Seccional de Salud de Antioquia, 2010.

Esta última condición, 'bebedor de riesgo', presentó variaciones entre hombres y mujeres (hombres $15,1 \%$ y mujeres $8,9 \%$ ). Por otro lado, la prevalencia de consumo de alcohol en Antioquia en la población entre 11 y 18 años para el año 2011, estuvo entre el 40 y $50 \%$ con respecto a la prevalencia nacional (39,81\%) (ASIS, 2013, pp.195 - 196).

En lo que respecta a la población adolescente, la Encuesta Nacional en Salud Mental-2015 (MinSalud, 2015), encontró acerca del consumo de alcohol, que la región Central, a la que pertenece Antioquia, ocupa el tercer lugar con un porcentaje del $18,6 \%$ respecto a la población Nacional. Información que guarda relación con la entregada por el ASISColombia (2013), en la que se expresa que para el año 2011 el consumo de alcohol de la población antioqueña con edades entre los 11 y 18 años está por encima del $40 \%$, entre tanto, la prevalencia nacional para ese año fue de $39,81 \%$.

En cuanto al consumo de tabaco en Antioquia, en el 2010 un $40,3 \%$ de la población entre 9 y 79 años fumaba tabaco diariamente; el promedio de cigarrillos consumidos diariamente por los fumadores habituales era de 7,65 \% (SSSPSA, 2010).

Respecto a las drogas ilegales, la SSSPSA (2010), con base en los datos epidemiológicos más relevantes en la población general antioqueña, muestra que la marihuana es la droga ilegal de consumo más prevalente. En el año 2011 un 19,3 \% de los antioqueños entre 9 y 79 años la había consumido alguna vez en la vida; de estos, un 59,1\% en los últimos 12 meses y un $37,7 \%$ en la última semana. El resto de las drogas ilegales (cocaína, bazuco, éxtasis) presentan prevalencias de consumo inferiores en la población general, igual sucede con otras drogas como, hongos, cacao sabanero, heroína, diablo e inhalables.

\footnotetext{
12 "El consumo de riesgo es un patrón de consumo de alcohol que aumenta el riesgo de consecuencias adversas para la salud si el hábito del consumo persiste. La Organización Mundial de la Salud (OMS) lo describe como el consumo regular de 20 a 40g diarios de alcohol en mujeres y de 40 a $60 \mathrm{~g}$ diarios en varones" (oMs, 2008, p. 2).
} 
Los actores consultados en el ejercicio investigativo, señalan que este evento (consumo de sustancias) tiene importante influencia en la salud mental de las subregiones visitadas, no solo por las implicaciones que en sí mismo posee, sino también, porque desde su perspectiva, el consumo de SPA se encuentra correlacionado con otros eventos tales como, trastornos mentales, microtráfico, embarazo en adolescentes, indigencia y diferentes manifestaciones de la violencia.

\subsubsection{Trastornos mentales}

Las fuentes de información consultadas para Antioquia consideraron: los Registros Individuales de Prestación de Servicios de Salud (RIPS), a través de los reportes de morbilidad en consulta externa, hospitalización y urgencias (SSSPSA, 2015); la Encuesta Nacional en Salud Mental-2015 (MinSalud, 2015) y el Tamizaje de Salud Mental del Departamento de Antioquia, 2009-2010 (SSSPSA, 2015).

La información hallada tras la revisión de los RIPS permitió identificar que al 2015, el reporte de análisis global de salud mental del departamento no presenta datos referentes a los trastornos mentales. De tal manera que la aproximación debió realizarse atendiendo a los reportes que presentan las diferentes subregiones y municipios que las componen.

Así las cosas, en lo que respecta a consulta externa, la subregión del Bajo Cauca fue la única en reportar que el 1,01 \% (6.251 casos) de las consultas atendidas, corresponden a los trastornos mentales y del comportamiento debidos al uso de múltiples drogas y al uso de otras sustancias psicoactivas, lo que constituye esta en la novena causa de morbilidad para esta subregión (SSSPSA, 2016).

Los reportes de urgencias y hospitalización no relacionan información relativa a los trastornos mentales.

Por otro lado, la información referida por municipios revela que tanto en Caucasia (Bajo Cauca) como en Caicedo (Suroeste), los trastornos mentales y del comportamiento debidos al uso de múltiples drogas y al uso de otras sustancias psicoactivas es la sexta causa de morbilidad reportada en consulta externa (ver tabla 15). 
Tabla 15. Reporte de trastornos mentales en consulta externa por municipio

\begin{tabular}{|l|c|c|}
\hline \multicolumn{1}{|c|}{ Municipio } & \% de consultas & \# de casos \\
\hline Caucasia & $2,08 \%$ & 6.071 \\
\hline Caicedo & $1,10 \%$ & 250 \\
\hline
\end{tabular}

Fuente: Estadísticas morbilidad consulta externa - SSSPA, 2016.

En Gómez Plata (Nordeste) la demencia de enfermedad de Alzheimer no especificada, representa el $1,02 \%$ ( 250 casos) de las consultas, siendo así la octava causa de morbilidad; y en el Carmen de Viboral (Oriente) el Episodio depresivo moderado se constituye en el 0,79\% (411 casos) de las consultas atendidas, ubicándose en la novena causa de atención por consulta externa.

En cuanto a hospitalización, el reporte de los trastornos mentales por municipio hace referencia a los trastornos mentales por consumo de sustancias psicoactivas y a los trastornos psicóticos, tal como se observa en la tabla 16.

Tabla 16. Reporte de trastornos mentales en hospitalización por municipio

\begin{tabular}{|l|l|l|c|c|c|}
\hline \multicolumn{1}{|c|}{ Trastorno } & Municipio & Región & $\begin{array}{c}\text { \% de } \\
\text { hospitalizaciones }\end{array}$ & $\begin{array}{c}\text { \# de } \\
\text { casos }\end{array}$ & $\begin{array}{c}\text { Lugar que } \\
\text { ocupa como } \\
\text { causa de } \\
\text { hospitalización }\end{array}$ \\
\hline $\begin{array}{l}\text { Trastornos } \\
\text { mentales y del } \\
\text { comportamiento } \\
\text { debidos al uso } \\
\text { de múltiples } \\
\text { drogas y al uso de } \\
\text { otras sustancias } \\
\text { psicoactivas: } \\
\text { síndrome de } \\
\text { dependencia }\end{array}$ & Caicedo & Suroeste & 1,63 & 5 & 9 \\
\hline $\begin{array}{l}\text { Esquizofrenia } \\
\text { paranoide }\end{array}$ & Carolina & Norte & 2,1 & 3 & 8 \\
\cline { 2 - 6 } & Alejandría & Oriente & 1,46 & 2 & 8 \\
\hline $\begin{array}{l}\text { Trastorno afectivo } \\
\text { bipolar, episodio } \\
\text { maniaco presente } \\
\text { con síntomas } \\
\text { psicóticos }\end{array}$ & Sabanalarga & Occidente & 1,49 & 4 & 10 \\
\cline { 2 - 6 } & Peñol & Oriente & 1,3 & 11 & 8 \\
\hline
\end{tabular}

Fuente: Estadísticas morbilidad hospitalización (SSSPSA, 2016). 
Finalmente, en el reporte relacionado con la atención a trastornos mentales por Urgencias solo se halla información del municipio de Marinilla (Oriente); esta hace alusión a que el trastorno afectivo bipolar no especificado representa el 1,12 \% (9 casos) de la atención por urgencias.

Por su parte, la Encuesta Nacional de Salud Mental (2015), utilizando el instrumento SRQ (Self Reporting Questionnaire) ${ }^{13}$, muestra que, en lo que respecta a la región Central, para personas entre 18 y 44 años, se reporta prevalencia de síntomas relacionados con depresión (más de 7 síntomas), ansiedad (más de 5 síntomas), y psicosis (de 1 a 2 síntomas). En población mayor de 45 años, se observa un comportamiento similar, predominando los síntomas de depresión (más de 7), seguidos por los síntomas relacionados con la ansiedad (más de 5).

Al comparar los datos arrojados por la Encuesta Nacional en Salud Mental, 2015, con los presentados por la SSSPSA en el 2010, se observa una correspondencia con los trastornos referidos; es decir, la SSSPSA informa que en la población adulta el 14,5 \% (6.647 personas) de la muestra del departamento presenta sintomatología relacionada con depresión, ansiedad o angustia; de ellos un 12,7 \% están en alto riesgo de suicidio, en tanto que se entiende que la depresión implica pensamientos de muerte recurrentes, y en algunos casos ideación suicida.

Finalmente, las entrevistas realizadas a los representantes de las subregiones permitieron identificar que su percepción coincide con la información reportada por las fuentes documentales consultadas. Ahora bien, los representantes manifestaron que las enfermedades mentales a su vez se asocian con condiciones sociales como la indigencia, así como con problemáticas familiares; situación que se señala de alta relevancia toda vez que, desde su perspectiva, las dinámicas internas de las familias llegan a convertirse en potenciadoras de los síntomas de la enfermedad mental.

\subsubsection{Dimensión positiva de la salud mental}

La dimensión positiva de la salud mental se constituye en un aspecto, en gran medida, ausente en el discurso de las fuentes consultadas; tanto en las entrevistas obtenidas durante el trabajo de campo como en la revisión de los documentos oficiales, se identificó una tendencia a

\footnotetext{
${ }^{13}$ Cuestionario de auto reportaje de síntomas psiquiátricos.
} 
concentrar las referencias a salud mental en problemas psicosociales y en trastornos mentales. No obstante, el último estudio nacional al orientar la indagación de la salud mental desde las categorías (1) estar bien individual y colectivo y (2) salud mental y sufrimiento emocional, permitió un reconocimiento de variables positivas de esta dimensión humana. Así entonces, la información retomada en este apartado presenta datos relativos a la primera categoría en lo que a la región Central respecta.

Al indagarse por la autopercepción de salud mental, se encuentra que el grupo poblacional comprendido entre los 18 y 44 años la define como excelente ( $42,4 \%$ de las personas encuestadas). Así mismo, la aproximación al bienestar emocional, muestra que hay una mayor valoración global de sentimientos positivos ("muy feliz" y "feliz") en el grupo poblacional que comprende las edades de 12 a 17 años, sin embargo, a medida que avanza la edad esta percepción global disminuye. En lo que respecta a la funcionalidad familiar se observa que la medición arrojó resultados similares en las regiones estudiadas, así por ejemplo, en adolescentes varió entre 34,8 \% (región Oriental) y 25,4 \% (región Central), lo que ubica el margen entre algún grado de disfunción y disfunción leve.

En un sentido general, la encuesta refiere que, si bien hay una tendencia mayoritaria a percibir un panorama positivo de la salud mental, en gran medida asociado a la satisfacción de las necesidades individuales, esta percepción tiende a afectarse con la edad, el género y las situaciones de pobreza. Así mismo, resalta la persistencia a asociar la salud mental al funcionamiento biológico, reflejando que aún hoy, persiste en la sociedad colombiana, un imaginario que releva del constructo salud componentes culturales, simbólicos y ambientales.

\subsubsection{Principales características de la atención, desde la perspectiva de los actores de la investigación}

Atañe mencionar que la atención en salud mental, se convierte en una preocupación manifiesta en los actores de la investigación toda vez que hacen referencia a las dificultades que se presentan en las diferentes subregiones para acompañar la enfermedad mental, dificultades que cronifican estos padecimientos. Igualmente se hace referencia a problemáticas relacionadas con los subregistros y enfermedades mentales no diagnosticadas, en particular en lo que concierne con la relación entre trastornos mentales y suicidio. 
Ahora bien, es importante considerar que de acuerdo con el análisis realizado a la categoría atención, emergieron 73 códigos que fueron usados 189 veces, aludiendo a temas de manejo público, condiciones institucionales desfavorables, características de la atención ofrecida por el profesional, así como a algunos elementos asociados al contexto.

La referencia más frecuente estuvo asociada al manejo de los recursos públicos para las atenciones en salud mental, particularmente a la escasa disposición de estos, bien sea en términos de recurso humano o de recursos económicos para el desarrollo de programas/proyectos o gestión de las diferentes instituciones, vale mencionar que esto último está relacionado con la discontinuidad en la contratación de los profesionales que acompañan la atención de la salud mental de las poblaciones; lo anterior deriva en la poca estabilidad de los programas y proyectos, en la poca efectividad e impacto social de las intervenciones y en las limitaciones que las personas experimentan para el acceso al sistema de salud, limitaciones que tienden a ser mayores para la población rural.

Adicionalmente, se hizo referencia a la desarticulación intersectorial como una de las dificultades que se presentan en la atención a los diferentes eventos en salud mental; como efecto de dicha desarticulación, se expresa la falencia en la construcción de rutas de atención que articulen a los diferentes sectores y propicien atenciones pertinentes y oportunas.

Por otra parte, en lo que respecta a las condiciones institucionales desfavorables, se hace mención a las dificultades que se presentan en la atención del paciente psiquiátrico, llegando a constituirse en una problemática para los diferentes hospitales, en tanto la mayoría de ellos no están acondicionados para la atención de la enfermedad mental; esto trae como consecuencia una atención que es percibida como deshumanizada y una brecha entre la oferta institucional y las necesidades en salud mental de la población. Esta brecha se traduce muchas veces en la falencia de programas relacionados con la psicoeducación familiar, en la falta de protocolos para la atención de problemas en salud mental, así como en la falta de estrategias para contrarrestar los eventos negativos reconocidos en salud mental, particularmente entre jóvenes y adolescentes. Igualmente, se señala que algunas condiciones institucionales relacionadas con la contratación de talento humano y la disposición de recursos internos no favorecen el trabajo interdisciplinario e interinstitucional. 
Con relación a las características de la atención ofrecida por algunos profesionales, se alude a falencias en la ética profesional y a la rivalidad que se sostiene, de manera particular entre algunos profesionales de psicología y psiquiatría. También se expone una preocupación por los subregistros de los diferentes eventos atendidos en salud mental; esto puede guardar relación con lo mencionado en párrafos anteriores, toda vez que, en tanto no existan rutas claras de atención, se dificultará la identificación y derivación de las personas que presentan problemáticas o trastornos en salud mental.

Finalmente, lo antes dicho, permite identificar que las dificultades manifiestas frente a la atención no corresponden a elementos que aluden exclusivamente a la formación del profesional de pregrado, sino también a las condiciones institucionales con las que dicha atención es prestada.

Lo último mencionado se convierte en un aspecto que genera cuestionamientos, a propósito de la concepción de recurso que se posee, aspecto que se relaciona con el tipo de atención que se promueve; es decir, pareciera que la institución en salud es el único recurso que se reconoce para la atención en salud mental, lo que revela que la atención desinstitucionalizada y la atención comunitaria sigue siendo un campo por explorar en Colombia. Aspecto que, a su vez, evidencia la necesidad de renovar los modelos de formación (MinSalud y Organización Internacional para las Migraciones, 2013).

\subsection{Una perspectiva transdisciplinar para la propuesta de modelo de formación}

Ya en 2004, Max-Neef planteaba que los problemas que se presentan en la realidad contemporánea exigen trascender el abordaje desde el ámbito de las disciplinas individuales específicas, en tanto se trata de desafíos de carácter transdisciplinario; ahora bien, como el mismo autor lo señalaba, este hecho "no sería preocupante si la formación que se ofrece en las instituciones de educación superior fuera coherente con tal desafío" (Max-Neef, 2004, p. 2). 
En ese sentido, comprender qué antecede a una tendencia formativa centrada en intereses disciplinares implica atender a la dualidad objetosujeto propio de la época moderna, que trajo consigo la división de las ciencias y con ello la fragmentación que, a su vez, llevó a la especialización (Peñuela, 2005).

La asociación entre disciplinas y departamentos e institutos es un fenómeno relativamente moderno, que comienza a consolidarse a fines del siglo XIX. Tal departamentalización ha sido significativa para la mantención de las autonomías disciplinarias, para la competencia por recursos de la investigación, y para la consolidación de prestigios académicos (Max-Neef, 2004, p. 3).

Ahora bien, el problema de esta tendencia radica en que la especialización que de allí se deriva conlleva un aislamiento, en tanto se trata de formas cerradas de abordar los fenómenos objeto de estudio.

Desde esta perspectiva, surgen cuestionamientos acerca de las implicaciones que este tipo de educación tiene sobre la transformación de las problemáticas que hoy son preocupación para el mundo, pues sugiere que los profesionales estarán capacitados para atender parcelas de dichas problemáticas más no para tener comprensiones integradoras; al respecto, en Max-Neef (2004) se encuentra que, considerando que en términos generales las universidades refuerzan la formación unidisciplinaria, especialmente en los programas de pregrado, la acción que dé pie a una solución debe ocurrir "a nivel de posgrados orientados, toda vez que sea posible, hacia áreas temáticas más que a disciplinas específicas" (p.2).

Lo planteado en el párrafo anterior coincide con lo expresado en el panel de expertos que se llevó a cabo en el desarrollo de la investigación "Formación del talento humano en salud mental en seis programas de pregrado en Colombia, 2015", en el que se reconoció que las falencias de la formación en salud mental se atienden en el nivel de posgrado, sin embargo, esto a su vez es cuestionable en tanto la formación posgradual se constituye en una salida que no permite atender a las necesidades en salud mental que se presentan en el contexto antioqueño, toda vez que tal como se indica en apartados anteriores el equipo profesional 
básico de atención primaria en salud está conformado por profesionales de las diferentes disciplinas, que no en todos los casos cuentan con formación posgradual. No obstante, son quienes se encargan de prestar la atención a los diferentes eventos en salud mental, propiciar escenarios intersectoriales e interinstitucionales, todo ello en pro del beneficio de las poblaciones.

Esto, en conjunto con lo presentado en el primer capítulo, da pie a pensar en la necesidad de abordar la salud mental como una temática que trasciende los alcances disciplinares. De esta manera, la primera pregunta que aparece producto de la reflexión es ¿qué se entiende por transdisciplinariedad? Según Max-Neef (2004), esta corresponde a la coordinación de todos los niveles de aproximación al conocimiento, hecho que está más allá de la reunión de diferentes representantes de las disciplinas. Así, la trandisciplinariedad en un sentido aplicado se alcanza cuando se logran coordinar los niveles jerárquicos en los que se organizan las interdisciplinas, a saber, nivel empírico (¿qué existe?), nivel pragmático (¿qué somos capaces de hacer con lo que hemos aprendido?), nivel normativo (¿qué es lo que queremos hacer?) y finalmente el nivel superior, el valorativo (¿qué deberíamos hacer? o ¿cómo deberíamos hacer lo que queremos hacer?).

Ahora bien, tal como lo plantea Peñuela (2005), la transdisciplinariedad

debe tomarse no solo como un concepto que evoluciona de la mano del desarrollo de las disciplinas, sino que debe ubicarse como un concepto con dos perspectivas complementarias: "la antigua y la nueva", según Morin (1984). Lo cual plantea una nueva problemática que no se reduce a la discusión de qué es y qué no es interdisciplinar y transdisciplinar, sino que además se debe tener en cuenta que cada una de las perspectivas de este concepto depende, y está determinada, por el paradigma en el cual se inscribe el investigador: el paradigma clásico o el de la complejidad. (p.64).

De acuerdo con lo desarrollado por Peñuela (2005), para Morin, la ciencia clásica no solo ofreció una unidad de método, sino que con ello encontró los principios fundamentales de toda ciencia desde una perspectiva disciplinar, y se convirtió, con ello, en la antigua transdisciplina; sin embargo, es preciso que el paradigma de la complejidad otorgue fortaleza al trabajo de integración que requieren los desafíos de la 
ciencia moderna. Ahora bien, la dificultad para este propósito radica en la relación que se establece entre dichos paradigmas y su aplicabilidad; "la creciente ruptura en la comunicación es en buena parte producto de la exacerbación del pensamiento racional, manifestado por el claro reduccionismo de la lógica binaria, que entre otras cosas, separa al observador de lo observado" (Max-Neef, 2004, p.11).

La siguiente pregunta sería entonces ¿qué se entiende por complejidad? "Un sistema complejo es todo aquel, que, entre otras cosas, se caracteriza por impredecibilidad, inestabilidad, fluctuaciones, turbulencias, emergencias, en fin, no-lineabilidad" (Maldonado, 2016, p. 26).

De acuerdo a lo planteado por el autor en mención (Maldonado, 2016), conviene aclarar que no solo se trata de sistemas complejos, sino de sistemas de complejidad creciente, es decir, un sistema capaz de aprendizaje y de adaptación. Esto quiere decir que el carácter creciente de la complejidad es directamente proporcional a la historia y a las dinámicas del mismo. No en vano, los sistemas complejos constituyen la expresión y comprensión de un sistema dinámico (p. 26).

De esta manera, al buscar la articulación de los conceptos desarrollados hasta ahora, transdisciplinariedad y complejidad, hay algo cierto que se presenta: dada la complejidad de los sistemas sociales, la salud mental puede ser entendido como un problema múltiple e irreductible (Maldonado, 2016), es decir un fenómeno complejo que no logra ser abordado desde una sola perspectiva disciplinar, y que además invita a la integración interinstitucional e intersectorial. Aspecto que entra en diálogo con la perspectiva socioeconómica de la salud mental, en tanto de acuerdo con la Declaración de Alma-Ata (OPS, 1978), la promoción y protección de la salud de las poblaciones guarda una relación inmanente con el desarrollo económico y social, lo que a su vez destaca "la responsabilidad de los gobiernos frente a la salud de los pueblos, no solamente a través de la asistencia sanitaria, sino también de medidas sociales" (Restrepo y Jaramillo, 2012, p.206).

En consecuencia, si se retoma el reto sugerido por Max-Neef (2004) y los resultados de las investigaciones que respaldan la producción de este texto, pensar que la educación del talento humano encargado de atender la salud mental de las poblaciones propicie comprensiones 
transdisciplinares y con ello la emergencia de procesos de intervención que atiendan a las necesidades del contexto, se convierte en una acción que, por un lado, invita a trascender la perspectiva dualista mentecuerpo, y por el otro, responde al nivel valórico propuesto por Max-Neef (2004), es decir, una propuesta en la que se resalta la importancia de que el profesional no solo esté en capacidad de pensar los problemas con un referente académico, sino que además logre comprenderlos en su funcionamiento contextual.

Ahora, si se retoma lo planteado por Peñuela (2005), acerca de que la transdisciplinariedad "es tomada como concepto, cuando en realidad es un proceso", y por lo tanto debe trazarse un camino que permita ir más allá de lo conceptual para hallar un método de aplicación, la propuesta de modelo de formación transdisciplinar en salud mental, retoma, los objetos de las disciplinas para las cuales se presentan posibilidades de relación inter y transdisciplinar, tal como se expresa a continuación.

Para la descripción de los objetos disciplinares se hizo revisión, en algunos casos, de los códigos de ética y, en otros, de las leyes colombianas en las que se ampara el ejercicio de estas profesiones. En el caso de psicología, se retomó la Ley 1090 de 2006; en enfermería se hizo revisión del Código de Ética; para Trabajo Social, el Artículo 030 de 2015; y en el caso de medicina, la Ley 23 de 1981 y el Proyecto de Reforma de 2010 en el que se proponen modificaciones a su Código de Ética.

El ejercicio realizado permitió hallar que la psicología es una profesión que estudia los procesos de desarrollo cognoscitivo, funcional y social del ser humano con la finalidad de propiciar el desarrollo del talento y las competencias humanas en los diferentes dominios y contextos sociales (Congreso de la República de Colombia, 2006); con respecto a enfermería, se encuentra que se trata de una disciplina que propende por la protección y el cuidado de la vida humana, esta se convierte en el centro de la reflexión, el objeto del conocimiento, del saber y del quehacer de la enfermería (Tribunal Nacional Ético de Enfermería, 1998); así mismo, para el trabajo social, se expresa que este configura el reconocimiento del otro y de los otros como sujetos sociales 
y políticos capaces de transformar realidades sociales en los procesos de formación, participación, movilización y acción colectiva (Consejo Nacional de Trabajo Social, 2015); y la medicina se presenta como una disciplina que cuida de la salud del hombre y propende por la prevención de las enfermedades (Congreso de la República de Colombia, 1981).

Se encuentran entonces elementos que permiten establecer relaciones interdisciplinares, por ejemplo, entre medicina y psicología se sugiere que el hombre es una unidad psíquica y somática (Congreso de la República de Colombia, 1981); entre medicina y trabajo social se establece que el mejoramiento de los patrones de vida hace parte del interés de estas disciplinas (Congreso de la República de Colombia, 1981); entre enfermería y medicina, el propósito de promover la salud, prevenir e intervenir la enfermedad, trabajar en la rehabilitación y recuperación en salud, aliviar el dolor, promover medidas de bienestar y contribuir a una vida digna (Congreso de la República de Colombia, 1996); así mismo, se encuentra una relación entre enfermería y psicología, toda vez que, ambas propenden por ayudar a desarrollar al máximo los potenciales individuales y colectivos para mantener prácticas de vida saludables que permitan salvaguardar el estado óptimo de la salud en todas las etapas de la vida (Congreso de la República de Colombia, 1996); y entre enfermería y trabajo social, en tanto sus objetos de atención son la persona, la familia y la comunidad, sus necesidades y derechos así como el ambiente físico y social que influye en la salud y el bienestar (Congreso de la República de Colombia, 1996).

Resultado de esta revisión se hallan elementos que permiten plantear el carácter transdisciplinar de la propuesta de modelo de formación, dado que en el encuentro de los objetos se trascienden los propios límites disciplinares, dando lugar a un campo de conocimiento, tal como se planteó en el primer capítulo. Ahora bien, se hace relevante aclarar que esta apuesta transdisciplinar se legitima en el encuentro de las formas de entender y atender a las necesidades en salud mental, mas no en una reflexión epistemológica. La figura 14 ilustra la relación transdisciplinar en salud mental que emerge entre las cuatro disciplinas para las que se presenta esta propuesta. 
Figura 14. Relación inter y transdisciplinar entre Enfermeria, Medicina, Trabajo Social y Psicología

"Reconocimiento de las condiciones estructurales y coyunturales de las realidades sociales en la que los mismos sujetos, las organizaciones, las instituciones y el Estado se desenvuelven cotidianamente" (Acuerdo 013 de 2015).

"Se concibe como una profesión-disciplina constitutiva de las ciencias sociales, que se desarrolla en el ámbito de las interacciones entre los sujetos, las instituciones, las organizaciones sociales y el Estado, de manera dialógica y crítica. Comporta referentes de intervención que se constituyen en el eje que estructura el ejercicio profesional, confiriéndole un sentido social y político para potenciar procesos de transformación social" (Acuerdo 013 de 2015).

"Disciplina de carácter social, cuyos sujetos de atención son la persona, la familia y la comunidad, con sus características socioculturales, sus necesidades y derechos, así como el ambiente físico y social que influye en la salud y en el bienestar".

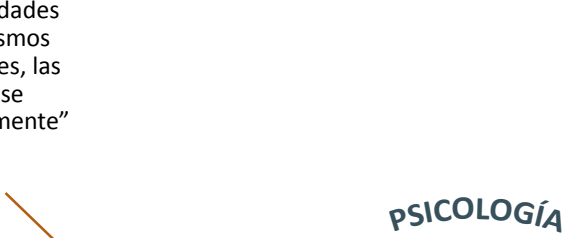

(Ley 266 de 1996). y contextos sociales"

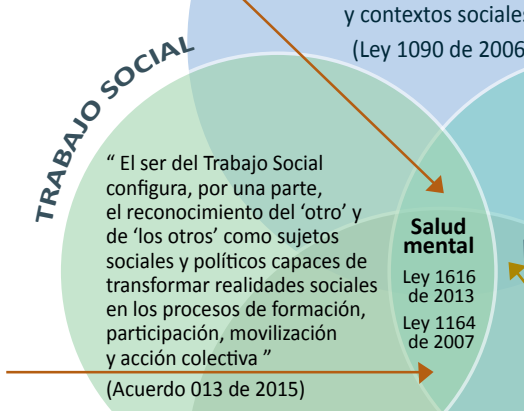
ética de enfermería.

\section{ENFERMERIAA}

"El hombre es unidad psíquica y somática"

(Ley 23 de 1981).

"Profesión que estudia los procesos de desarrollo cognoscitivo, emocional y social del ser humano, con la finalidad de propiciar el desarrollo del talento y las competencias humanas en los diferentes dominios
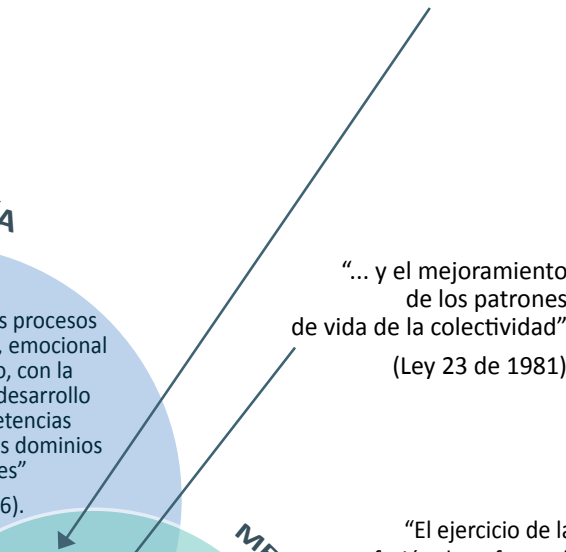

de los patrones de vida de la colectividad"

(Ley 23 de 1981).

"El ejercicio de la profesión de enfermería tiene como propósito general promover

la salud, prevenir la enfermedad, intervenir

en el tratamiento, rehabilitación y recuperación de la salud, aliviar el dolor, proporcionar medidas de bienestar y contribuir a una vida digna de la persona"

(Ley 266 de 1996).

"La protección [y cuidado] de una vida humana que es el centro de la reflexión, el objeto del conocimiento, del saber y del quehacer en enfermería." Código de
"Ayudar a desarrollar al máximo los potenciales individuales y colectivos, para mantener prácticas de vida saludables que permitan salvaguardar un estado óptimo de salud en todas las etapas de la vida"

(Ley 266 de 1996) 


\subsection{Competencias de los profesionales en el campo de la salud mental: lecturas acordes a las necesidades de los contextos}

De acuerdo con la Guía 21: Aportes para la construcción de currículos pertinentes, del Ministerio de Educación Nacional (2012), en Colombia se hace necesario incluir la formación por competencias en los planes de educación, puesto que se trata de una apuesta integradora que favorece la articulación teoría-práctica, y, por lo tanto, propicia la aplicación de los aprendizajes a la vida cotidiana; aspecto que a la postre contribuye al mejoramiento de la calidad de la educación en el país.

Sin embargo, no puede decirse que esta sea una propuesta reciente (Galdeano y Valiente, 2010), puesto que la tendencia a formar profesionales desde un enfoque por competencias, responde a las exigencias de una sociedad que demanda en los profesionales flexibilidad y creatividad al momento de incorporarse al ambiente laboral. De esta manera, se entiende que este tipo de formación se justifica en razones como:

1. Permite que el estudiante recree posibles escenarios próximos a la realidad en la que debe actuar, para lo cual se sitúa en la resolución de problemas o construcción de proyectos (Galdeano y Valiente, 2010).

2. Propicia en los estudiantes el desarrollo de recursos que les permita gestionar nuevos aprendizajes, buscando con ello la actualización constante de los saberes adquiridos (Galdeano y Valiente, 2010).

En un sentido general, podría decirse entonces, que la educación basada en competencias se fundamenta en la resolución de problemas factibles de presentarse en la vida real, razón por la cual entrelaza e integra "lo afectivo, lo psicomotriz y lo cognitivo en una nueva síntesis en el momento de llevar a cabo la acción, la evaluación y la reflexión sobre la acción" (Galdeano y Valiente, 2010, p.29).

Como puede verse, el concepto de competencia dialoga con lo planteado en el apartado anterior respecto a la perspectiva transdisciplinar de esta propuesta de modelo de formación, en tanto se convierte en 
un mecanismo que propicia la transición de una educación basada en objetos disciplinares, a una educación basada en problemas; dicho en otros términos, una educación dirigida a la atención a los desafíos que la realidad de hoy plantea a la academia.

Ahora, en un intento de ampliar la discusión asumiendo una posición crítica frente a lo aquí planteado, surgen cuestionamientos acerca de qué tanto esta tendencia en la educación realmente permite atender a las necesidades de las poblaciones, o bien, como se encuentra en Martha Nussbaum (2011), responde a acciones a través de las cuales un país procura "solo el crecimiento económico en su grado máximo" (p.38); acciones en las que la educación no es más que un vehículo.

Un país puede crecer sin dificultades, aunque los sectores más pobres de la población rural sigan siendo analfabetos y carezcan de los mínimos recursos informáticos (...) Éste fue siempre el primero y principal de los conflictos con el paradigma del desarrollo basado en el PBI per cápita: se trata de un paradigma que deja de lado la distribución y puede llegar a calificar positivamente a las naciones o los estados donde se registran los niveles alarmantes de desigualdad. En el caso de la educación, ese fenómeno es muy real: dada la naturaleza de la economía de la información, los países pueden aumentar su PBI sin preocuparse demasiado por la distribución en materia educativa, siempre y cuando genere una élite competente para la tecnología y los negocios. (Nussbaum, 2011, p. 41-42).

Como consecuencia, una educación que responde a un modelo económico limita el desarrollo de un pensamiento crítico respecto a las condiciones que entrañan las necesidades más apremiantes de una población, en tanto este tipo de pensamiento amenaza los intereses de las estructuras que sustenta.

La libertad de pensamiento en el estudiante resulta peligrosa si lo que se pretende es obtener un grupo de trabajadores obedientes con capacitación técnica que lleven a la práctica los planes de las élites orientados a las inversiones extrajeras y el desarrollo tecnológico. (Nussbaum, 2011, p. 42). 
Este asunto permite traer a colación una de las conclusiones más relevantes que emergió de la descripción de las características de la atención a los eventos en salud mental, en tanto el acercamiento a las subregiones del departamento de Antioquia, permitió reconocer que no basta con profesionales idóneamente formados para garantizar adecuados procesos de atención; se precisa que las instituciones públicas y privadas provean los recursos humanos y tecnológicos acordes a las necesidades de cada contexto. En su lugar, se hallan condiciones en las que se sugieren que entre más alejadas se encuentren las poblaciones del centro de la ciudad, menos probabilidades tienen de acceder a una atención apropiada y oportuna, hecho que se acentúa aún más en las zonas rurales.

Sin embargo, también es cierto que si la formación permitiera que los profesionales lograran comprensiones acerca de las problemáticas que intervienen, integrando aspectos políticos, sociales, económicos, culturales y éticos, podrían emitir juicios o asumir posiciones que contribuyeran a la transformación de las condiciones de la atención; de tal suerte, la educación debe trascender las barreras técnicas y propender porque se alcancen propuestas reflexivas acerca de los efectos que un modelo basado en el crecimiento económico genera sobre la democracia de un país.

A este momento conviene citar la pregunta que Nussbaum (2011) se plantea: "¿qué otras alternativas existen para concebir el tipo de ciudadanos que pretendemos formar?" (p.47). Se trata de una pregunta pertinente a los intereses de esta propuesta de modelo de formación en salud mental, puesto que da lugar a zanjar las diferencias que emergen alrededor del concepto competencias, cuando este es valorado desde la perspectiva de un modelo que propenda por el crecimiento económico, y no necesariamente por el beneficio de los sectores pobres, segregados y desde los enfermos.

A propósito de una respuesta a la pregunta, la autora hace alusión al paradigma del desarrollo humano, en tanto: 
Según este paradigma, lo que importa son las oportunidades o "capacidades" que posee cada persona en ciertas esferas centrales que abarcan desde la vida, la salud y la integridad física hasta la libertad política, la participación política y la educación. (Nussbaum, 2011, p. 47).

De esta manera, si se regresa a las aproximaciones conceptuales presentadas al comienzo del apartado, en las que se indicaba en un sentido general que la competencia implica la síntesis teoría-práctica, en la que se ponen el juego atributos afectivos, cognitivos y psicomotrices por parte del profesional, para ponerlas a dialogar con la propuesta de Nussbaum respecto a las capacidades, podría decirse que se hace pertinente esta propuesta de modelo de formación en salud mental en los términos en los que se ha presentado, en tanto lo que se busca es que el profesional esté en capacidad de hacer una lectura acorde a las necesidades del contexto, asumiendo a su vez posiciones responsables, en tanto su lugar no trata solo de un profesional que observa un fenómeno desde el foco que su disciplina determinada, sino, y fundamentalmente, desde el lugar de un profesional que construye sociedad, que reflexiona sobre el alcance de sus acciones, que gestiona recursos, que reconoce al otro, o en palabras de Nussbaum (2011), profesionales que puedan "desarrollar de modo más completo su capacidad para el ejercicio de la ciudadanía y la interacción política respetuosa" (p. 85) .

En consecuencia, si se retoman las ideas expuestas, se hace manifiesto que pensar la formación profesional desde esta perspectiva, no solo da pie a trazar caminos que conduzcan al abordaje de los desafíos que presenta la realidad contemporánea, sino a la apertura de nuevas combinaciones entre los niveles del conocimiento que expone Max-Neef (2004), particularmente en lo que respecta al nivel valórico; es decir, líneas de reflexión orientadas por principios éticos, en los que las respuestas a preguntas como “¿qué deberíamos hacer?”, o “¿cómo deberíamos hacer lo que queremos hacer?" se sustentan en "una preocupación global por la especie humana y por la vida en general" (Max-Neef, 2004. p. 9).

Finalmente, y fundamentado en los hallazgos de la investigación a partir de la cual se construyó la propuesta de modelo de formación en salud mental, se encuentra que las competencias que los actores 
partícipes de la investigación señalaron en estado de falencia, pueden a su vez, organizarse en función de las dimensiones del ser, el saber y el hacer.

En relación a las competencias asociadas al saber, se identificaron falencias o necesidades en los currículos respecto a: el reconocimiento de las diferentes políticas públicas pertinentes a las necesidades en salud mental, que se presentan en los diferentes contextos; la elaboración de proyectos de intervención que respondan a dichas necesidades; la intervención a las diversas manifestaciones de la violencia; la atención psicosocial en personal sanitario y la atención a los eventos en salud mental con una visión integral que trascienda lo psicopatológico, lo que a su vez, incluye una disposición del profesional en salud mental al trabajo interdisciplinario e intersectorial teniendo en cuenta los factores sociales, económicos y políticos que rodean las problemáticas de salud mental.

Respecto a las competencias asociadas al hacer, se enfatiza en la necesidad de que el profesional en salud mental esté en la capacidad de hacer una lectura acorde a las necesidades del contexto en el cual se encuentra ejerciendo su profesión, toda vez que esto favorece que esté en capacidad de hacer un acertado diagnóstico y, por lo tanto, una intervención pertinente que incluya las respuestas de otras disciplinas sin centrarse solo en las de su profesión.

Por último, como competencias asociadas al ser se hace referencia a la necesidad de fortalecer la ética profesional y a lo que de allí se deriva en el quehacer, en lo que se menciona el reconocimiento del alcance de la intervención, las prácticas humanizadas y el uso de un lenguaje apropiado a la comunidad atendida.

\subsection{Componentes de la propuesta de modelo de formación con visión transdisciplinar en salud mental: componentes temático y metodológico}

El modelo de formación que aquí que propone se basa en una visión constructivista de los procesos de enseñanza aprendizaje, en tanto, se reconoce que estos son dinámicos, participativos e interactivos 
(Cerezo, 2007). De esta manera, se entiende que el conocimiento es una construcción producto de las relaciones y que está en constante evolución (Moreno, 2012). Igualmente, se realza el lugar activo y creativo de la persona que aprende, quien desde una posición indagativa/investigativa "aprende reflexionando a partir de su propia acción en colaboración con otros, discutiendo, resolviendo problemas, construyendo conocimientos a través de sus experiencias significativas" (Illesca, Lagos y Navarro, 2005, p. 94), así como, el rol facilitador del docente quien orienta la relación estudiante-docente hacia la construcción conjunta.

A continuación, se presentan los componentes temáticos y metodológicos de la propuesta de modelo de formación transdisciplinar en salud mental, construidos a partir de los resultados de la investigación que lleva este mismo nombre.

\subsubsection{Componente temático de la propuesta de modelo de formación con visión transdisciplinar}

Los hallazgos producto del trabajo de campo sugieren que, en la formación del profesional en salud mental, deben considerarse aspectos como: la conceptualización de salud mental y la formación en el área clínica de este campo; esto último, implica, por un lado, una actualización de la formación para la atención individual, en la que se consideran aspectos como psicopatología, atención al paciente psiquiátrico y estrategias de intervención clínica; y por el otro, la formación para la atención colectiva y psicosocial, propendiendo por la promoción de la salud, la lectura crítica en contexto, el trabajo intersectorial, entre otros; igualmente se señala la importancia de incluir en los planes de formación cursos orientados a la comprensión e intervención de las violencias, el consumo de SPA, la salud mental familiar y la salud mental comunitaria. Así mismo, se hace referencia a la necesidad de acercar a los estudiantes a los conocimientos en rutas de atención en salud mental, atención primaria en salud mental y los diferentes enfoques para la atención en salud mental tales como, enfoque psicosocial, enfoque de determinantes sociales de la salud mental y enfoques diferenciales (considerando en ello: ciclo vital, aspectos étnicos y de género y grupos vulnerables), especialmente por ciclo vital en lo referente a infancia y adolescencia; se enfatiza también, en la importancia de formar en políticas públicas, 
salud pública y funcionamiento del Sistema General de Seguridad Social y en Salud, esto constituye la base para comprender los contextos en los cuales las intervenciones tendrán acogida o por el contrario, aumentarán la inequidad en el acceso a servicios.

Adicionalmente, se hizo referencia a aspectos de carácter metodológicos orientados a la práctica profesional, a la elaboración de proyectos de intervención y a la investigación en salud mental, puesto que es en estos escenarios donde se pone a prueba la formación transdisciplinar y el desarrollo de competencias tales como lectura de los diversos contextos posibles. Frente a la práctica profesional, se señala la importancia de articular la formación académica con las necesidades que se manifiestan en los diferentes escenarios de práctica, con el fin de encontrar respuestas coherentes con las necesidades de los contextos.

Si bien algunos de los aspectos enunciados en los párrafos anteriores fueron referidos por los informantes del trabajo de campo, tanto en términos de fortalezas como de falencias, el proceso de codificación de la información obtenida en esta investigación permitió identificar que la mayoría de los aspectos mencionados se constituyen en debilidades de la formación profesional en salud mental; este hecho se complejiza al encontrar que esta formación se adquiere, sobre todo, a través de cursos electivos, formación posgradual e incluso, en aprendizajes que se derivan del contexto mismo.

En esta perspectiva, los actores entrevistados recomiendan que los aspectos antes mencionados sean incluidos en los planes de formación de los profesionales en psicología, enfermería, trabajo social y medicina, particularmente en los cursos y actividades obligatorias. Adicionalmente, recomiendan formar en derechos humanos, en primeros auxilios psicológicos, en resolución de conflictos, en psicoeducación familiar y en promoción de la salud y prevención de la enfermedad.

Finalmente, se expresa la importancia de considerar aspectos asociados al ser del estudiante que, si bien no están garantizados por los planes de formación profesional, sí pueden favorecerse a partir de estrategias complementarias orientadas a la reflexión ética, a la salud mental del estudiante y al fortalecimiento de su vocación de servicio en cualquiera de estas disciplinas. 
A continuación, se relacionan los contenidos correspondientes al componente temático de la propuesta de modelo de formación con visión transdisciplinar en salud mental. Esto, con base en la información suministrada por los participantes de la investigación, así como, por la información obtenida del análisis de los diferentes documentos emitidos por la OMS, algunas leyes del Congreso de la República de Colombia y estudios realizados por entidades territoriales que hacen seguimiento a la salud mental de la población antioqueña, así como por los resultados de la investigación "Formación del talento humano en salud mental en seis programas de pregrado en Colombia, 2015" que fue desarrollada en el capítulo 2.

\section{Bases teóricas}

- Conceptualización en salud mental

- Eventos en salud mental: problemas psicosociales y trastornos mentales

- Problemas ligados al conflicto y posconflicto

- Salud mental familiar / comunitaria.

\section{Bases normativas}

- Formación política: legislación derechos en salud y en salud mental estructura y funcionamiento del Sistema General de Seguridad Social y de Salud para garantizar los derechos.

\section{Bases de la intervención}

- Rutas y protocolos de atención

- Lectura en contexto: problemáticas de cada contexto y respuestas sociales

- Ética del profesional de servicios de salud

- Atención primaria en salud mental

- Diferentes niveles de atención en salud mental, incluyendo la promoción de la salud mental y la prevención de la enfermedad mental y de otros problemas psicosociales 
- Primeros auxilios psicológicos. Prevención y atención en desastres

- Enfoques de atención en salud mental (diferencial, biopsicosocial, determinantes sociales de la salud, de derechos, de desarrollo humano)

- Psicoeducación en salud mental

- Atención de colectivos y acción comunitaria

Es anotar que en el listado anterior los entrevistados no hicieron alusión a temas que vinculen también una perspectiva positiva de la salud mental, y con ello la promoción del bienestar y el fortalecimiento de las redes comunitarias, razón por la cual las autoras del presente libro aportan su inclusión en la categoría bases de la intervención, en tanto desde la visión interdisciplinar, intersectorial e interinstitucional que está a la base de esta propuesta se reconoce la necesidad de visibilizar los saberes de la comunidad y la participación de otros sectores (diferentes del sector) y redes de base comunitaria que contribuyen a la promoción de la salud y ofrecen espacios de atención.

\subsubsection{Componente metodológico}

Con base en los resultados de la investigación se encuentra que los informantes recomiendan algunas estrategias metodológicas que pueden implementarse tanto en el componente básico profesional como en el complementario de los cuatro programas de universitarios a los que se dirige la propuesta, estas son:

1. Implementar trabajos prácticos asociados a salud mental en los cursos.

2. Incorporar las temáticas en salud mental a los cursos con los que ya cuenta cada programa.

3. Ofrecer cursos obligatorios en salud mental y no solamente electivos.

4. Ofrecer cursos interdisciplinarios (profesores de diferentes disciplinas y cursos compartidos entre profesionales de diferentes disciplinas). 
5. Implementar actividades de análisis de problemáticas en salud mental a través de investigaciones.

6. Implementar estrategias que desarrollen estudios de caso y que involucren un staff o comité de revisión multidisciplinario.

7. Fortalecer los escenarios de práctica y el acompañamiento al estudiante, preferiblemente involucrando otras profesiones.

8. Articular la academia con los escenarios en los que se desenvuelve el profesional y contribuir a las mesas de participación política.

9. Participar en los observatorios en salud mental de manera directa e indirecta, incentivando el papel que juegan los diferentes profesionales en la generación de la información veraz y oportuna.

10. Ofertar servicios en consultorios universitarios a partir de análisis de contextos y dirigidos a diversas poblaciones.

11. Realizar pasantías en servicios compartidos con otras disciplinas de la salud.

Ahora, luego del análisis de los datos suministrados por las diferentes fuentes de la investigación - actores y material bibliográfico-, se encuentra pertinente considerar la formación en salud mental para los formadores, toda vez que, estará a cargo de ellos la implementación del modelo de formación en salud mental que aquí se propone. Dicha formación no solo está sujeta al acceso a programas de posgrados, sino también a otras posibilidades como diplomaturas, seminarios, entre otras ofertas de formación continua y actualización.

En este sentido, las submodalidades a través de las cuales puede darse aplicabilidad del modelo se presentan en la tabla 17; para la aplicación de estas submodalidades se propone incluir estrategias pedagógicas que favorezcan el desarrollo de habilidades para el trabajo en equipo, el análisis y solución de problemas, el desarrollo de pensamiento crítico, la comprensión y el abordaje de experiencias de grupos poblacionales, entre otros. Es así que, en una revisión de literatura relacionada con pedagogía sociocultural de carácter constructivista, se encuentra en 
Ferreiro (2009) referencia a estrategias pedagógicas que en su aplicación favorecen y potencian los aspectos antes mencionados; dentro de estas, el autor expone:

- Aprendizaje cooperativo

- Solución de problemas

- Método de proyectos

- Método de caso

- Método socrático

- Investigación en grupo

- Observación tríadica

- Seminario

- Coloquio

- Simulación didáctica

- Taller

En esta perspectiva, las once estrategias listadas se consideran pertinentes para la aplicación del modelo que proponemos, tanto en su modalidad curricular como complementaria (ver tabla 17).

Considerando la diversidad de las modalidades de aplicación del modelo, los tiempos y recursos físicos para su desarrollo pueden ser definidos por cada institución de acuerdo a las características de su oferta curricular. Sin embargo, en la tabla 17 se relacionan las submodalidades sugeridas con una aproximación a los tiempos y recursos físicos necesarios para su aplicación. Adicionalmente, los facilitadores serían profesores con formación en salud mental, estudiantes y profesionales de los diferentes programas; este último aspecto se señala de suma relevancia en tanto la posibilidad de compartir los cursos con estudiantes de diferentes disciplinas, de recibir clases con profesores de otras disciplinas, propiciar espacios y estrategias de intervención inter y transdisciplinares. 
Tabla 17. Componente metodológico de la propuesta de modelo de formación transdisciplinar en salud mental

\begin{tabular}{|c|c|c|c|c|c|}
\hline $\begin{array}{l}\text { Estrategias } \\
\text { pedagógicas }\end{array}$ & Modalidades & Submodalidades & Tiempos & Facilitadores & Recursos físicos \\
\hline \multirow{4}{*}{$\begin{array}{l}\text { - Aprendizaje } \\
\text { cooperativo } \\
\text { - Solución de } \\
\text { problemas } \\
\text { - Método de } \\
\text { proyectos } \\
\text { - Método de } \\
\text { caso }\end{array}$} & \multirow{4}{*}{$\frac{\frac{1}{\pi}}{\frac{0}{3}}$} & $\begin{array}{l}\text { Cursos } \\
\text { obligatorios/ } \\
\text { electivos }\end{array}$ & Semestral & $\begin{array}{l}\text { Profesores de } \\
\text { pregrado con } \\
\text { formación en } \\
\text { salud mental }\end{array}$ & $\begin{array}{l}\text { Aulas de clase, insumos y } \\
\text { materiales }\end{array}$ \\
\hline & & $\begin{array}{l}\text { Temáticas/ } \\
\text { estrategias al } \\
\text { interior de otros } \\
\text { cursos }\end{array}$ & $\begin{array}{l}\text { De acuerdo a } \\
\text { los tiempos } \\
\text { destinados al } \\
\text { desarrollo de } \\
\text { las unidades } \\
\text { temáticas de } \\
\text { los cursos }\end{array}$ & $\begin{array}{l}\text { Profesores de } \\
\text { pregrado con } \\
\text { formación en } \\
\text { salud mental }\end{array}$ & $\begin{array}{l}\text { Aulas de clase, insumos y } \\
\text { materiales }\end{array}$ \\
\hline & & $\begin{array}{l}\text { Prácticas } \\
\text { profesionales }\end{array}$ & Semestral & $\begin{array}{l}\text { Asesores } \\
\text { de práctica } \\
\text { profesional }\end{array}$ & $\begin{array}{l}\text { Escenarios de práctica y } \\
\text { espacios de atención a } \\
\text { estudiantes }\end{array}$ \\
\hline & & $\begin{array}{l}\text { Proyectos de } \\
\text { grado }\end{array}$ & Semestral & $\begin{array}{l}\text { Asesores con } \\
\text { experiencia en } \\
\text { investigación }\end{array}$ & $\begin{array}{l}\text { Material bibliográfico, } \\
\text { software para investigación, } \\
\text { laboratorios, espacios de } \\
\text { atención a estudiantes }\end{array}$ \\
\hline \multirow{4}{*}{$\begin{array}{l}\text { - Investigación } \\
\text { en grupo } \\
\text { - Observación } \\
\text { tríadica } \\
\text { - Seminario } \\
\text { - Coloquio }\end{array}$} & \multirow{4}{*}{ 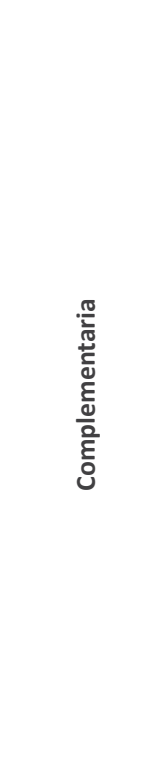 } & Diplomados & 120 horas & $\begin{array}{l}\text { Profesores con } \\
\text { formación en } \\
\text { salud mental }\end{array}$ & $\begin{array}{l}\text { Aulas de clase, espacios } \\
\text { de atención a estudiantes, } \\
\text { insumos y materiales }\end{array}$ \\
\hline & & $\begin{array}{l}\text { Observatorios en } \\
\text { salud mental }\end{array}$ & Permanente & $\begin{array}{l}\text { Profesores y } \\
\text { estudiantes de } \\
\text { los diferentes } \\
\text { programas }\end{array}$ & $\begin{array}{l}\text { Material bibliográfico, } \\
\text { software para investigación, } \\
\text { laboratorios, espacios de } \\
\text { atención a estudiantes, sede } \\
\text { del observatorio, equipos de } \\
\text { cómputo, plataforma virtual. }\end{array}$ \\
\hline & & $\begin{array}{l}\text { Semillero de } \\
\text { investigación }\end{array}$ & Permanente & $\begin{array}{l}\text { Profesores y } \\
\text { estudiantes de } \\
\text { los diferentes } \\
\text { programas }\end{array}$ & $\begin{array}{l}\text { Material bibliográfico, } \\
\text { software para investigación, } \\
\text { laboratorios, espacios de } \\
\text { atención a estudiantes }\end{array}$ \\
\hline & & $\begin{array}{l}\text { Consultorios } \\
\text { universitarios }\end{array}$ & Permanente & $\begin{array}{l}\text { Profesores, } \\
\text { profesionales } \\
\text { y estudiantes } \\
\text { en práctica de } \\
\text { los diferentes } \\
\text { programas }\end{array}$ & $\begin{array}{l}\text { Sede para consultorio } \\
\text { universitario }\end{array}$ \\
\hline
\end{tabular}




\section{CONSIDERACIONES FINALES}

Este modelo de formación del talento humano en salud mental invita a incluir estrategias que permitan desarrollar lecturas transdisciplinares de las problemáticas relativas a la salud mental, como se reconoce en las investigaciones que inspiraron este libro; lo que evidencia, en este sentido, la necesidad de considerar elementos adicionales a la formación profesional de cada programa con el fin de propiciar el diálogo de saberes y la construcción conjunta de prácticas de acompañamiento de la salud mental de personas y poblaciones. Esta consideración se basa en primera instancia, en la propuesta de un concepto de salud mental como campo del conocimiento que reconoce la diversidad de esta área que incluye dimensiones analíticas que comprenden lo positivo y lo negativo del término.

La revisión del concepto de salud mental permitió identificar que en su dimensión positiva es ampliamente trabajada en términos científicodisciplinares y no así, desde lo institucional, es decir, pareciera que las comprensiones y teorizaciones de lo que es salud mental no se traducen en abordajes institucionales de los componentes que comprenden su dimensión positiva. Esto da pie a plantear que una atención idónea en salud mental no solo requiere de una adecuada formación sino también de disposiciones políticas que así lo favorezcan. En consecuencia, se resalta la necesidad de que la sociedad se empodere del derecho a la salud mental, a través del conocimiento de los mecanismos de reclamación y participación, así como de la responsabilización frente a su bienestar. 
Por otro lado, se encuentra que tanto los manuales de clasificación del trabajo como la Ley del Talento Humano en Salud y la Ley de Salud Mental, se describen para los profesionales de psicología, trabajo social, medicina, enfermería y terapia ocupacional, funciones asociadas a la promoción de la salud, la prevención y atención de la enfermedad, la rehabilitación biopsicosocial, la participación en la construcción de políticas públicas y la investigación; funciones que bien pueden desarrollarse desde el sector salud o desde otros sectores -como el educativo, el deportivo, el laboral, entre otros - y que se encaminan, en el sentido de lo definido en las normas colombianas, en búsqueda de la garantía del derecho a la salud mental. Esto indica que las acciones de estos profesionales son acciones que deben enmarcarse en el trabajo interdisciplinario e intersectorial, atendiendo a una perspectiva biopsicosocial de lo humano e incorporando enfoques diferenciales, de derechos y de desarrollo humano.

El desarrollo de estas acciones por parte de estos profesionales supone, entre otras cosas, contar con una formación que no solo considere temáticas asociadas a dichas funciones -como: niveles de atención y acompañamiento en salud mental, diferentes enfoques $y$ modelos de atención, eventos en salud mental-, sino que presente estas mismas en contexto, donde el profesional en formación pueda, además de saber, saber hacer y aplicar creativamente sus conocimientos de una forma responsable, crítica y reflexiva.

En lo concerniente a las temáticas, se halló que la salud mental no es un componente que está presente de manera explícita en los cursos obligatorios en los planes de formación, encontrando pertinente extender una invitación a los comités curriculares de los diferentes programas universitarios a incorporar, temática y metodológicamente, la dimensión de salud mental en dichos planes de formación. Esto último, orienta el ejercicio investigativo que dio como resultado la construcción de una propuesta de modelo de formación en salud mental con perspectiva transdisciplinar.

En consideración de lo anterior, la transiciplinariedad sugiere que, sin desconocer la importancia de los objetos disciplinares, se atienda fundamentalmente a las situaciones problémicas, en ese sentido, reconocer que la salud mental es un fenómeno complejo invita al diálogo entre diferentes disciplinas, sectores e instituciones. En consecuencia, 
favorecer en la formación del talento humano en salud mental el encuentro entre profesionales de diversos saberes e implementar estrategias que propendan por el desarrollo de la capacidad de hacer lecturas críticas de los contextos, redundará en el mejoramiento de la atención a la salud mental de los individuos y poblaciones.

Así entonces, las recomendaciones que se derivan de los anteriores análisis pretenden 1) generar diálogos interdisciplinares que puedan materializarse en la administración curricular de los diferentes programas de pregrado, en términos de visibilizar la salud mental y sus componentes conceptuales; 2) promover en las prácticas profesionales y en las investigaciones, trabajo de tipo intersectorial que incluyan una lectura de contextos y de los fenómenos de salud mental más allá de la propia disciplina; 3) revisar la reglamentación de los procesos académicos básicos para que esta garantice la interdisciplinariedad e intersectorialidad; 4) continuar con la reflexión del constructo epistemológico del concepto de salud mental para comprender los diferentes paradigmas disciplinares y trascender a un planteamiento de salud mental como componente del bienestar y el desarrollo humano. 


\section{REFERENCIAS}

Aktouf, O. (1998). La administración: entre tradición y renovación. Cali, Colombia: Artes Gráficas Universidad del Valle.

Alba, P., Agrest, M. y Stagnaro, J. (2010). Salud mental, la polisemia de un concepto. Vertex Revista Argentina de Psiquiatría, 23(101), 16-19. Recuperado de http://www.polemos.com.ar/vertex101.php

Alles, M. (2007). Desarrollo del talento humano basado en competencias. Buenos Aires, Argentina: Granica.

Ardila, S., y Stolkiner, A. (Mayo, 2010). Los derechos humanos: categoría central para la evaluación de programas y servicios de salud mental. Trabajo presentado en el V Congreso Argentino de Salud Mental: Trauma, Historia y Subjetividad. Buenos Aires, Argentina.

Ardila, S. y Stolkiner, A. (2012). Conceptualizando la Salud Mental en las prácticas: Consideraciones desde el pensamiento de la Medicina Social/Salud Colectiva Latinoamericanas. Vertex Revista Argentina de Psiquiatría, 23(101). Recuperado de http://www.psi. uba.ar/academica/carrerasdegrado/psicologia/sitios_catedras/ obligatorias/066_salud2/material/unidad1/subunidad_1_1/ stolkiner_ardila_conceptualizando_la_salud_mental.pdf 
Arrivillaga, M., Collazos, J., Posada-Villa, J., Molina, C. y González, J. (2009). Salud mental: problema y reto de la salud pública. Bogotá: Universidad Nacional de Colombia. Recuperado de http://www. doctoradosaludp.unal.edu.co/wp-content/uploads/2017/01/ cuaderno9.pdf

Barnsteiner, J., Disch, J., Hall, L., Maye, D. y Moore, S. (2007). Promoting interprofessional education. Nurs Outlook, 55(3), 144-150. doi: https://doi.org/10.1016/j.outlook.2007.03.003

Barrón, A. y Sánchez, E. (2001). Estructura social, apoyo social y salud mental. Psicothema, 13(1), 17-23. Recuperado de http://www. psicothema.com/psicothema. asp?id=408

Bedoya-Gallego, D., Buitrago-Duque, D. y Vanegas-Arbeláez, A. (2019). Transdisciplinariedad en salud mental: una propuesta de modelo de formación. Interdisciplinaria, 36(1), 119-132. Recuperado de http://www.ciipme-conicet.gov.ar/ojs/index.php/interdisciplinaria/ article/view/587/101

Berbesi, D. y Bareño, J. (2010). Diagnóstico de oferta de servicios en salud mental en municipios de Antioquia (2004, 2006 y 2007). Hacia la promoción de la salud mental, 15(1), 41-54. Recuperado de http:// www.scielo.org.co/pdf/hpsal/v15n1/v15n1a03.pdf

Bertolote, J. (2008). Las raíces del concepto de salud mental. World Psychiatry. The official journal of the World Psychiatric Association, 7(2), 113-116. Recuperado de https://www.ncbi.nlm.nih.gov/pmc/ articles/PMC2408392/

Basabe, N. y Páez, D. (2006). Alienación, anomia y la escala de frustración anómica de Srole y Christie (Documento técnico). España: Universidad del País Vasco.

Betancur, C., Restrepo, D. A., Ossa, Y. J., Zuluaga, G. y Pineda, C. (2014). Representaciones sociales sobre salud mental en un grupo de profesionales en la ciudad de Medellín: análisis prototípico y categorial. Revista CES, 7(2), 96-107. Recuperado de http://revistas. ces.edu.co/index.php/psicologia/article/view/3086/2201 
Blanco, A. y Díaz, D. (2006). Orden social y salud mental: Una aproximación desde el bienestar social. Clínica y Salud, 17(1), 7-29. Recuperado de http://www.redalyc.org/articulo.oa?id=180613873001

Bowlby, J. (1968). Los cuidados maternos y la salud mental. Washington, D.C.: Estados Unidos: Organización Mundial de la Salud. Recuperado de: http://hist.library.paho.org/English/SPUB/41545.pdf

Buitrago, D. y Bedoya, D. (2016). Formación del talento humano en salud mental en seis programas de pregrado en Colombia, 2015 (Informe N C114-033). Colombia: Corporación Universitaria Minuto de Dios - UNIMINUTO.

Campos, A. (2004). De cotidianidades y utopías, una visión psicosocial preventiva sobre los riesgos de desastres. España: Plaza y Valdés.

Caponi, S. (2010). Georges Canguilhem: del cuerpo subjetivo a la localización cerebral. Salud colectiva, 6(2), 149-161. doi: 10.18294/ sc. 2010.363

Carballeda, J. M. (2012). La intervención del Trabajo Social en el campo de la Salud Mental. Algunos interrogantes y perspectivas. Margen (65). Recuperado de https://www.margen.org/suscri/margen65/ carballeda.pdf

Carrazana, V. (2002). El concepto de salud mental en psicología humanistaexistencial. Ajayu Órgano de Difusión Científica del Departamento de Psicología UCBSP, 1(1). Recuperado de http://www.scielo.org.bo/ scielo.php?script=sci_arttext \&pid=S2077-21612003000100001\&ln $\mathrm{g}=\mathrm{es} \& \operatorname{tn} \mathrm{ln}=\mathrm{es}$

Casallas, A. L. (2017). La medicina social-salud colectiva latinoamericanas: una visión integradora frente a la salud pública tradicional. Revista Ciencias de la Salud, 15(3), 397-408. doi: http://dx.doi.org/10.12804/ revistas.urosario.edu.co/revsalud/a.6123

Cerezo, H. (2007). Corrientes pedagógicas contemporáneas. Odiseo Revista Electrónica de Pedagogía, 4(7). Recuperado de http://www. odiseo.com.mx/2006/07/cerezo-corrientes.html 
Chávez, A. M., Macías, L. F. y Klein, A. (2013). Salud mental y malestar subjetivo. Debates en Latinoamérica. Revista Derecho y Ciencias Sociales, (8), 212-218. Recuperado de http://sedici.unlp.edu.ar/ bitstream/handle/10915/27184/13_Salud+Mental+y+Malestar+Subjetivo+;jsessionid=C7BC26D6976365595FBBC9318428E88F?sequence $=1$

Congreso de la República de Colombia. (18 de febrero de 1981). Ley 23 de 1981. Por la cual se dictan normas en materia de ética médica. DO: 35711.27. Recuperado de http://suin.gov.co/viewDocument. asp?id $=1579130$

Congreso de la República de Colombia. (25 de enero de 1996). Ley 266 de 1996. Por la cual se reglamenta la profesión de enfermería en Colombia y se dictan otras disposiciones. Recuperado de http://www.mineducacion.gov.co/1621/articles-105002_archivo _pdf.pdf

Congreso de la República de Colombia. (6 de septiembre de 2006). Ley 1090 de 2006. Por la cual se reglamenta el ejercicio de la profesión de Psicología, se dicta el Código Deontológico y Bioético y otras disposiciones. DO: 46.383. Recuperado de http://colpsic.org.co/ aym_image/files/LEY_1090_DE_2006.pdf

Congreso de la República de Colombia. (3 de octubre de 2007). Ley 1164 de 2007. Por la cual se dictan disposiciones en materia del Talento Humano en Salud. DO: 46.771. Recuperado de http://www.secretariasenado.gov.co/senado/basedoc/ley_1164_2007.html

Congreso de la República de Colombia. (19 de enero de 2011). Ley 1438 de 2011. Por medio de la cual se reforma el sistema de seguridad social en salud y se dictan otras disposiciones. DO: 47.957. Recuperado de http://www.secretariasenado.gov.co/senado/ basedoc/ley_1438_2011.html

Congreso de la República de Colombia. (21 de enero de 2013). Ley 1616 de 2013. Por medio de la cual se expide la Ley de Salud Mental y se dictan otras disposiciones. DO: 48.680. Recuperado de http://www. secretariasenado.gov.co/senado/basedoc/ley_1616_2013.html 
Consejo Nacional de Trabajo Social. (2015). Código de ética de los Trabajadores Sociales en Colombia [en línea]. Recuperado de http:// www.consejonacionaldetrabajosocial.org.co/cnts/images/Codigode-etica-2015-.pdf

Cruz-Ortiz, M., Jenaro-Río, C., Pérez-Rodríguez, M., Hernández-Blanco, M. y Flores-Robaina, N. (2011). Cambios en el contexto del cuidado: desafío para la enfermería. Revista Latino-Americana de Enfermagem, 19(4). Recuperado de http://www.scielo.br/pdf/rlae/ v19n4/es_25.pdf

Cubas, M. (2006). Lo saludable: una propuesta para la comprensión de la salud mental desde el psicoanálisis. (Tesis de maestría). Pontificia Universidad Católica del Perú. Lima, Perú. Recuperada de http:// tesis.pucp.edu.pe/repositorio/handle/123456789/108

Departamento Administrativo Nacional de Estadística (DANE). (2005). Clasificación Internacional Unificada Ocupacional Adaptada para Colombia (cluo-88 AC) [en línea]. Recuperado de https://www. dane.gov.co/files/sen/nomenclatura/ciuo/CIUO_88A_C_2006.pdf

Dirección de Empleo y Trabajo, Dirección General Servicio Nacional de Aprendizaje (SENA). (2014). Clasificación Nacional de Ocupaciones (CNO) [en línea]. Recuperado de https://observatorio.sena.edu.co/ content/pdf/cno2014.pdf

Esguerra, I. (1991). Rol del profesional de enfermería en salud mental y psiquiátrica. Avances en Enfermería, 9(1), 27-34. Recuperado de https://revistas.unal.edu.co/index.php/avenferm/article/view/ $16731 / 17618$

Feldman, S. (1984). Enfermedad mental y economía. Boletín de la oficina Panamericana de la Salud, 18(4), 201-210. Recuperado de http:// hist.library.paho.org/Spanish/BOL/v98n3p201.pdf

Ferreiro, R. (2009). Nuevas alternativas de aprender yenseñar: aprendizaje cooperativo. México: Trillas.

Foucault, M. (1998). Historia de la locura en la época clásica l. Bogotá: Fondo de Cultura Económica. 
Frances, A. (2012). Abriendo la caja de pandora: las 19 peores sugerencias del DSM-V. Recuperado de http://www.altxa.com/documentos/ documentos-tecnicos/criticas-al-dsm-v-allen-frances/

Galdeano, C. y Valiente, A. (2010). Competencias profesionales. Educación química, 21(1). Recuperado de http://www.scielo.org.mx/scielo. php?script=sci_arttext\&pid=S0187-893X2010000100004\&lng=es\&t Ing=es

Galvis, M. A. (2015). Teorías y modelos de enfermería usados en la enfermería psiquiátrica. Revista Cuidarte, 6(2), 1108-1120. doi: https://doi.org/10.15649/cuidarte.v6i2.172

García, H., Ferreira, M., Titus, J., De Almeida, I., Harvasi, P. y Riveiro, R. (2015). Uso de drogas, salud mental y problemas relacionados con el crimen y la violencia: estudio transversal. Revista LatinoAmericana de Enfermagem, 23(6), 1173-1180. doi: 10.1590/01041169.0478.2663

García, R. (2004). Salud mental comunitaria ¿Una tarea interdisciplinar? Cuadernos de Trabajo Social, (17), 273-287. Recuperado de http://revistas.ucm.es/index.php/CUTS/article/viewFile/ CUTS0404110273A/7617

Goldchluk, A. (2012). La salud mental vista desde la perspectiva de la psiquiatría. Vertex Revista Argentina de Psiquiatría, 23(101), 20-24. Recuperado de http://www.polemos.com.ar/vertex101.php

Gómez-Arias, R. (2014). Contexto de la planificación de la salud en Latinoamérica: un intento por resolver problemas políticos con acciones técnicas. UniverSalud, 10(20), 7-22. Recuperado de https:// www.uv.mx/msp/files/2014/04/Universalud-20.pdf

Henao, S., Restrepo, V., Alzate, A. y González, P. (2009). Percepción sobre el acceso a los servicios de salud mental que tienen los residentes de tres municipios de Antioquia, 2004-2006. Revista Facultad Nacional de Salud Pública, 27(3), 271-281. Recuperado de http://www. redalyc.org/pdf/120/12016344004.pdf 
Horwitz, J. y Marconi, J. (1966). El problema de las definiciones en el campo de la salud mental: Definiciones aplicables estudios epidemiológicos. Boletín de la Organización Mundial de la Salud (OPS), 60(4). Recuperado de http://hist.library.paho.org/Spanish/ BOL/v60n4p300.pdf

Illesca, M., Lagos, X., y Navarro, N. (2005). Modelos de formación docente base para una innovación curricular. RECS: Revista Educación en Ciencias de la Salud. 2(2), 93-96. Recuperado de http://www2.udec. cl/ofem/recs/anteriores/vol222005/art2205a.pdf

Jarne, A. y Arch, M. (2009). DSM, salud mental y síndrome de alienación parental. Papeles del Psicólogo, 30(1), 86-91. Recuperado de http:// www.papelesdelpsicologo.es/pdf/1659.pdf

Keegan, E. (2012). La salud mental en la perspectiva cognitivo-conductual. Vertex Revista Argentina de Psiquiatría, 23(101), 52-56. Recuperado de http://www.polemos.com.ar/docs/vertex/vertex101.pdf

Klappenbach, H. (1999). El movimiento de la higiene mental y los orígenes de la Liga Argentina de Higiene Mental. Temas de Historia de la Psiquiatría Argentina, (10). Recuperado de https://www.researchgate.net/publication/290605159_XXX\&enrichSource=Y292ZXJQYWdIOzI5MDYwNTE1OTtBUzozMTg1NTAwOTMzMDM4MDhAMTQ1Mjk10TY2ODc10Q\%3D\%3D\&el=1_x_3\&_esc=publicationCoverPdf

Levav, I. (ed.). (1992). Temas de salud mental en la comunidad. Washington, D.C: Organización Panamericana de la Salud. Recuperado de http:// iris.paho.org/xmlui/handle/123456789/3141

Londoño, C., Valencia, S. y Vinaccia, S. (2006). El papel del psicólogo en la salud pública. Revista Psicología y Salud, 16(002), 199-205. Recuperado de http://redalyc.uaemex.mx/pdf/291/29116209.pdf

Lopera Echavarría, J. (2012). Salud mental y sabiduría práctica. Un intento de integración y aproximación conceptual. Tesis Psicológica, (7), 60-75. Recuperado de http://www.redalyc.org/articulo.oa?id $=139025258009$ 
Madariaga, C. (abril, 1995). Tortura, proceso salud-enfermedad y psiquiatría. Trabajo presentado en el Simposio Regional de la Asociación Mundial de Psiquiatría (WPA) y XI Congreso Argentino de Psiquiatría. San Carlos de Bariloche, Argentina. Recuperado de http://www.cintras.org/textos/reflexion/r23/TTproceso.pdf

Maldonado, C. (2016). Complejidad de las ciencias sociales. Y de otras ciencias y disciplinas. Bogotá, Colombia: Ediciones Desde Abajo.

Malvárez, S. (2011). Salud mental comunitaria: trayectoria y contribuciones de la enfermería. Revista Ridec, 4(2), 22-30. Recuperado de https:// www.enfermeria21.com/revistas/ridec/articulo/27040/saludmental-comunitaria-trayectoria-y-contribuciones-de-la-enfermeria/

Martín-Baró, I. (1990). Psicología Social de la Guerra: Trauma y terapia. San Salvador, El Salvador: UCA Editores. Recuperado de http://www.uca. edu.sv/coleccion-digital-IMB/wp-content/uploads/2015/11/1990@-Psicolog\%C3\%ADa-social-de-la-guerra-trauma-y-terapia.pdf

Matus, C. (1987). Política, planificación y gobierno. Buenos Aires: Fundación Altadir. Recuperado de https://eva.udelar.edu.uy/mod/ resource/view.php?id=316162

Max-Neef, M. (2004). Fundamentos de la transdisciplinariedad. Valdivia, Chile: Universidad Austral de Chile.

McKeown, T. y Lowe, C.R. (1989). Introducción a la Medicina Social. España: Siglo XXI Editores.

Mebarak, M., De castro, A., Del Pilar, M. y Quintero, M. (2009). Salud mental: un abordaje desde la perspectiva actual de la psicología de la salud. Psicología desde el Caribe, (23), 83-11. Recuperado de http://www.scielo.org.co/pdf/psdc/n23/n23a06.pdf

Megías, F., Martínez, M., y Pacheco, G. (2003). Apoyo de la enfermera especialista en salud mental a la enfermera de atención primaria de salud. Medwave, 3(8). doi: 10.5867/medwave.2003.08.2776 
Méndez, A. (2016). Terapia ocupacional, cultura y salud mental: una revisión bibliográfica. (Trabajo de fin de grado, Universidad Da Coruña. Recuperado de https://ruc.udc.es/dspace/bitstream/ handle/2183/17189/M\%C3\%A9ndezM\%C3\%ADguez_Angela_ TFG_2016.pdf?sequence=2\&isAllowed=y

Mendoza, C. (2009). Sociología y salud mental: una reseña de su asociación. Revista colombiana de psiquiatría, 38(3), 554-573. Recuperado de http://www.redalyc.org/articulo.oa?id=80615422012

Mendoza, F. (2004). Las relaciones entre trabajo social y salud mental: un recorrido histórico. Trabajo presentado en el XVIII Seminario Latinoamericano de Escuelas de Trabajo Social. San José, Costa Rica. Recuperado de http://www.ts.ucr.ac.cr/binarios/congresos/reg/ slets/slets-018-055.pdf

Meyer, I. H. (2003). Prejudice, social stress, and mental health in lesbian, gay, and bisexual populations: Conceptual issues and research evidence. Psychological Bulletin, 129(5), 674-697. doi: http://doi. org/10.1037/0033-2909.129.5.674

Sistema Nacional de Educación Superior -SNIES- (2015). Programas académicos activos. Recuperado de: http://snies.mineducacion.gov.co/

Ministerio de Educación Nacional de Colombia. (2012). Articulación de la educación con el mundo productivo. Competencias laborales generales. Serie Guías No. 21 [en línea]. Recuperado de http:// www.mineducacion.gov.co/1621/articles-106706_archivo_pdf.pdf

Ministerio de Salud de Colombia y Organización Internacional para las Migraciones. (2013). Modelo para la desinstitucionalización de personas con trastorno mental y larga estancia hospitalaria, en el marco del Sistema General de Seguridad Social en Salud y Protección Social en Colombia [en línea]. Recuperado de https://www.minsalud. gov.co/sites/rid/Lists/BibliotecaDigital/RIDE/VS/PP/ENT/modelodesinstitucionalizacion-trastorno-mental.pdf 
Ministerio de Salud y Protección Social. (2010). Proyecto de reforma al Código de Ética Médica. Documento preparado por el Grupo de Médicos Expertos para la reforma al Código de Ética Médica [en línea]. Recuperado de https://www.minsalud.gov.co/Documentos\%20 y\%20Publicaciones/DOCUMENTO\%20DE\%20TRABAJO\%20 PARA\%20LA\%20REFORMA\%20AL\%20C\%C3\%93DIGO\%20DE\%20 \%C3\%89TICA\%20M\%C3\%89DICA.pdf

Ministerio de Salud y Protección Social. (7 de noviembre de 2018). Resolución 4886. Por la cual se adopta la Política Nacional de Salud Mental. Recuperado de https://www.minsalud.gov.co/ Normatividad_Nuevo/Resoluci\%C3\%B3n\%20No.\%204886\%20 de\%202018.pdf

Ministerio de Salud y Protección Social. (Noviembre, 2012). Programa de atención psicosocial y salud integral a víctimas en el marco de la Ley 1448 de 2011 [en línea]. Recuperado de https://www.minsalud.gov. co/Documentos\%20y\%20Publicaciones/PAPSIVI\%20VERSION\%20 PRELIMINAR\%2025\%20Febrero\%202013.doc

Ministerio de Salud y Protección Social, Colciencias, Pontificia Universidad Javeriana y Datos, Procesos y Tecnologías SAS (2015). Encuesta Nacional de Salud Mental 2015 [en línea]. Recuperado de https:// www.minsalud.gov.co/sites/rid/Lists/BibliotecaDigital/RIDE/DE/ presentacion-encuesta-nacional-salud-mental-2015.pdf

Ministerio de Salud y Protección Social y Fundación FES. (2003). Estudio Nacional de Salud Mental Colombia [en línea]. Recuperado de https://www.minsalud.gov.co/Documentos\%20y\%20Publicaciones/ ESTUDIO\%20NACIONAL\%20DE\%20SALUD\%20MENTAL\%20EN\%20 COLOMBIA.pdf

Ministerio de Sanidad, Consumo y Bienestar Social. (2005). Declaración europea de salud mental [en línea]. Recuperado de https://www. mscbs.gob.es/organizacion/sns/planCalidadSNS/pdf/excelencia/ salud_mental/opsc_est17.pdf.pdf

Miranda, G. (2018). ¿De qué hablamos cuando hablamos de salud mental? Utopía y Praxis Latinoamericana, 23(83), 86-95. doi: https://www. redalyc.org/jatsRepo/279/27957772009/html/index.html 
Moreno, C. (2012). La construcción del conocimiento: un nuevo enfoque de la educación actual. Sophia, Colección de Filosofía de la Educación, (13), 251-267. Recuperado de https://www.redalyc.org/ pdf/4418/441846102011.pdf

National Institute of Mental Health. (2017). NAMHC Concept Clearances. Approved Concepts for Requests for Applications (RFAs), Program Announcements (PAs), and Requests for Proposals (RFPs). Recuperado de http://www.nimh.nih.gov/about/advisory-boardsand-groups/namhc/namhc-concept-clearances.shtml

Novoa-Gómez, M. (2012). De la salud mental y la salud pública. Revista Gerencia y Políticas de Salud, 11(23), 5-9. Recuperado de http:// www.scielo.org.co/pdf/rgps/v11n23/v11n23a01.pdf

Nussbaum, M. (2011). Sin fines de lucro. Por qué la democracia necesita de las humanidades. Buenos Aires: Katz Editores.

Oramas, A., Santana, S., y Vergara, A. (2006). Bienestar psicológico, un indicador positivo de la Salud Mental. Revista Cubana de Salud y Trabajo, 7(1-2), 34-39. Recuperado de http://www.sld.cu/galerias/ pdf/sitios/insat/rst06106.pdf

Organización de las Naciones Unidas para la Educación, la Ciencia y la Cultura (Unesco). (2006). Qué hace a un currículo de calidad [en línea]. Recuperado de http://unesdoc.unesco.org/images/0024 /002439/243975s.pdf

Organización de las Naciones Unidas. (2017). Informe del Relator Especial sobre el derecho de toda persona al disfrute del más alto nivel posible de salud física y mental [en línea]. Recuperado de https://amsm. es/2017/07/21/nacionesunidas-informe-del-relator-especial-sobreel-derecho-de-toda-persona-al-disfrute-del-mas-alto-nivel-posiblede-salud-fisica-y-mental/

Organización Internacional del Trabajo. (2010). Clasificación Internacional Uniforme de Ocupaciones (clvo-88) [en línea]. Recuperado de http://www.ilo.org/public/spanish/bureau/stat/isco/isco88/major.htm 
Organización Mundial de la Salud y Organización Panamericana de la Salud. (2017). Recursos humanos para la salud [en línea]. Recuperado de https://www.paho.org/hq/index.php?option=com_ content \&view=article\&id=13672\&ltemid=42273\&lang=es

Organización Mundial de la Salud. (2006). Constitución de la OMS, Conferencia Sanitaria Internacional [en línea]. Recuperado de http://www.who.int/governance/eb/who_constitution_sp.pdf

Organización Mundial de la Salud. (2001). Informe sobre la salud en el mundo 2001. La salud mental: nuevos conocimientos, nuevas esperanzas [en línea]. Recuperado de www.who.int/whr/2001/es/

Organización Mundial de la Salud. (2004). Promoción de la salud mental. Conceptos, evidencia emergente, prácticas. Informe Compendiado [en línea]. Recuperado de http://www.who.int/mental_health/ evidence/promocion_de_la_salud_mental.pdf

Organización Mundial de la Salud. (2006). Informe sobre la salud en el mundo 2006. Colaboremos por la salud [en línea]. Recuperado de http://www.who.int/whr/2006/whr06_es.pdf?ua=1

Organización Mundial de la Salud. (2006). Manual de recursos sobre salud mental, derechos humanos y legislación de la oMs [en línea]. Recuperado de http://www.who.int/mental_health/policy/ legislation/WHO_Resource_Book_MH_LEG_Spanish.pdf

Organización Mundial de la Salud. (2011). Salud mental: un estado de bienestar [en línea]. Recuperado de http://www.who.int/features/ factfiles/mental_health/es/index.html

Organización Mundial de la Salud. (2013). Plan de acción sobre salud mental 2013-2020 [en línea]. Recuperado de http://apps.who. int/iris/bitstream/handle/10665/97488/9789243506029_spa. pdf?sequence $=1$

Organización Mundial de la Salud. (2008). mhGAP programa de acción para superar las brechas en salud mental [en línea]. Recuperado de https://www.who.int/mental_health/evidence/mhgap_spanish. pdf?ua $=1$ 
Organización Mundial de la Salud. (2016). Salud mental: fortalecer nuestra respuesta. Notas descriptivas [en línea]. Recuperado de http://www.who.int/mediacentre/factsheets/fs220/es/

Organización Panamericana de la Salud. (1990) Enfermería en salud comunitaria: Un enfoque de sistemas [en línea]. Recuperado de http://iris.paho.org/xmlui/handle/123456789/3281

Organización Panamericana de la Salud. (2002). Informe mundial sobre la violencia y la salud [en línea]. Recuperado de http://www.who.int/ violence_injury_prevention/violence/world_report/es/summary_ es.pdf

Organización Panamericana de la Salud. (2009). Estrategia y plan de acción sobre salud mental, 2009 [en línea]. Recuperado de http:// www1.paho.org/hq/dmdocuments/2009/SALUD_MENTAL_final_ web.pdf

Organización Panamericana de la Salud. (1978). Declaración de Alma-Ata. Conferencia Internacionalsobre Atención Primaria en Salud [en línea]. Recuperado de https://www.paho.org/hq/dmdocuments/2012/ Alma-Ata-1978Declaracion.pdf

Ortiz Monsalve, L., Cubides Zambrano, J. y Restrepo Miranda, D. (2013). Caracterización del talento humano en salud: Hacia el sistema de información del registro único nacional del talento humano en salud. Superintendencia Nacional de Salud. (4), 63-68. Recuperado de https://www.minsalud.gov.co/sites/rid/Lists/BibliotecaDigital/ RIDE/VS/TH/Caracterizacion-talento-humano-en-salud.pdf

Peñuela, A. (2005). La transdisciplinariedad: más allá de los conceptos, la dialéctica. Andamios, 1(2), 43-77. Recuperado de http:// www.academia.edu/9597339/LA_TRANSDISCIPLINARIEDAD _M\%C3\%81S_ALL\%C3\%81_DE_LOS_CONCEPTOS_LA _ DIAL\%C3\%89CTICA

Pérez, F. (2013). La salud mental y su relación con la desigualdad social. Revista Adicción y Ciencia, 3(2). Recuperado de http:// adiccionyciencia.info/la-salud-mental-y-su-relacion-con-ladesigualdad-social-2 
Pilgrim, D. (2009). Key Concepts in Mental Health. London: SAGE Publications.

Ramalho, R. (2009). Psiquiatría y Salud Mental. Anales de la Facultad de Ciencias Médicas, 42(1), 55-58. Recuperado de http:// revistascientificas.una.py/index.php/RP/article/view/228/159

Reeves, S. et al. (2008). Interprofessional education: effects on professional practice and health care outcomes. Cochrane Systematic Review, (1). doi: https://doi.org/10.1002/14651858.CD002213.pub3

Restrepo, D. A. y Jaramillo, J. C. (2012). Concepciones de salud mental en el campo de la salud pública. Revista Facultad Nacional de Salud Pública, 30(2), 202-211. Recuperado de http://www.redalyc.org/ pdf/120/12023918009.pdf

Rosen, G. (2005). De la policía médica a la medicina social. Ensayos sobre la historia de la atención en Salud. México: Siglo XXI Editores.

Sánchez, O. (2014). Dimensiones ocupacionales en el funcionamiento psicosocial y en los procesos de rehabilitación. Revista Electrónica de Terapia Ocupacional Galicia, 11 (9), 109-175. Recuperado de https://dialnet.unirioja.es/servlet/articulo?codigo $=4740701$

Santracruz, M. L. (2006). Calidad de vida, un reto para el terapeuta ocupacional en salud mental comunitaria. Revista Ocupación Humana, 11(3-4), 33-50. Recuperado de https://latinjournal.org/ index.php/roh/article/view/86/53

Secretaría Seccional de Salud y Protección Social de Antioquia - SSSPSA-. (2010). Tamizaje de Salud Mental del Departamento de Antioquia 2009-2010 [en línea]. Recuperado de https://www.dssa.gov.co/ index.php/descargas/881-tamizaje-salud-mental-1

Secretaría Seccional de Salud y Protección Social de Antioquia y Colombia. Ministerio de Salud y Protección Social Dirección de Epidemiología y Demografía. (2014). Análisis de situación en salud departamental y municipal Antioquia 2013 [en línea]. Recuperado de https://www. minsalud.gov.co/sites/rid/Lists/BibliotecaDigital/RIDE/VS/ED/PSP/ asis-antioquia-2013.zip 
Secretaría Seccional de Salud y Protección Social de Antioquia. (2015). Diez primeras causas de morbilidad en consulta externa, hospitalización y urgencias [en línea]. Recuperado de https://www.dssa.gov.co/ index.php/estadisticas/morbilidad/item/755-morbilidad-ano-2015

Secretaría Seccional de Salud y Protección Social de Antioquia. (2016). Estadísticas de morbilidad año 2016 [en línea]. Recuperado de https://www.dssa.gov.co/index.php?option=com_k2\&view=itemlist\&layout=category\&task=category\&id=42\&ltemid=201

Secretaría Seccional de Salud y Protección Social de Antioquia. (2017). Díez primeras causas de mortalidad por municipio 2005 Vrs. 2017 [en línea]. Recuperado de https://www.dssa.gov.co/index.php?option=com_k2\&view=itemlist \&layout=category\&task=category\&i$\mathrm{d}=27 \&$ Itemid $=120$

Sierra, R. (2010). De la enseñanza de la Medicina a la formación integral de médicos. Revista Colombiana de Reumatología, 17(1). Recuperado de http://www.scielo.org.co/scielo.php?script=sci_ arttext\&pid=S0121-81232010000100001\&lng=en\&tlng=es.

Sistema Nacional de Vigilancia en Salud Pública -SIVIGILA-. (2016). Eventos de interés en salud pública por subregiones y municipios. Antioquia 2007-2017 [en línea]. Recuperado de https://www.dssa. gov.co/index.php/estadisticas/eventos-en-salud-publica/item/71eventos-de-interes-en-salud-publica-por-subregiones-y-municipiosantioquia-2007-2014

Sistema Nacional de Vigilancia en Salud Pública -SIVIGILA-. (2014). Eventos de Interés en Salud Pública por subregión y municipio, Antioquia 2014 [en línea]. Recuperado de https://www.dssa.gov. co/index.php/estadisticas/eventos-en-salud-publica/item/71eventos-de-interes-en-salud-publica-por-subregiones-y-municipiosantioquia-2007-2014

Soto Fuentes, P. (2017). De la educación interprofesional al trabajo en equipo en salud. Horizontes de Enfermería, 28(1), 3-6. Recuperado de http://publicaciones.horizonteenfermeria.uc.cl/index.php/rhe/ article/view/50/31 
Tribunal Nacional Ético de Enfermería (1998). Código de Ética de Enfermería [en línea]. Recuperado de http://www.trienfer.org.co/ index.php/ley-911-de-2004/

Ubilla, E. (2009). El concepto de salud mental en la obra de Erich Fromm. Revista chilena de neuro-psiquiatría, 47(2), 153-162. doi: https://dx.doi.org/10.4067/S0717-92272009000200008

Vázquez, C. y Hervás Torres, G. (2009). La ciencia del bienestar. Fundamentos de una psicología positiva. Madrid, España: Alianza Editorial. 
Los capítulos que configuran la estructura del libro son el resultado de tres investigaciones que, en conjunto, revelan la necesidad de considerar elementos adicionales en la formación de los profesionales de enfermería, medicina, trabajo social y psicología, propiciando el diálogo de saberes y la construcción articulada de prácticas de acompañamiento de la salud mental de las personas y poblaciones. Así entonces, en el primer capítulo se presenta un ejercicio de conceptualización de la salud mental como campo del conocimiento que comprende dimensiones tanto positivas como negativas. Posteriormente, en el segundo capítulo se describen los hallazgos que emergieron de la revisión de las mallas curriculares de los programas universitarios antes mencionados y que según el Sistema Nacional de Información de la Educación Superior -SNIES- se encontraban activos en el año 2015; diagnóstico que permitió identificar las fortalezas y necesidades de la formación de estos programas en lo que a este campo del conocimiento respecta. Finalmente, el tercer capítulo concluye con la propuesta de un modelo de formación del talento humano en salud mental que invita a la inclusión de estrategias que permitan desarrollar lecturas transdisciplinares de las problemáticas relativas a la salud mental. En definitiva, este texto es una invitación a tender puentes de diálogo entre las disciplinas y a favorecer el trabajo intersectorial e interinstitucional en procura de un mejoramiento de la formación y la atención en salud mental.

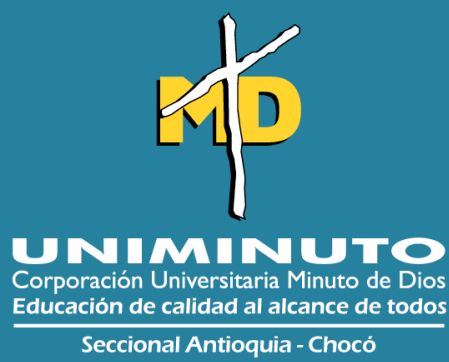

Bogotá D.C. Calle 81B No. $72 B$ - 70

Teléfono +(57)1 - 2916520

www.uniminuto.edu 